
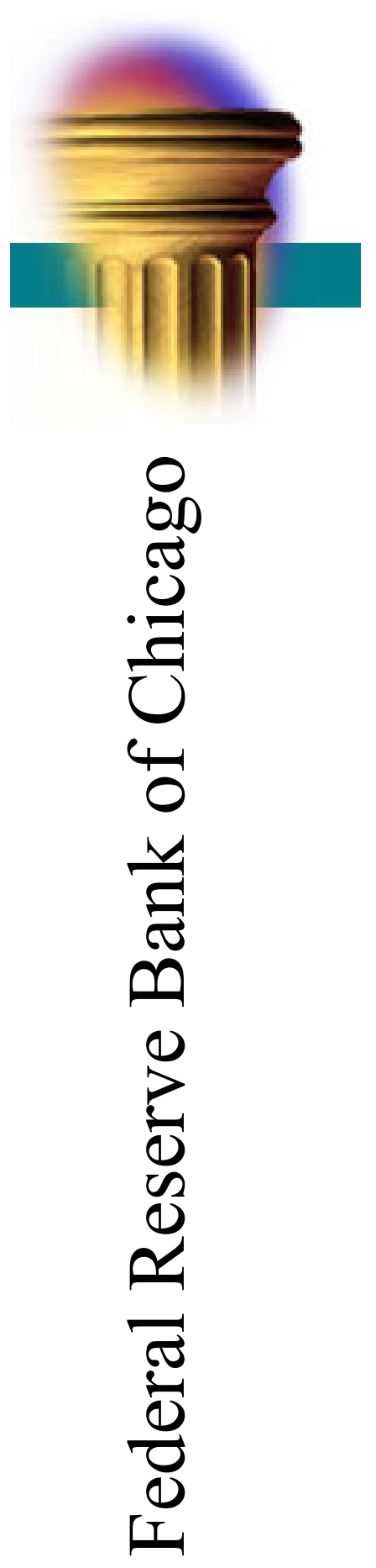

\title{
The Returns to Public Library Investment
}

Gregory Gilpin, Ezra Karger, and

Peter Nencka

\author{
REVISED \\ July 2021
}

WP 2021-06

https://doi.org/10.21033/wp-2021-06

${ }^{*}$ Working papers are not edited, and all opinions and errors are the responsibility of the author(s). The views expressed do not necessarily reflect the views of the Federal Reserve Bank of Chicago or the Federal Reserve System. 


\title{
The Returns to Public Library Investment
}

\author{
Gregory Gilpin* $\quad$ Ezra Karger $^{\dagger} \quad$ Peter Nencka
}

July, 2021

\begin{abstract}
Local governments spend over 12 billion dollars annually funding the operation of 17,000 public libraries in the United States, yet we know little about their effects. We use data describing the near-universe of public libraries to show that public library investment increases children's attendance at library events by $18 \%$, children's checkouts of items by $21 \%$, and library visits by $21 \%$. Increases in library use translate into improved test scores in nearby school districts: a $\$ 1,000$ or greater per-student capital investment in local public libraries increases reading test scores by 0.02 standard deviations and has no effects on math test scores.
\end{abstract}

${ }^{*}$ Department of Agricultural Economics and Economics, Montana State University

$\dagger$ Federal Reserve Bank of Chicago

¥Department of Economics, Miami University

§Thanks to Riley Acton, Matthew Birnbaum, Lauren Jones, Kurt Lavetti, Dean Lillard, and Bruce Weinberg for helpful comments on prior versions of this work. We also thank seminar participants at the Association for Public Policy and Management, Association for Education Finance and Policy, Case Western Reserve University, Miami University, and the Institute for Museum and Library Science for their feedback. The views expressed in this paper do not necessarily reflect those of the Federal Reserve Bank of Chicago or the Federal Reserve System. 


\section{Introduction}

Research shows that neighborhoods play a critical role in child development. Where a child grows up affects their academic performance, long-term educational attainment, and labor market outcomes (e.g., Chetty and Hendren, 2018a; Chetty and Hendren, 2018b; Chyn, 2018). But despite a recognition that location matters for child development, there is much to learn about which local policies and institutions create beneficial neighborhoods. In particular, while a large literature has studied whether and how local public school spending translates into student achievement, less is known about the effects of other policy levers available to local governments.

In this paper, we analyze a ubiquitous yet understudied local institution: the public library. In 2018, there were 9,261 library systems across the United States with 15,427 branches. Libraries spent 12 billion dollars on operating costs and patrons checked out over 2 billion items..$^{1}$ This funding supports widespread library use: more than 50\% of Americans visit public libraries each year. Beyond their collections, libraries also provide instructional programs on topics ranging from literacy to computer usage, job search, and tax preparation; and they serve as one of the few non-commercial indoor spaces available to the public $\left.\right|^{2}$ A particularly important focus of library services is child development. In 2018, children checked out more than 750 million library items and attended events more than 80 million times at libraries nationwide.

Despite the popularity and abundance of libraries, there is little evidence about their effects. This is due to two major challenges. First, the vast majority of public library operations funding is determined locally; in 2018, 86 percent of library funding was provided by city and county governments, with only 6.8 and 0.3 percent, respectively, coming from state and Federal sources ${ }^{3}$ This local operating spending is relatively stable from year-to-year, limiting researchers' ability to

\footnotetext{
${ }^{1}$ All statistics from the 2018 version of the Institute of Museum and Library Services' (IMLS) Public Library Survey. We discuss the construction of these data in Section 2

${ }^{2}$ Building on Andrew Carnegie's observation that libraries are "palaces for the people," Kleinberg (2018) argues that libraries improve community health outcomes by providing vulnerable residents with a refuge of last resort.

${ }^{3}$ The remainder of funding is classified as coming from "other" sources in the IMLS data, and includes private foundations and philanthropists.
} 
exploit policy-generated changes in annual expenditures. When operating expenditures do change, it is often due to shifts in local finances that may affect other locally provided services, like public schools. Second, there is limited understanding of how changes in library expenditures affect library resources and patron usage. Without estimating the public library production function, it is difficult for researchers and policymakers to understand how library investment generates community benefits.

We use new data and methods to address these challenges. We study how capital investment in public libraries affects library operations, patron usage, and local communities, with a focus on student achievement. We use detailed panel data on the near-universe of public libraries and school districts in the U.S. We compile library spending, revenue, and usage data collected annually in the Institute of Museum and Library Services' Public Library Survey. We link this data to district-level test scores from the Stanford Education Data Archive (SEDA) and zip code-level housing price indices from Zillow. Using this data, we examine a specific type of library expenditure: capital spending on major renovations and new library buildings. Unlike day-to-day expenses, capital investments are lumpy, allowing us to identify discrete changes in public library investment across every library system in the United States between 1992 and 2018. We show that the timing of these large-scale investments is orthogonal to changes in other local government spending and local demographics.

Using these sharp changes in investment, we estimate the causal effects of library capital spending with dynamic difference-in-difference models. We use a recent method that avoids biases common in staggered difference-in-difference designs (Callaway and Sant'Anna, 2020). We first estimate the effect of capital spending on library resources and usage. We find that capital investment sharply increases library visits (by 21\%), children's checkouts of items (by 21\%), and children's attendance at library events (by 18\%). These increases in usage persist for at least 10 years after capital investment. Capital investment also increases library book holdings, employees, spending on salaries, and operating expenditures. In other words, library capital investment 
increases both the quality and usage of libraries.

Next, we test whether library capital investment affects children's academic achievement. We find that library capital spending increases nearby children's reading test scores by 0.02 standard deviations on average in the seven years following the library investment shock. This is the first quasi-experimental causal evidence that public libraries improve the academic performance of children. We find no evidence that library investment affects math test scores, consistent with the reading-focused mission of libraries. We test for heterogeneous effects of libraries across community and student characteristics. We find that effects are largest in smaller districts and in districts that spent the least per-student on school capital improvements over our sample period. Together, these results suggests that the effects of libraries are larger when libraries are more salient in the local community and that libraries may play a compensatory role when communities are investing small amounts in school infrastructure. Across child characteristics, we see no evidence of differential effects by grade or socioeconomic status. We find some evidence that our effect sizes are smaller for Black and Asian students and larger for white and Hispanic students, but we cannot reject sizable effects for all subgroups.

How do these increases in student test scores affect broader community outcomes? School spending often translates to increases in local housing values (e.g., Cellini, Ferreira, and Rothstein, 2010; Nielson and Zimmerman, 2014; Conlin and Thompson, 2017), implying that such spending is under-provided. In our case, similar logic suggests that if local communities under-invest in public libraries, then each dollar of local tax revenue spent to increase the quality of local libraries will cause more than a dollar increase in each resident's willingness to pay to live near to the higher-quality library, which will be reflected in increased housing prices.$^{4}$ We find that library investment has no positive or negative effect on local housing prices, implying that homeowners value the improvement in local amenities enough to offset the cost of local tax increases that

\footnotetext{
${ }^{4}$ For a theoretically-founded discussion of the capitalization of school quality into housing prices, see Cellini, Ferreira, and Rothstein (2010) and Nguyen-Hoang and Yinger (2011).
} 
fund the public library investment. Our results are precise enough to reject a 2 percentage point increase or decrease in housing prices following a sharp increase in public library investment.

We show that our results are robust to measurement and specification choices, paying particular attention to the possibility that our test score findings could be affected by other time-varying, local characteristics that are correlated with library expansions. First, we show that library capital spending does not correlate with changes in student demographics, local adult characteristics, or local school spending. Second, we show that our results are robust to controlling flexibly for these local characteristics in standard two-way fixed effect event study models. Third, we show that our results pass two placebo tests: (1) small library capital investment shocks have no effect on test scores; and (2) large library capital investment shocks near a school district, but outside of commuting distance (20-50 miles from the district), have no impact on student achievement.

To benchmark our findings, we use a back-of-the-envelope calculation to compare the magnitude of our test score results to the effects of public school capital spending. Jackson and Mackevicius (2021) argue in a recent meta-analysis that the balance of credible work suggests that capital school spending boosts test scores. Using Jackson and Mackevicius's estimates, we find that the typical large-scale library capital investment increases test scores by a larger per-dollar basis than typical school investments. This suggests that library investment can be an important complement to public school investment. However, we caution that precise dollar-to-dollar cost/benefit comparisons are complicated by two facts: (1) the typical library capital investment is smaller than the typical school capital investment, making dollar-to-dollar comparisons difficult, and (2) test scores are only one measure of the social return to public library and public school investment. Public library investment may have broader effects on local communities. In this paper, we only focus on the effect of public libraries on student achievement and property values, two important but non-exhaustive outcomes. 


\section{Related literature}

Our paper is methodologically similar to a large literature on the causal effects of school spending. Most relevantly, a subset of this literature focuses on the effects of capital investment in schools. For example, Nielson and Zimmerman (2014) measure the effects of a 15-year, \$1.4 billion school construction program in New Haven, Connecticut. They find that school construction increases reading test scores by 0.15 standard deviations and has no effect on math test scores six years after the new school building opens. They also find that school construction increases local housing prices by $10 \%$. By contrast, Baron (2019) finds that Wisconsin districts which narrowly passed a capital bond referendum experience no gains in student achievement relative to districts that narrowly fail to pass these referenda.$^{5}$ Summarizing this literature, Jackson and Mackevicius (2021) find that, on balance, school capital spending positively affect student test scores. We benchmark our findings to the school literature and show that library capital spending complements school spending.

Our research also builds on a large descriptive literature that discusses and structurally models the public finances of libraries. Early work recognized that libraries may be a public good and their characteristics could justify the government provision of library services (Tiebout and Willis, 1965). In public finance, a literature analyzes the efficiency of public library spending relative to theoretical benchmarks and other public institutions (e.g. Goddard, 1973; Feldstein, 1976; Getz, 1980; DeBoer, 1992; Vitaliano, 1998; Worthington, 1999; Vitaliano, 1997; Hemmeter, 2006; Neto and Hall, 2019). Papers in this literature often estimate library production functions by comparing library spending to usage. But in the absence of exogenous variation in library spending these comparisons may suffer from reverse causality. As local communities demand more library services, libraries are likely to increase spending. Once a production function is estimated, changes in library use can be converted into dollar valuation by assigning services a market value. This

\footnotetext{
${ }^{5}$ Baron (2019) does find large effects of school operational referenda on child test scores.
} 
literature is reviewed in Missingham (2005). While policymakers and interest groups often rely on cost-based valuations of library services - multiplying service usage by a market price proxy for similar services - most academic work uses survey-based contingent value preference elicitation to value public libraries (e.g., Casper, 1978; Aabø, 2005a; Aabø, 2009b; Aabø, 2009).

Our setting is closely related to a smaller literature that tries to directly estimate the effects of public libraries on communities and individuals ${ }^{6}$ Bhatt (2010) instruments for library usage with the distance to the nearest public library and finds that libraries increase the amount of time that children spend reading and reduce children's television consumption. Rodríguez-Lesmes, Trujillo, and Valderrama (2014) use a difference-in-difference approach to show that the construction of two public libraries in Bogota, Colombia had no effect on nearby high school students' test scores. Porter (2015) finds that when libraries stayed open for longer hours in Los Angeles, crimes rates declined. Neto (2019) finds no effect of library programming on local labor market conditions using a lagged funding instrument. Our paper uses variation in local community investment in public libraries as a shock to available resources and we focus on children's test scores as our main outcome.

Finally, another set of papers examines the historical impact of public library investment in the early 1900s. Using data from the late 1800s and early 1900s, Kevane and Sundstrom (2016) find that public library investment had no effect on political participation; Berkes and Nencka (2021) use a database of public libraries funded by Andrew Carnegie to show that libraries increased patenting rates in affected towns; and Karger (2021) finds that public library construction increased the long-run educational attainment and earnings of exposed children. These papers use identification strategies that exploit the lack of commonplace, high-quality libraries in the early 1900 s. We test for the benefits of public libraries in a modern context.

\footnotetext{
${ }^{6}$ This literature often relies on changes in the demand for library services. For example, James (1985) studies how changes in local economic conditions impact public library use. Palmer (1981) and Ottensmann (1997) estimate the impact of patrons' distance to public library on the demand for services. Bekkerman and Gilpin (2012) estimate the impact of access to high-speed residential Internet access on the demand for library services. Goldhor and McCrossan (1966) and Guryan et al. (2014) study the impact of summer reading clubs on reading skills.
} 


\section{Data}

In this section we describe our data and discuss how we identity capital construction shocks.

\subsection{Library data}

Our data on libraries come from the Public Library Survey (PLS), a census of public library systems collected annually by the Institute for Museum and Library Services (IMLS) since 1988. The survey unit in the PLS is a library system, which can contain multiple library branches. Survey response rates are extremely high. In 2017, 9,042 of 9,216 eligible public libraries responded to the survey, a 98 percent response rate corresponding to over 17,000 library branches (IMLS, 2019). The PLS contains a rich set of information about library finances and usage. IMLS (2019) provides a detailed overview and summary of the variables that they collect. Most information about spending and usage is reported at the library system level, and not at the branch level.

We are particularly interested in capital expenditures, so we use the PLS's measure of capital spending as one of our main treatment variables. IMLS defines capital expenditures as spending on major one-time projects that add to fixed assets, including purchasing land, building new structures, and renovating existing structures. Public libraries finance capital expenditures either directly from operating budgets or through one-off government transfers or bond issuance. We do not observe the source of capital funding. In our analysis, we focus on large capital investment shocks, which are more likely to be funded by one-off transfers and bonds. We also analyze operating expenditures, which the PLS separates out in its survey into several components, including spending on staff salaries, staff benefits, and collections.

In addition to financial library inputs, the PLS contains comprehensive information on library usage and holdings. As measures of library usage and resources, we analyze the number of children who attend library-based events, the total circulation of a library's collections, the circulation of 
children's material, the number of visits, the total stock of books, and annual operating expenses.7

\subsection{Test score data}

We measure the effect of public library capital investment on test scores using a standardized dataset of district-level test scores from the Stanford Educational Data Archive (SEDA), compiled by The Educational Opportunity Project at Stanford University (Reardon et al., 2020; Fahle et al., 2020). The basis for these data is annual standardized tests that public school students were required to take following the passage of the Federal No Child Left Behind Act in 2002. In our main analyses, we use reading and math test scores for 3rd-8th graders in over 5,000 school districts across the United States. The SEDA panel reports test scores in two types of units: standard deviation units (on a national scale) and grade equivalence units, where a value of 8 indicates that students are testing at an 8th grade level, and a value of 3 indicates that students are testing at a 3rd grade level $\left.\right|^{8}$ Our results our robust to using either test score measure. For our main analysis, we use standard deviation units so that we can compare our effect sizes to the school spending literature.

\subsection{Housing price data}

We use housing price indices from Zillow at the five-digit zip code-level. Zillow constructs its housing price index by forecasting the sales price of all houses in its national database of more than 100 million properties. Zillow calls these forecasts 'Zestimates.' Zillow then calculates the index for a zip code as the value-weighted average Zestimate in the area, excluding houses that

\footnotetext{
${ }^{7}$ There is no individual-level library usage information in these data. This means that we do not observe the number of unique users of library services, for example. Instead, we observe the number of unique user-by-visit events.

${ }^{8}$ The team that compiled the SEDA data construct the mean and standard deviation of the test score measure for each grade, subject, and year using a heterogeneous ordered probit model and restricted-access data from the US Department of Education. For more details, see Fahle et al., 2019.
} 
undergo significant construction or renovation? 9

\subsection{Summary statistics}

In Table 2, we summarize our library-by-year panel constructed from IMLS data. We focus on library systems with 0 or 1 branch from 1992-2018 and each observation in our panel is a libraryyear ${ }^{10}$ The average library in the sample has seven employees and spends $\$ 503,000$ annually on operating expenses (in 2015 dollars). Libraries in the sample serve an average of 13,000 people, have an average of 68,000 visits, and check out 103,000 books or other resources each year. ${ }^{11}$ The average library has 3,000 annual attendees at children events and a collection stock of 43,000 books.

In an average year, each library spends $\$ 70,000$ on capital expenditures (in 2015 dollars). But the distribution of capital expenditures is heavily skewed. In the median year, libraries spend no money on capital expenditures, in $10 \%$ of years libraries spend more than $\$ 71,000$, and the standard deviation of capital spending in our panel is $\$ 535,000$. When a library system replaces an entire building or builds a new branch library, capital spending jumps dramatically and significantly. We use these jumps as the main source of variation in this study.

Because the SEDA test score data is available at the district level, Table 2 also provides equivalent library summary statistics at the district level. To construct our district-year panel, we identify all libraries within 5 miles of a school district. We subset to districts that have at most 20 library buildings (including branches) within 5 miles of the modal zip code of the district to avoid

\footnotetext{
${ }^{9}$ For more details about Zillow's methodology, see https://www.zillow.com/research/ zhvi-methodology-2019-deep-26226/

${ }^{10}$ If a library system begins as a single-library system with 0 or 1 branch, but then grows into a multi-unit library system, we include the system in our panel (as one library) to avoid selecting library systems out of our sample if they endogenously grow over time, but $90.8 \%$ of the observations in our library-by-year panel represent a library system with only 1-2 buildings. Our library data, subset to these $0-1$ branch systems, describes an average of 8,314 library systems each year from 1992-2018.

${ }^{11}$ If one person visits the same library five times in a year, they are counted as five independent visits. Similarly, if patrons check out Harry Potter and the Sorcerer's Stone five times, the same rule applies for counts of circulating items.
} 
dense urban areas where treatment effects are more difficult to disentangle from hundreds of concurrent local policies ${ }_{12}^{12}$ When we analyze library spending shocks within 5 miles of a school district, we focus on library outcomes in 2009-2018 to match the timing of available SEDA data.

In an average year, our data describe 5,512 school districts. The average district in our final sample has two library systems (and 2.1 branches) within 5 miles. In Table 2 we show additional statistics describing both the library systems within 5 miles of each school district and student enrollment at the schools in that district. For example, the average district in the sample has 13 percent Hispanic students and the nearby adult unemployment rate is 7 percent. The number of students enrolled in each district is much smaller than the number of people served by the libraries within 5 miles of that school district for three reasons: (1) elementary and middle school students make up only a small fraction of the population that could use a given library; (2) library systems often serve a larger area than is covered by one school district; and (3) our geographic rule for assigning libraries to school districts is broad: a school district may have one library system 5 miles to its east and one library system 5 miles to its west. In these cases, those two library systems likely serve many people who are not represented by the geographic bounds of the school district.

\section{Effects of capital investment on library resources}

In this section we describe our empirical framework and library-level outcome results. We discuss standard event study methods, their limitations in our context, and recent advances in the difference-in-difference literature that we use to overcome these limitations. We then discuss our results.

\footnotetext{
${ }^{12}$ Results are robust to using alternative cutoffs.
} 


\subsection{Event study framework}

A standard approach for estimating dynamic treatment effects is to use an event study regression with unit and time fixed effects. In our context, the estimating equation to evaluate the effects of library capital investment shocks on library-level outcomes is:

$$
Y_{l t}=\sum_{e=-10}^{10} \beta_{e} 1(\text { CapitalShock })_{l t e}+\eta X_{l t}+\delta_{l}+\gamma_{t}+\epsilon_{l t}
$$

where $Y_{l t}$ is an outcome measure of library resources, patron use, or student achievement in library system $l$ and year $t$. The indicator variable 1 (CapitalShock) $)_{l t e}$ tracks the year surrounding a capital investment shock for library system $l, X_{l t}$ is a vector of time-varying library covariates, and $\delta_{l}$ and $\gamma_{t}$ are library and year fixed effects (respectively). The coefficients of interest are the vector $\beta_{e}$. Typically, researchers interpret $\beta_{e}$ as the causal effect of the treatment on the outcome of interest $e$ periods from the shock. However, this interpretation can be incorrect if there are heterogeneous treatment effects across cohorts or time. In particular, since standard event studies use early-treated units as controls for later-treated units, treatment effect dynamics can introduce bias 13

For this reason, our main results use a difference-in-difference and event study procedure developed by Callaway and Sant'Anna (2020) that accounts for dynamic treatment effects. They provide an estimation procedure to identify group-specific average treatment effects on the treated-denoted $A T T(g, t)$-reflecting average treatment effects on the treated in time period $t$ for the group treated at time $g$. For example, in our setting we observe a group of units which experience a capital shock in 2009, 2010,... and 2018 (these years are our groups $g$ ). We also observe outcome data in the years $(t)$ leading up to and after the treatment. We follow Callaway and Sant'Anna and formalize the idea of group-specific average treatment effects using standard

\footnotetext{
${ }^{13}$ For a discussion of this bias and evidence of how this bias can change the magnitude and statistical significance of estimated causal parameters in published research, see Baker, Larcker, and Wang (2021).
} 
potential outcome notation:

$$
A T T(g, t)=\mathbb{E}\left[Y_{t}(1)-Y_{t}(0) \mid G_{g}=1\right]
$$

where $G_{g}$ is a dummy variable equal to one if the unit is in treatment time group $g, Y_{t}(1)$ is the outcome variable at time $t$ for treated units, and $Y_{t}(0)$ is the potential outcome for those units had they not been treated. As in standard difference-in-difference settings, $Y_{t}(0)$ is not observed for periods after $g-$ we do not observe the counterfactual non-treated outcome for treated units. This fundamental problem of causal inference motivates the use of a control group of never-treated units $(C)$ as a proxy for what would have occurred if a unit had not been treated. Callaway and Sant'Anna show that under the assumption that the control and treatment groups follow counterfactual parallel trends, we can express the treatment effect in Equation 2 as:

$$
\operatorname{ATT}(g, t)=\mathbb{E}\left[Y_{t}-Y_{g-1} \mid G_{g}=1\right]-\mathbb{E}\left[Y_{t}-Y_{g-1} \mid C=1\right]
$$

where the first term is the evolution of the outcome for the treatment group and the second term is the equivalent evolution of the outcome for the control group. Both quantities are simple averages and are easily calculated from the data. Notice that Equation 3 makes no comparisons across groups treated at different times, avoiding the issues that occur when researchers use early-treated units as controls for later-treated units.

Once we have calculated $\operatorname{ATT}(g, t)$ from Equation 3 for every treatment group $g$ and time period $t$, we combine our estimates into a more manageable set of parameters. We follow Callaway and Sant'Anna's dynamic aggregation approach, since we expect that the causal effect of library investment will differ as a function of years relative to the treatment period $g$. For each time-period $e$ relative to a treatment date (e.g., 2 years after $g$ ), we find the relevant $A T T(g, t)$ for each $g$ that corresponds to that relative time period. For example, for units treated in 2010; $e=2$ corresponds to 2012 , for units treated in 2011, $e=2$ corresponds to 2013. We then take an average of those ATTs 
across groups, weighting by the group size. This procedure results in a single average treatment effect estimate for every relative time period $e$, including time periods before the treatment occurs $(e<0)$. We plot these averages, which are analogous to the relative time coefficients generated from the standard regression in Equation 1. To create a single, overall point estimate, we take the average of these aggregated relative time estimates when $t \geq g{ }^{14}$

For inference, we use Callaway and Sant'Anna's recommended bootstrapping procedure. We report simultaneous confidence bands that are robust to multiple hypothesis testing and cluster errors by library system or school district, depending on the context ${ }^{15}$

We rely on the standard difference-in-difference parallel trend assumption for identification: treatment and control units would have followed parallel outcome trends after $g$ if not for the existence of the treatment ${ }^{16}$ In our setting, this implies that outcomes in areas that invested in library systems would have followed parallel paths as outcomes in areas that did not invest in public libraries, if the investing areas had instead not invested in libraries. This assumption is untestable, but we gauge its plausibility by seeing: (1) whether outcome trends in the years leading up to the treatment year $g$ are parallel across treatment and control units, and (2) whether other observable characteristics between treatment and control units were parallel before and after the treatment. This second test helps mitigate the concern that other characteristics of the community that could affect outcomes changed at the same time as library investments. We find that our result are robust to both tests, bolstering the plausibility of our estimates.

The Callaway and Sant'Anna procedure can also incorporate pre-treatment covariates to create propensity-score-based matches between treatment and control units. This adjustment is

\footnotetext{
${ }^{14}$ In Section 4.1 we discuss alternative weighting procedures. For a full discussion of this method, see Section 2 of Callaway and Sant'Anna (2020). We calculate all treatment effects using Callaway and Sant'Anna's R Package, DiD, version 2.0.1.901. See https://bcallaway11.github.io/did/ for more information on this package.

${ }^{15}$ If we use pointwise standard errors, our results are more precisely estimated, but this precision may be overstated. Unlike pointwise confidence intervals, simultaneous confidence intervals include the path of treatment over time with $95 \%$ confidence and account for the dependence of the presented coefficients across event-times.

${ }^{16}$ For a technical definition of this assumption in a potential outcomes framework, see Callaway and Sant'Anna (2020).
} 
needed if one believes that the parallel trend assumption only holds conditional on covariates. We observe flat unconditional pre-trends for every outcome in our analysis, so we do not match on any pre-treatment variables in our main results. However, in Section 4.1 we show that our results are similar if we incorporate covariates into the Callaway and Sant'Anna setup. In this case, we augment Equation 3 with propensity score weights for each group $g$ so that we weight control units more if they are similar to members of the treatment group across included covariates ${ }^{17}$ Because this procedure matches on pre-treatment covariates, it does not adjust for any timevarying confounders orthogonal to pre-treatment observables ${ }^{18}$ To address this limitation, we also show in Section 4.1 that when we estimate standard, two-way fixed effect event study models, our results are not affected by the inclusion of time-varying covariates 19

\subsection{Library use results}

We begin by presenting event studies at the library system level. We define a capital spending shock as the first year in the PLS data (1982-2018) with at least \$100-per-person of capital library spending ${ }^{20}$ We also require that in year $t-1$, the library system has less than $\$ 50$ per person of capital spending to ensure that our capital spending shocks represent sudden changes from prior levels. In Figure 1, we show the library-level average treatment effects on the treated (ATTs) for four logged library-level outcomes. We present the logged outcomes as $\log (X+1)$ to account for zeroes ${ }^{21}$ Importantly, unlike in a standard event study framework, there is no omitted category.

\footnotetext{
${ }^{17}$ See Callaway and Sant'Anna (2020), Section 2 for the full discussion of this method and the assumptions that underlie it. Importantly, there must be enough common support across treatment and control group covariates to create reasonable propensity score matches, a common assumption in the broader matching literature.

${ }^{18}$ For example, suppose that some areas receive a random positive financial shock that allows them to invest in libraries in addition to other local institutions that affect outcomes. Since this fictional shock is orthogonal to pre-treatment characteristics by assumption, pre-treatment covariate adjustment would not remove bias.

${ }^{19}$ We use this approach since current implementations of the Callaway and Sant'Anna method does not allow for time-varying covariates after the treatment.

${ }^{20}$ So, in a library system serving our sample average 13,000 people, this would represent a one-time capital investment of $\$ 1,300,000$ or greater.

${ }^{21}$ These results are robust to alternative transformations, including measuring the outcomes in their original units or using an inverse hyperbolic sine transformation.
} 
Instead, each coefficient measures the causal effect of a capital spending shock on shocked library systems, $e$ years after that shock, where $e$ is the running variable on the $\mathrm{x}$-axis and the coefficient measures the average treatment effect on the treated (ATT) $e$ years after the shock, averaging over the event-time coefficients for cohorts treated in each year.

In Panel A of Figure 1, we see a small run-up in capital spending in the years leading up to a major capital expenditure for a given library system. This may reflect planning expenses or small-scale preliminary construction. In the year of the first large capital expenditure for a library system, we see a sharp increase in capital spending that decreases quickly to low levels after three years. 'Shocked' library systems have less capital spending in the post-period than in the pre-period because they have just initiated a big capital outlay for improvements, and so are less likely than 'untreated' library systems to invest in major capital spending again soon after the initial expense.

In Panels B and C we present the causal effect of capital spending shocks on children's circulation and children's attendance at library events. We observe a sharp and persistent $30 \%$ increase in child library use that persists for ten years after the capital investment. Interestingly, we also observe a sharp drop in children's event attendance in the year of the shock. This is consistent with a brief decline in library capacity in the year when a library is under construction. Panel D shows the effect of capital spending on total visits to the library. There is a small decline in visits during the year of capital investment followed by a sharp and persistent $30 \%$ increase in visits after investment. Across all three library usage outcomes, there are no pre-trends in the years leading up to library use.

To summarize, Figure 1 shows that library capital spending has sharp, positive, and persistent effects on library use. In Figures A2 and A3, we show the effect of capital spending shocks on additional library system-level outcomes. Here, we see large increases in the number of books, the number of employees, payroll, and total operating expenditures in library systems after a capital shock. These figures imply that libraries improve the quantity of services offered after a capital 
investment 22

Because our main outcome of interest is children's test scores, which are only available nationally at the district level, Figure 2 replicates the same four panels as Figure 1 for capital spending shocks defined as a $\$ 1,000$ or greater increase in per-student capital spending at libraries within 5 miles of the school district (during the years 2009-2018, to match the timing of our test score data) ${ }^{23}$ We focus on the event coefficients within seven years of the capital spending shock because the district level data are available for fewer years than the IMLS library data ${ }^{24}$ Figure 2 shows qualitatively similar patterns as our library-level event studies: positive effects of capital expenditures on children's circulation, attendance at children's events, and total visits to the library. We find smaller effect sizes at the school district-level in these figures than we did in the library system-level event studies in Figure 1. This is unsurprising because districts are often adjacent to multiple library systems. In these cases, a capital spending shock in any one library system can have a more muted effect on overall library usage because other nearby libraries did not experience a capital shock.

\section{Effects of capital investment on student test scores}

In this section we estimate the effects of capital library investment on the test scores of children attending school nearby using the Callaway and Sant'Anna (2020) approach described in the previous section. We define capital shocks as a $\$ 1,000$ or greater increase in per-student capital spending at libraries within 5 miles of each school district. This is comparable to the $\$ 100 /$ person

\footnotetext{
${ }^{22}$ As a robustness check, we show results using logged per-user library use (Figure A1) and library resource (Figure A3 outcomes. This identifies intensive-margin effects by taking into account each library system's potential expansion of their service area in the years following the capital investment shock-we find similar results as in our main specifications.

${ }^{23}$ Because our count of students is based on grade 3-8 public school test-takers, this is roughly equivalent to a $\$ 100 /$ person library-level expenditure, since 3rd-8th grade students represent around $10 \%$ of the U.S. population as a whole.
}

${ }^{24}$ The SEDA test score data is available from $2009-2018$ 
increase in capital spending at the library system-level, as discussed in the previous section. We also require that per-student spending in the past year was less than $\$ 600$. If a district experiences multiple shocks, we take the earliest one. Finally, we only analyze shocks that happen between 2010 and 2017 so that we have at least one year of pre- and post-shock data for every treated unit in our analysis set. Using this shock definition, $10 \%$ of all school districts in our sample experience a shock between 2010-2017. Figure 3 shows the distribution of shock years conditional on observing a shock.

Our outcome of interest from the SEDA panel is district-grade-year measures of average reading and math test scores normalized to be mean zero and standard deviation one at the subject-grade-year level. A one-unit increase in these test scores corresponds to a one-standard deviation increase in test scores. Throughout, the standard errors are clustered at the school district level.

Figure 4 shows the results of the analysis for reading (Panel A) and math (Panel B) test scores. For both subjects, we observe no pre-trend in test scores in the years leading up to a capital library shock, suggesting that districts are not positively selected on test score dynamics in the years preceding major library investments. After capital investment shocks, we observe gradual increases in reading test scores. On average, reading scores increase by approximately 0.02 standard deviations, with the largest effects (0.04-0.05 standard deviations) emerging in the later years of the estimation window. The timing of these results corresponds to the increases in library use following capital expenditures observed in Figures 1 and 2 Panel B of Figure 4 shows no similar increase in math scores following library capital expenditure shocks. Instead, effects are concentrated in reading, plausibly the subject in which children are most likely to benefit from improvements in their local library. 


\subsection{Test score results robustness}

In this subsection we demonstrate the robustness of our test score results. First, we show that our results are unlikely to be driven by time-varying, district-level confounders. Second, we show that our findings are robust to alternative specification and measurement decisions.

A potential concern is that our results are biased by time-varying changes in local communities or school districts that correlate with the timing of library investments and also affect test scores. We find no evidence of pre-trends in our event studies, implying that test scores and library usage in communities that invest in libraries are not changing differentially in the years leading up to library capital investment. However, if local policies or demographics that affect test scores change at the same time as library spending, our analysis could be biased.

We address this concern in multiple steps. First, as a placebo check, we vary the distance from school districts used to calculate shock exposure. Our baseline estimate uses all capital spending that occurs within 5 miles of a school district. Libraries are local institutions, and it would be difficult for far-away libraries to affect students' scores. Consistent with this intuition, our results in Figure 5 show that capital spending shocks that occur between 20-50 miles from a given district have no effect on either reading or math test scores. Similarly, Figure 5 shows that small capital investment - between 50 and 150 dollars per student - has no effects on either math or reading test scores. Our main finding that public library investment causes an increase in reading test scores is unique to large, local public library investments.

Next, we check whether the timing of library capital investment is correlated with changes in local characteristics that could affect student test scores. Importantly, the null math test results suggest that the reading results are not contaminated by any time-varying changes in student characteristics that are correlated with broad student success. Student in-migration that could bias the results would need to be positively selected on reading-but not math-ability. To explore this further, we test whether changes in library spending are correlated with the timing of changes in 
local community demographics or other government spending. We estimate identical versions of our baseline model with these local characteristics-instead of test scores-as outcome variables. In Figures A5 A8 we show that point estimates are very small and statistically indistinguishable from zero for a wide variety of these local characteristics in years following a sudden increase in library capital spending.

In particular, Figures $\mathrm{A} 5$ and $\mathrm{A} 6$ show that the composition of students does not change after library capital investment: the shares of Black, Hispanic, Asian, and American Indian students, the share of student eligible for free/reduced-lunch, and the share of economically disadvantaged students remain stable in years following library investment. Figure A7 shows that the share of nearby adults with more than a bachelor's degree, the share of single mothers, the fraction of adults on SNAP assistance, and the fraction of unemployed adults do not change after library investment ${ }^{25}$ Finally, Figure A8 shows that local school district expenditures, including spending on capital projects and instructional staff, do not change in the years after library investment. This provides evidence that the timing of library capital investment is plausibly orthogonal to local changes that might have affected reading test scores 26

To further demonstrate the robustness of the main results, we explore alternative shock sizes. Our baseline estimates define a per-student capital shock as $\$ 1,000$ dollars or more of nearby library capital spending. Figure A10 shows reading results for this baseline shock size (Panel C) and alternative thresholds of $\$ 600, \$ 800$, and $\$ 1200$ in Panels A, B, and D, respectively. These shocks produce results that behave as expected: smaller (larger) shock thresholds lead to smaller (larger) effects on reading test scores.

Next, we estimate the reading and math test score results using a standard event study design equivalent to the model described in Section 3.1. While these models may introduce bias, we

\footnotetext{
${ }^{25}$ These community-level variables are compiled by SEDA program staff from the American Community Survey and matched to standardized schooling districts.

${ }^{26}$ Note that we make no adjustment in this analysis for multiple hypothesis testing, making it easier for us to find differences between places that do and do not invest in libraries.
} 
present them for robustness and so that we can include time-varying controls ${ }^{27}$ Figure A11 shows a baseline version of a standard event study controlling for district-grade and year fixed effects, but with no other covariates. Figure A11 shows a similar pattern as the main results: a positive 0.02-0.05 standard deviation increase in reading test scores following a capital spending shock. This effect increases over time. We also see smaller effects on math test scores that are significantly different from zero 6-7 years after the shock.

In Figure A12, we show results from same specifications but include time-varying, district-level covariates. These covariates include the fraction of students who are Native American, Black, Hispanic, and the share of students who are eligible for free or reduced price lunch programs. In addition, we include as covariates the fraction of nearby adults who have a bachelor's degree or greater, are below the poverty line, are unemployed, are receiving SNAP benefits, and who are single mothers. The inclusion of these time-varying covariates has no effect on the main results. Lastly, Figure A13 provides results from estimation that also includes district-level financial controls, including information on school district revenue, overall spending, and spending on capital projects and instructional staff. Adding these covariates does not significantly change the results (see Figures A12 and A13).

Building on this idea, in Figure A14 we show results after incorporating Callaway and Sant'Anna's covariate matching procedure. We match treatment and control units using the district-level demographics covariates by augmenting Equation 3 with propensity score weights for each group $g$. This weights control units more if they are similar to members of the treatment group across covariates. Importantly, this matching occurs only in the pre-period, so it does not adjust for any post-treatment time-varying potential confounders. Figure A14 shows that our estimates using this covariate matching procedure are nearly identical to the main results, consistent with the lack of dynamic selection observed across covariates. In Figure A15, we show

\footnotetext{
${ }^{27}$ For these figures, we plot the event study coefficients but we do not calculate the average pre-post treatment effect since it is not well-defined.
} 
the same results after additionally matching on district-level financial covariates. Once again, we observe a similar pattern of results, though the overall estimated point estimates are lower because we use a treatment window of $+/-6$ years due to data availability ${ }^{28}$ These findings are consistent with the null effects of capital spending on local and district covariates shown in Figures A5,A8. While many local covariates are correlated with changes in test scores, they are not correlated with the timing of library capital investment. Thus, controlling for these covariates does not affect our test score estimates.

Lastly, we show additional robustness to different weighting and estimation strategies. In our main event studies, we report a simple unweighted average of the Callaway and Sant'Anna $e=0$ to $e=7$ coefficients as our overall average treatment effect on the treated (ATT). In Figure A9 we show three alternate weighting strategies: Panel A constructs an overall, average ATT by weighting each group's post-treatment ATT(g,t) by group size; Panel B calculates group-specific average treatment effects (from post-treatment period $\operatorname{ATT}(g, t)$ values) and reports as an overall estimate of the ATT the unweighted average of these group-specific average treatment effects across groups; and Panel C first calculates year-specific averages of the $A T T(g, t)$ values across groups treated during that year (from 2010 to 2017), and then reports as an overall estimate of the ATT the unweighted average of these year-specific average treatment effects across years. All three alternative weighting estimates are statistically significantly larger than zero and modestly smaller than our main estimates. Lastly, in Panel D we implement the staggered rollout algorithm of Roth and Sant'Anna (2021) which is valid and efficient under the additional assumption of conditionally random treatment timing. Panel D shows modestly larger and more precisely estimated effects relative to our baseline model. For all four robustness exercises in Figure A9, the overall ATT is statistically indistinguishable from our preferred specification.

\footnotetext{
${ }^{28}$ Our district-level financial covariates are only available through 2017.
} 


\subsection{Reading results heterogeneity}

In this subsection we test whether library investment has heterogeneous effects by student or community characteristics. We focus on reading test scores in this subsection; for mathematics scores, we find similar, null effects for all the subgroups described below.

First, we explore how reading effects differ by race. In Figure 6 we show results from the baseline reading event study estimated separately for the test scores of (A) white students, (B) Black students, (C) Hispanic students, and (D) Asian students. These results are less precisely estimated than our baseline results; SEDA does not report test scores in districts when there is an insufficient number of observations to construct their test score measures and many districts have only a small number of students of a given race, leading to more year-to-year variability in the test scores of small groups ${ }^{29}$ The results in Figure 6 suggest that our findings are mainly driven by positive effects on the reading test scores of white and Hispanic students. However, the standard errors shown in these figures are large enough that we cannot rule out sizable, positive effects for all groups. Unfortunately, the PLS library data does not measure library use by race, so we cannot compare these results to similar measures of library usage. But these results suggest that programs aimed at boosting library engagement for specific racial groups may be needed to realize the full benefits of library investment 30

Second, we estimate heterogeneous effects by student economic status. Figure 7 shows results estimated separately by students who SEDA classifies as "economically disadvantaged" (Panel A) and "not economically disadvantaged" (Panel B), respectively. Families from higher-income and education families are more likely to use public libraries (Pew, 2015). However, the marginal value of library materials and programming may be higher for families with fewer resources. On balance, it is therefore unclear which group of students would benefit more from library investment. Figure

\footnotetext{
${ }^{29}$ Note that the $y$-axis in each of these figures changes, in order to clearly show the variability in the estimates.

${ }^{30}$ Importantly, these results may be complicated by the higher concentration of white students in smaller school districts, where we see larger effects.
} 
7 shows similar patterns of results in both groups of students, with a larger point estimate for the non-disadvantaged. As with race, we do not observe information on library usage after investment by economic status. Future work on library use and benefits by socioeconomic status would be valuable to understand how library investment affects educational inequality.

Third, we investigate how effect sizes differ by grades. Students across all age groups may benefit from library services, though the types of books consumed and events attended varies by age. Figure 8 shows the baseline results estimated separately for student test scores reported in grades 3-4 (Panel A), 5-6 (Panel B), and 7-8 (Panel C). We observe similar results in all grades, suggesting no large differences in the effectiveness of public libraries by age.

Next, we explore heterogeneous effects across district sizes. Students in smaller school districts are likely to be more affected by a given per-capita library shock, since they are more likely to live near only one library system. This implies that they are "fully treated" by any library spending shock. By contrast, students in larger districts are more likely to live near multiple library branches. For these students, when one nearby library improves, it does not necessarily improve the local library they regularly visit. In addition, students in large districts may have more local educational amenities, like parks and museums, nearby. In Figure 9 we show results separately after splitting the sample into school district size terciles ${ }^{31}$ Panel A of Figure 9 shows that our reading test score effects are largest in the smallest school districts, consistent with the increased salience of libraries in those communities 32

Finally, we estimate how our library results differ across levels of investment in school capital spending using Common Core data on annual district expenditures. Per-student school capital spending has a weak, positive correlation with school district size $(r=0.082)$, so this exercise is distinct from estimating heterogeneity by district size. In Figure 10 we show our baseline reading

\footnotetext{
${ }^{31}$ We split the whole sample, so both treatment and control school districts in each subsample are similarly sized.

${ }^{32}$ Our baseline results in the paper use unweighted event studies, giving equal weight to small and large districts. Consistent with this heterogeneity, we find positive but smaller and statistically indistinguishable from zero effects when we weight our baseline specifications by the number of grade 3-8 test-takers in each school district.
} 
test score results after splitting the sample into district capital spending terciles. We find that our results are driven by districts that have moderate and lower amounts of school capital spending, with the largest effects in districts that spent the least in capital expenditures. These results imply that libraries are a particularly important form of infrastructure investment when school capital spending is lowest, suggesting a possible compensatory role of library investment in the education production function 33

\section{Housing prices}

We now measure the effect of public library investment on local housing prices. Housing prices represent home-buyers' willingness to pay for local amenities. We use Zillow's estimates of the home prices in each zip code within five miles of a library system that experienced a capital spending shock to estimate the housing price responses to increased library investment. A large literature explains why this type of housing price capitalization is a useful way to measure the value of local amenities. In recent empirical work, researchers examine the relationship between public school investment, resulting increases in children's test scores, and changes in local housing prices. For recent examples, see Cellini, Ferreira, and Rothstein, 2010; Nielson and Zimmerman 2014; Conlin and Thompson, 2017; and Bayer, Blair, and Whaley (2020). These papers discuss and cite an underlying theoretical literature on hedonic regressions and the value of local amenities. The intuition behind this literature is that (1) local taxes are capitalized into housing prices-if a local community charges a $\$ 1,000$ tax for each home-owner and does nothing with the money (disposes of it), then housing prices should decrease in proportion to the net present cost of the tax; and (2) if local amenities improve, then the increased willingness to pay for those amenities will be reflected in equilibrium housing prices. So, if housing prices increase after local school

\footnotetext{
${ }^{33} \mathrm{By}$ contrast to this result, when we test for heterogeneous effects of library capital spending across total perstudent school spending levels, we see no clear pattern of heterogeneous results.
} 
spending increases, then home-buyers are revealing a preference for an equilibrium increase in school spending-because home-buyers are willing to pay more for these amenities than the cost they experience as taxpayers in funding these amenities.

In our case, if library investment causes a decrease in housing prices, then it is evidence that home-buyers believe the money spent to improve local public libraries was not worth the cost of those improvements. If library investment causes an increase in housing prices, then it is evidence that home-buyers believe the money spent to improve local public libraries was worth more than the cost of those improvements-implying that local communities were under-investing in public libraries. By contrast, if housing prices do not change following library investment, it is evidence that home-buyers believe the improvement in local amenities exactly offsets the added cost of those amenities.

To identify home-buyers' willingness to pay for local library investment, we again use the method from Callaway and Sant'Anna (2020)-this time to estimate the causal effect of public library capital spending shocks on the average housing prices of zip codes within 5 miles of the library system (using Zillow's zip code level indices defined in Section 2). Figure 11(Panel A) shows that capital spending shocks have no causal effect on house prices. We reject effects larger than 1 percentage point in either a positive or negative direction four years after the shock and there is no apparent pre-trend. Figure 11 (Panel B) provides event study coefficients at the school district-level and shows similar null effects of library spending shocks on housing prices for zip codes within 5 miles of each school district that experienced a shock.

These results suggest that households internalize the benefits of the library capital investments. While households face increased local taxes to pay for sizable library investments, they are willing to pay these increased taxes in return for perceived benefits. In our paper, we document several of these benefits: increases in library resources, library usage, and the reading test scores of students. For a detailed discussion of a different setting where local spending on amenities causes an increase in housing prices, see Bayer, Blair, and Whaley (2020), who argue that school spending 
shocks increase housing prices, implying that school spending is provided at inefficiently low levels in their setting. Based on the results from our paper, we do not find similar evidence for public library capital investment effects on house prices.

\section{Comparisons to public school capital investment}

In this section we conduct back-of-the-envelope calculations to benchmark our results to the school capital spending literature. We focus on school spending because there is an extensive literature that uses similar identifications strategies and outcomes as this paper.

Our baseline reading results in Figure 4 imply that library capital shocks greater than $\$ 1,000$ per student lead to an average 0.02 standard deviation increase in reading test scores and a null effect on math test scores in the seven years after library investment. The average size of the $\$ 1,000+$ per-student capital spending shock in our baseline specification is $\$ 2,496$ per student. Averaging across our two test score results, a $\$ 2,496$ per student library capital spending shock increases test scores by 0.01 standard deviations ${ }^{34}$ In a recent meta-analysis, Jackson and Mackevicius (2021) find that a $\$ 16,339$ per student capital expenditure on school buildings causes a 0.034 standard deviation increase in average test scores. Comparing our results to that paper, we find that our library capital spending shocks generate average test score increases that are $\frac{0.01}{0.034}=29 \%$ the size of a school capital spending shock at $\frac{2,496}{16,339}=15 \%$ of the cost.

This does not provide evidence that library capital projects have higher benefit-cost ratios and we caution against this direct comparison for several reasons. First, school capital spending is orders of magnitude more costly than library spending and both are subject to diminishing marginal returns. Jackson and Mackevicius (2021) report that the typical construction of a new elementary school costs $\$ 44,000$ per student. It is difficult to know if school capital spending effects

\footnotetext{
${ }^{34}$ Note that Jackson and Mackevicius (2021) equivalently calculate average effects of school capital spending by averaging over all available test subjects. We define per-student counts using the sum of all students in a particular district-year in grades $3-8$
} 
scale linearly in investment amounts - if the first dollars of school spending have larger effects, our comparison would overstate the relative benefit of libraries. Second, the 95\% confidence interval around our estimate contains test score effects that are significantly larger and significantly smaller than the meta-analyzed overall effect from Jackson and Mackevicius (2021). Third, our 3-8 grade test score effects likely underestimate the importance of libraries: a single library expansion could affect others in surrounding areas, students in grades $\mathrm{K}-2$ and 9-12, achievement in subjects where test scores are not measured in grades 3-8 (e.g., science), and adults and non-school-aged children (e.g., pre-K programs) ${ }^{35}$

For these reasons, we do not pursue direct, dollar-to-dollar cost/benefit comparisons of library and school capital investments. Rather, our results suggest that under reasonable assumptions: (1) library capital spending, like school capital spending, can have broad positive effects on local test scores, and (2) smaller-scale public investments in local amenities - like libraries - can positively affect children's academic performance at a lower absolute cost than typically more expensive school capital spending.

\section{Conclusion}

A growing literature suggests that neighborhoods can have long-lasting and important effects on child development. However, knowing that neighborhoods matter is not enough: for placebased policies to be effective, we need to know which characteristics of local communities cause changes in childhood experiences and which are simply correlated with desirable community characteristics. In this paper, we study the causal effects of investments into one of the most commonly used and lauded functions of local governments: the public library.

Every year, library administrators in local communities petition voters to approve additional

\footnotetext{
${ }^{35}$ School construction also may have broader public impacts beyond direct effects on children, since school facilities are often used by other members of the community. We do not attempt to compare the possible spillover effects across libraries and school districts.
} 
funds to expand and improve local public libraries. To date, little is known about the impact of these investments. We use an event study methodology to show that library capital spending has at least two effects. First, capital library investments cause patrons to use the library more. More residents visit the library, the stock of library materials increases, and more children attend library events. Second, library capital investments cause students to perform better on standardized tests. In particular, we observe persistent improvement in reading test scores in the seven years after library capital spending. These improvements in reading test scores coincide with increases in library use and are not driven by changing demographics in local communities. We study increases in capital spending in the post-smartphone era, so our results highlight the importance of public libraries to children, even in an era with widespread access to the internet and other new technologies that compete for children's attention. In the future, we hope to further investigate the many other ways that public libraries can affect local communities. 


\section{References}

[1] Aabø, Svanhild. “Are Public Libraries Worth their Price?” New Library World (2005).

[2] Aabø, Svanhild. "Valuing the benefits of public libraries." Information Economics and Policy 17, no. 2 (2005): 175-198.

[3] Aabø, Svanhild. "Libraries and Return on Investment (ROI): a Meta-Analysis." New Library World (2009).

[4] Baker, Andrew, David F. Larcker, and Charles C.Y. Wang. "How Much Should We Trust Staggered Difference-In-Differences Estimates?.' (2021).

[5] Bayer, Patrick, Peter Q. Blair, and Kenneth Whaley. "A National Study of School Spending and House Prices." (2020).

[6] Bekkerman, Anton, and Gregory Gilpin. "High-speed Internet Growth and the Demand for Locally Accessible Information Content.” Journal of Urban Economics 77 (2013): 1-10.

[7] Berkes, Enrico, and Peter Nencka. "Knowledge Access: The Effects of Carnegie Libraries on Innovation." (2021).

[8] Bhatt, Rachana. "The Impact of Public Library Use on Reading, Television, and Academic Outcomes." Journal of Urban Economics 68, no. 2 (2010): 148-166.

[9] Bogin, Alexander N., William M. Doerner, and William D. Larson. "Missing the Mark: House Price Index Accuracy and Mortgage Credit Modeling." (2016).

[10] Callaway, Brantly, and Pedro HC Sant'Anna. "Difference-in-differences with multiple time periods." Journal of Econometrics (2020).

[11] Casper, Cheryl. "Estimating the Demand for Library Service: Theory and Practice." fournal of the American Society for Information Science 29, no. 5 (1978): 232-237.

[12] Cellini, Stephanie Riegg, Fernando Ferreira, Jesse Rothstein. "The Value of School Facility Investments: Evidence from a Dynamic Regression Discontinuity Design." Quarterly fournal of Economics 125, no. 1 (2010).

[13] Chetty, Raj, and Nathaniel Hendren. "The impacts of neighborhoods on intergenerational mobility I: Childhood exposure effects." The Quarterly fournal of Economics 133, no. 3 (2018): 1107-1162.

[14] Chetty, Raj, and Nathaniel Hendren. "The impacts of neighborhoods on intergenerational mobility II: County-level estimates." The Quarterly fournal of Economics 133, no. 3 (2018): 1163-1228. 
[15] Chyn, Eric. "Moved to opportunity: The long-run effects of public housing demolition on children.” American Economic Review 108, no. 10 (2018): 3028-56.

[16] Conlin, Michael, and Paul N. Thompson. "Impacts of new school facility construction: An analysis of a state-financed capital subsidy program in Ohio." Economics of Education Review 59, (2017).

[17] DeBoer, Larry. "Economies of scale and input substitution in public libraries." fournal of Urban Economics 32 no. 2 (1992): 257-268.

[18] Fahle, Erin M., Benjamin R. Shear, Demetra Kalogrides, Sean F. Reardon, Belen Chavez, and Andrew D. Ho. "Stanford Education Data Archive Technical Documentation Version 3.0 July 2019." (2019).

[19] Feldstein, Kathleen Foley. "The Economics of Public Libraries." PhD dissertation, Massachusetts Institute of Technology, 1977.

[20] Getz, Malcolm. Public Libraries: An Economic View. Baltimore, MD: Johns Hopkins University Press, 1980.

[21] Goddard, Haynes. “An Economic Analysis of Library Benefits.” Library Quarterly 41 no. 3 (1971): 244-255.

[22] Goldhor, Herbert, and John McCrossan. "An exploratory study of the effect of a public library summer reading club on reading skills." Library Quarterly 36 no. 1 (1966)”: 14-24.

[23] Guryan, Jonathan, Kim, James, and David Quinn. "Does reading during the summer build reading skills? Evidence from a randomized experiment in 463 classrooms." NBER Working Paper 20689, 2014.

[24] Hausman, Jerry. “Contingent Valuation: From Dubious to Hopeless.” fournal of Economic Perspectives 26, no. 4 (2012): 43-56.

[25] Hemmeter, Andrew. "Estimating Public Library Efficiency Using Stochastic Frontiers.” Public Finance Review 34, no. 3 (2006): 328-348.

[26] Holtmann, A, Tabasz, T., and W. Kruse. "The Demand for Local Public Services, Spillovers, and Urban Decay: The Case of Public Libraries." Public Finance Quarterly 4 no. 1 (1976): 97-113.

[27] Jackson, C. Kirabo and Claire Mackevicius. "The Distribution of School Spending Impacts.” NBER Working Paper 28517, 2021.

[28] James, Stephen. "The Relationship between Local Economic Conditions and the Use of Public Libraries.” Library Quarterly 55, no. 3 (1985): 255-272.

[29] Karger, Ezra. “The Long-Run Effect of Public Libraries on Children: Evidence from the Early 1900s." (2021). 
[30] Kevane, Michael J., and William A. Sundstrom. "Public Libraries and Political Participation, 1870-1940." (2016).

[31] Klinenberg, Eric. Palaces for the People: How Social Infrastructure can Help Fight Inequality, Polarization, and the Decline of Civic Life. Broadway Books, 2018.

[32] Missingham, Roxanne. "Libraries and Economic Value: a Review of Recent Studies." Performance Measurement and Metrics. (2005).

[33] Neto, Amir B Ferreira. "Do Public Libraries Impact Local Labor Markets? Evidence from Appalachia." (2018).

[34] Neto, Amir B. Ferreira, and Joshua C. Hall. "Economies of Scale and Governance of Library Systems: Evidence from West Virginia.” Economics of Governance 20, no. 3 (2019): 237-253.

[35] Nguyen-Hoang, Phuong and John Yinger. "The capitalization of school quality into house values: A review.” Journal of Housing Economics 20, no. 1 (2011).

[36] Nielson, Christopher A., and Seth D. Zimmerman. "The effect of school construction on test scores, school enrollment, and home prices.” fournal of Public Economics 120 (2014): 18-31.

[37] Ottensmann, J. "Using Geographic Information Systems to Analyze Library Utilization." Library Quarterly 67, no. 1 (1997): 24-49.

[38] Palmer, E. “The Effect of Distance on Public Library Use: A Literature Survey." Library Research 3, no. 4 (1981): 315-354.

[39] Pew Research Center. "Chapter 1: Who Uses Libraries and What They do at Their Libraries.”(2015) https://www.pewresearch.org/internet/2015/09/15/who-uses-libraries-andwhat-they-do-at-their-libraries/.

[40] Reardon, Sean F., Erin M. Fahle, Demetra Kalogrides, Anne Podolsky, and Rosalía C. Zárate. "Gender Achievement Gaps in U.S. School Districts." American Educational Research fournal 56, no. 6 (2019): 2474-2508.

[41] Rodríguez-Lesmes, Paul, Josè D. Trujillo, and Daniel Valderrama. "Are public libraries improving quality of education? when the provision of public goods is not enough." Revista Desarrollo y Sociedad 74 (2014): 225-274.

[42] Roth, Jonathan and Pedro Sant'Anna. "Efficient Estimation for Staggered Rollout Designs." (2021).

[43] Tiebout, Charles M., and Robert J. Willis. "The Public Nature of Libraries." The Public Library and the City (1965): 94-101.

[44] Vitaliano, Donald F. "X-Inefficiency in the Public Sector: the Case of Libraries" Public Finance Review 25 no 6. (1997): 629-643. 
[45] Vitaliano, Donald F. “Assessing Public Library Efficiency using Data Envelopment Analysis.” Annals of Public and Cooperative Economics 69, no. 1 (1998): 107-122.

[46] Worthington, Andrew. "Performance Indicators and Efficiency Measurement in Public Libraries." Australian Economic Review 32, no. 1 (1999): 31-42. 
Figure 1: Effect of capital expenditure shock on library use (library-level shocks)

(A) Log capital spending

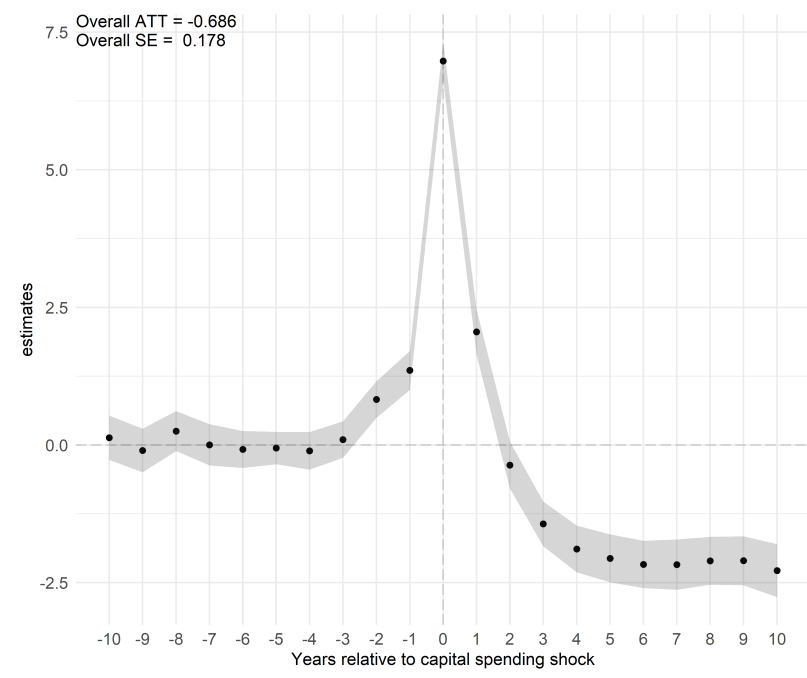

(C) Log children event attendance

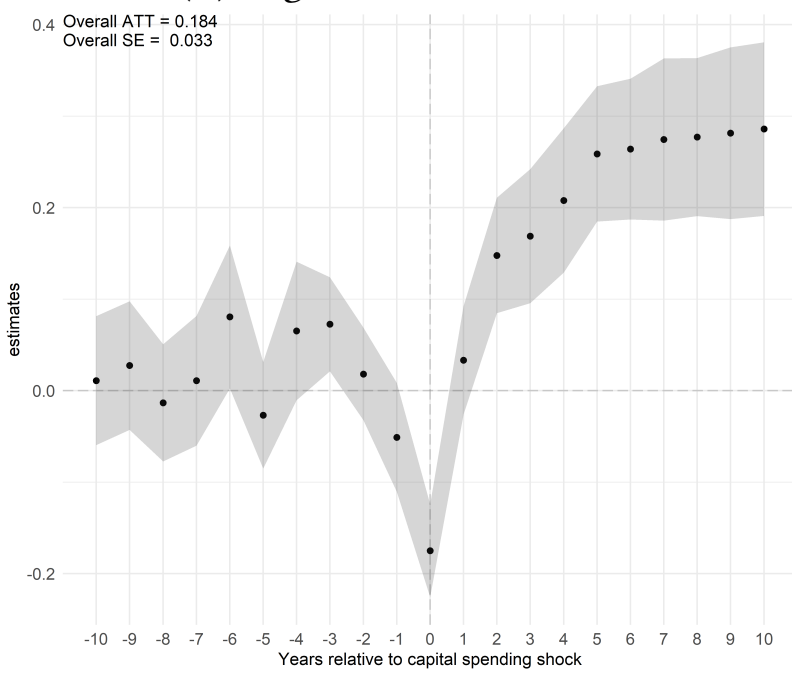

(B) Log children's circulation

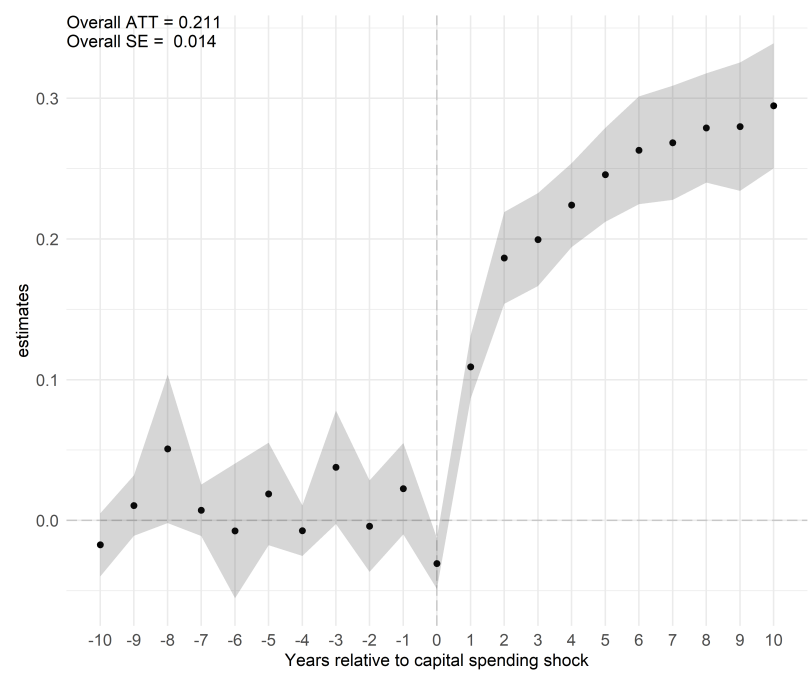

(D) Log visits

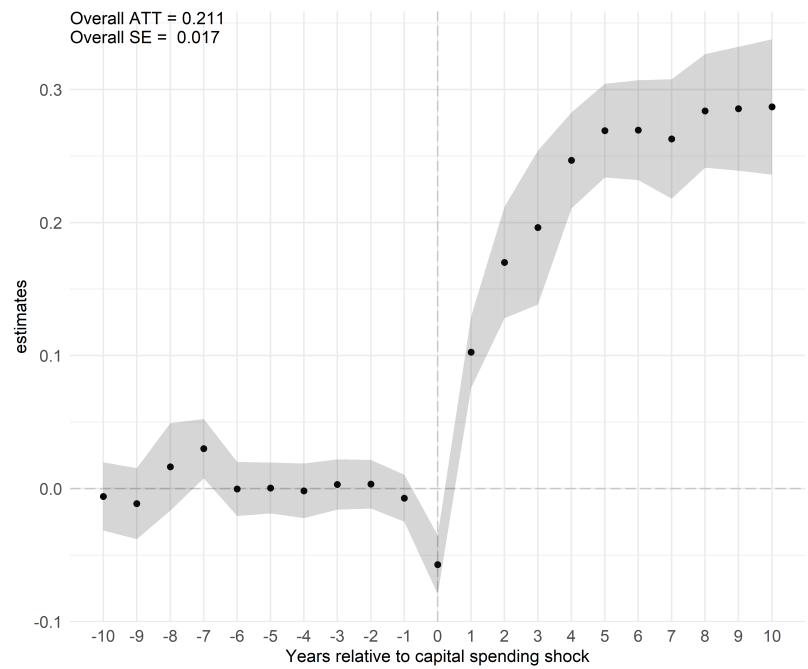

Event study estimates generated using the Callaway and Sant'Anna (2020) procedure described in Section 3 at the library-system level. A library spending shock is defined in Section 3 The outcome variables are (A) Log capital spending, (B) Log children's circulation, (D) log children's event attendance, and (D) log visits. All figures show bootstrapped 95 percent simultaneous confidence intervals. Unlike pointwise confidence intervals, simultaneous confidence intervals include the path of treatment over time with $95 \%$ confidence and account for the dependence of the presented coefficients across event-times. Standard errors are clustered by library system. 
Figure 2: Impact of capital expenditure shock on library use (school-district shocks)

\section{(A) Log capital spending}

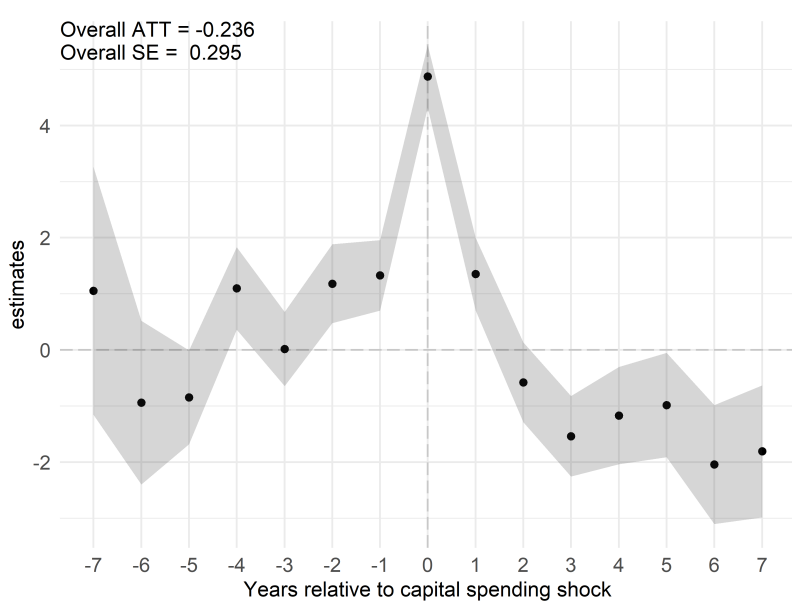

(C) Log children event attendance

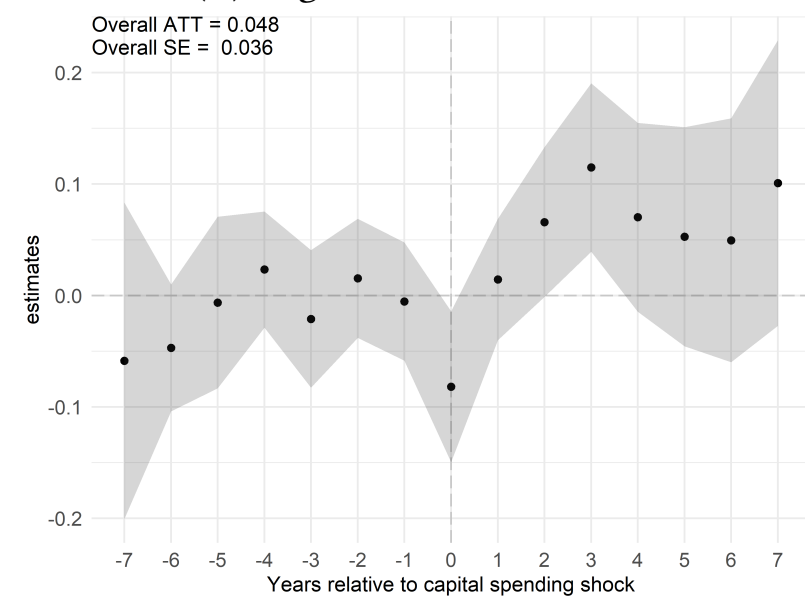

(B) Log children's circulation

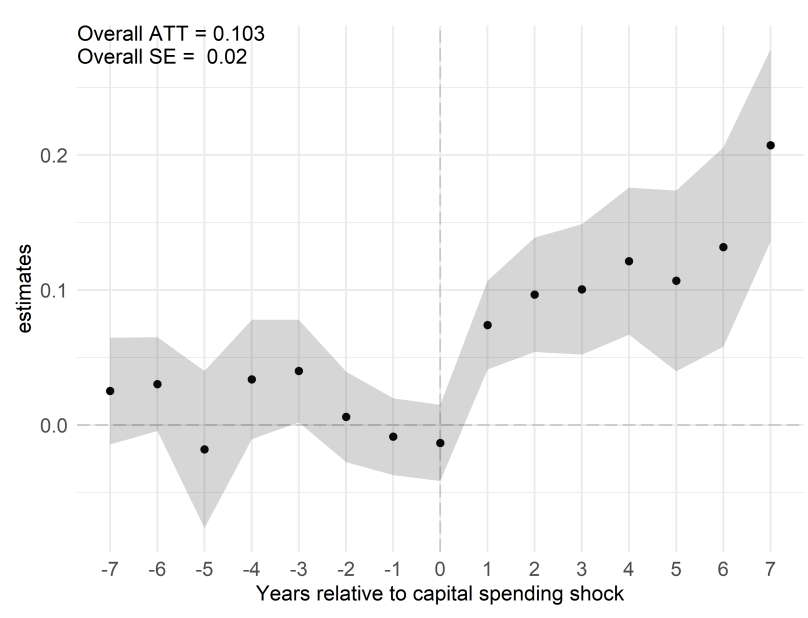

(D) Log visits

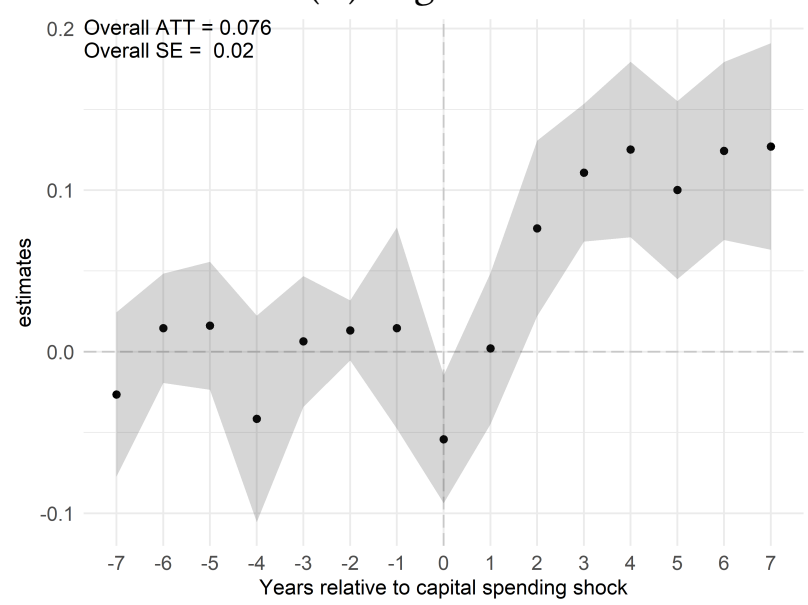

Event study estimates generated using the Callaway and Sant'Anna (2020) procedure described in Section 3 at the school district level. A library spending shock is defined in Section 3 The outcome variables are (A) Log capital spending, (B) Log children's circulation, (D) log children's event attendance, and (D) log visits. All figures show bootstrapped 95 percent simultaneous confidence intervals. Unlike pointwise confidence intervals, simultaneous confidence intervals include the path of treatment over time with $95 \%$ confidence and account for the dependence of the presented coefficients across event-times. Standard errors are clustered by school district. 
Figure 3: Distribution of library shocks in the school district sample

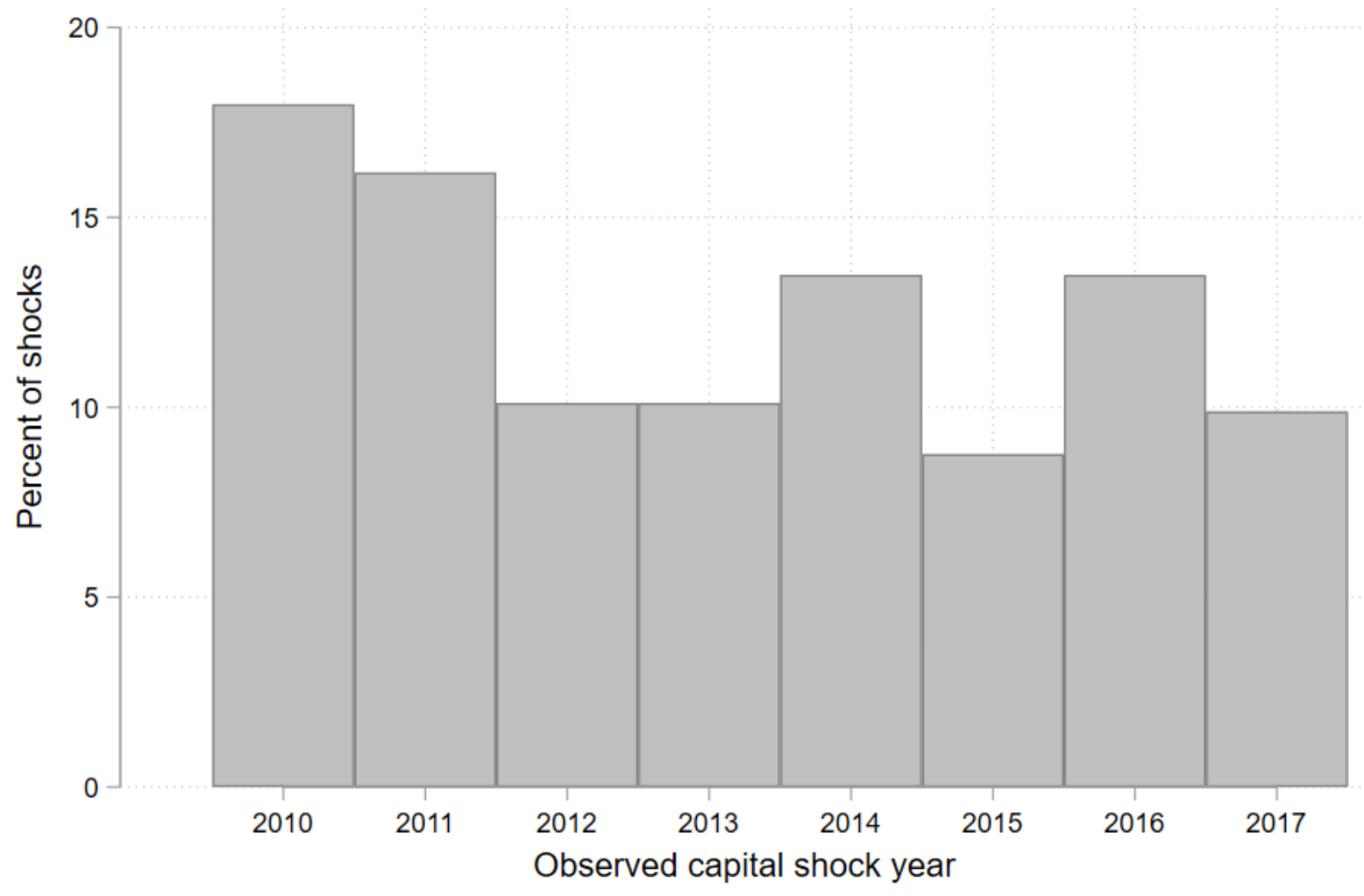

This figure shows the distribution of capital shock years in the school district sample for the sub-sample of districts with observed shocks. Approximately 10 percent of all districts have a shock between 2010 and 2017. 
Figure 4: Impact of library capital spending shocks on child test scores

(a) Reading test scores

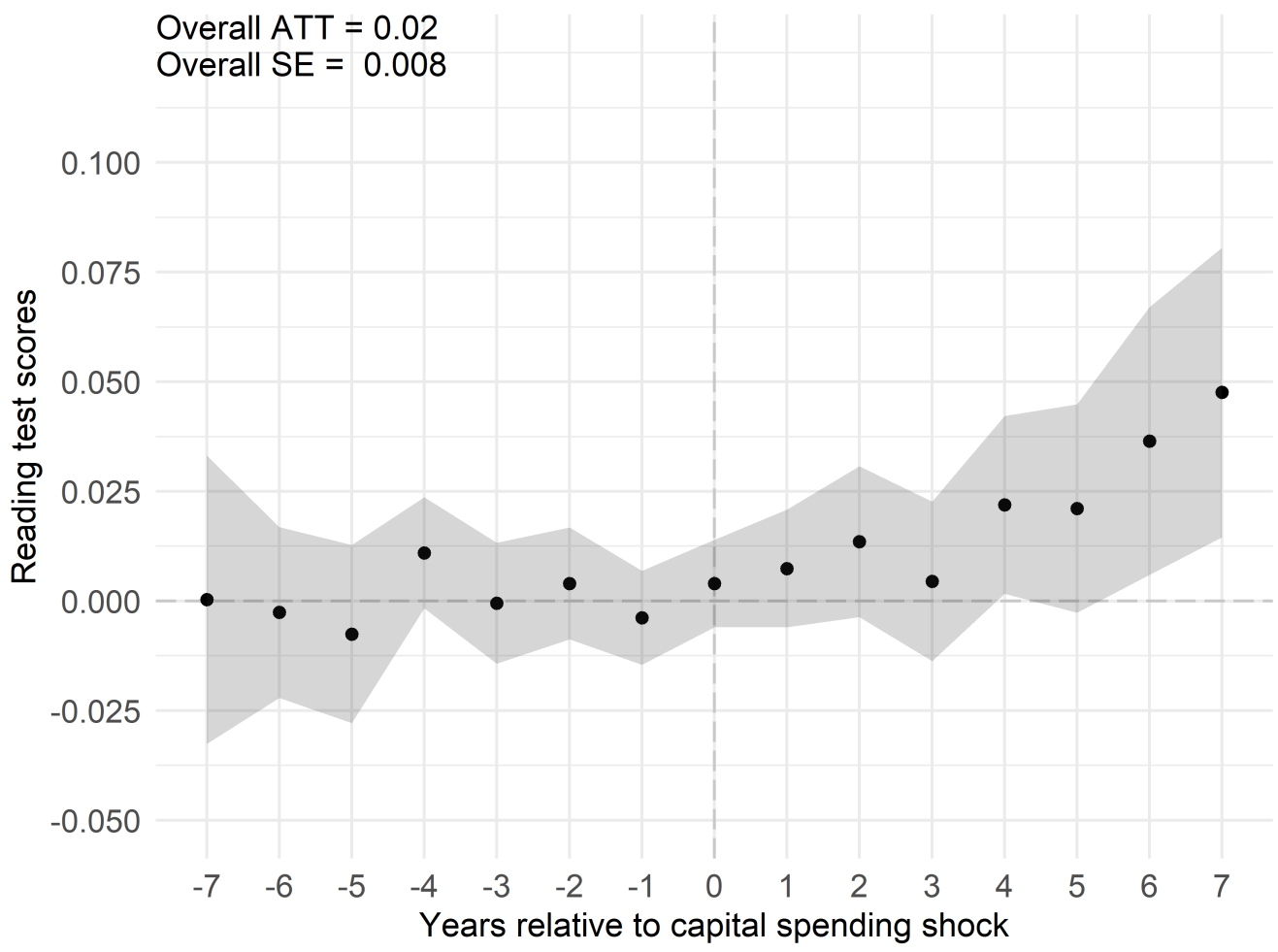

(b) Mathematics test scores

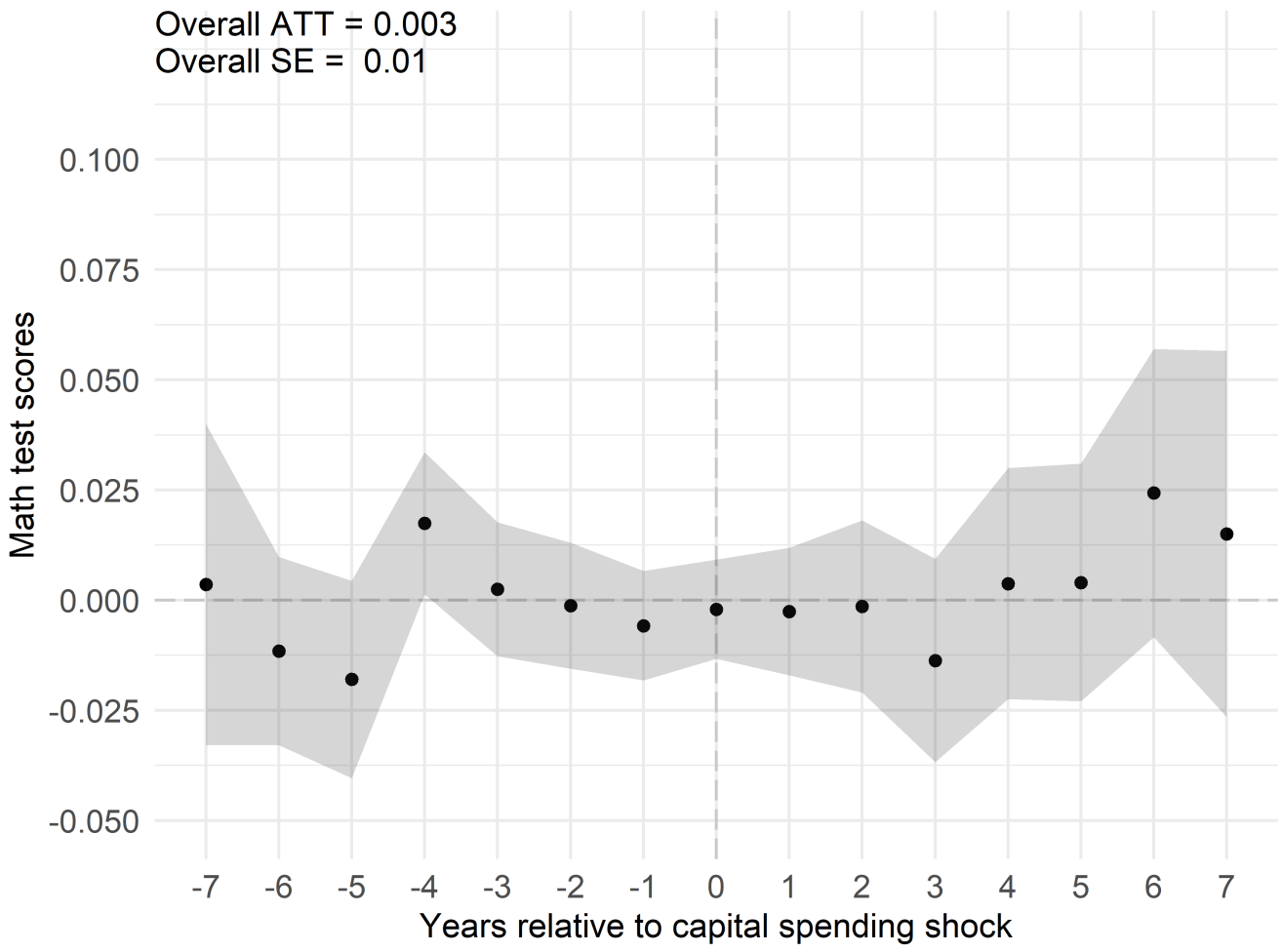

Event study estimates generated using the Callaway and Sant'Anna (2020) procedure described in Section 4 at the school district level. All figures show bootstrapped 95 percent simultaneous confidence intervals. Unlike pointwise confidence intervals, simultaneous confidence intervals include the path of treatment over time with $95 \%$ confidence and account for the dependence of the presented coefficients across event-times. Standard errors are clustered by school district. 
Figure 5: Test score shock size and distance placebo tests

(A) Reading, small shock

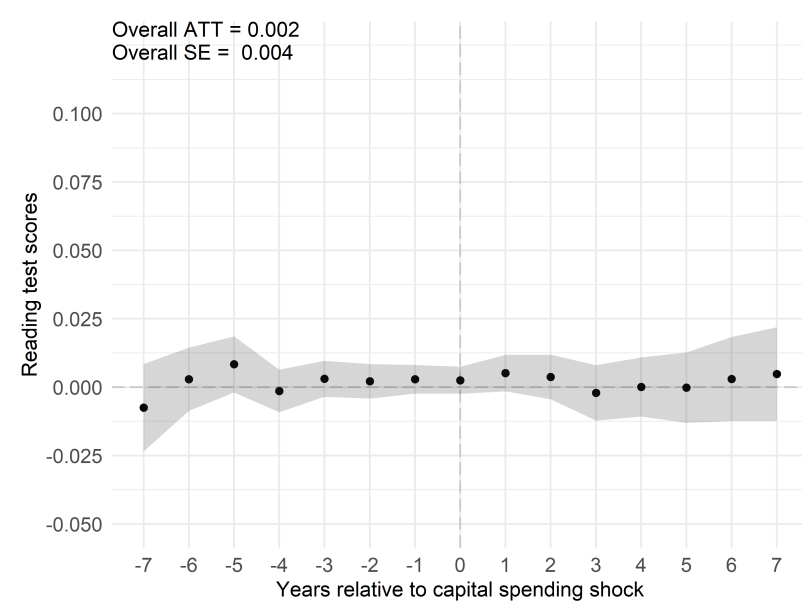

(C) Mathematics, small shock

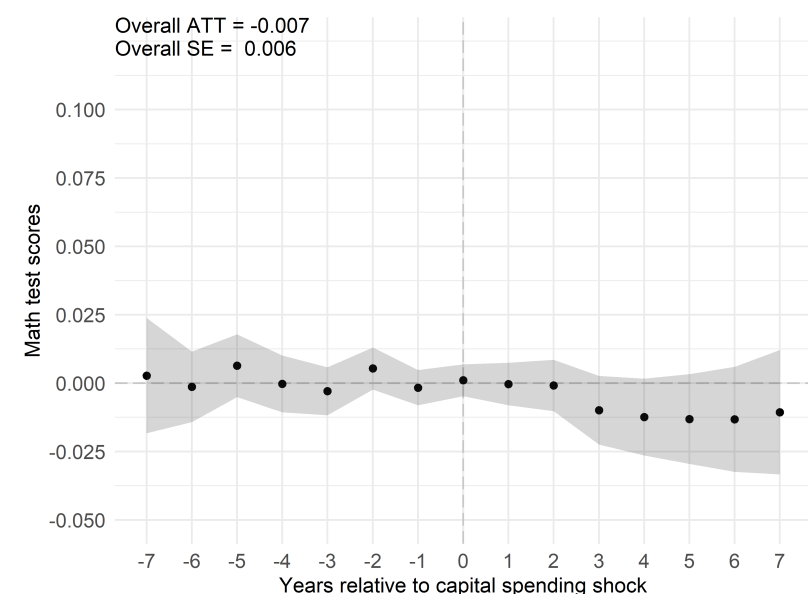

(B) Reading, distance placebo

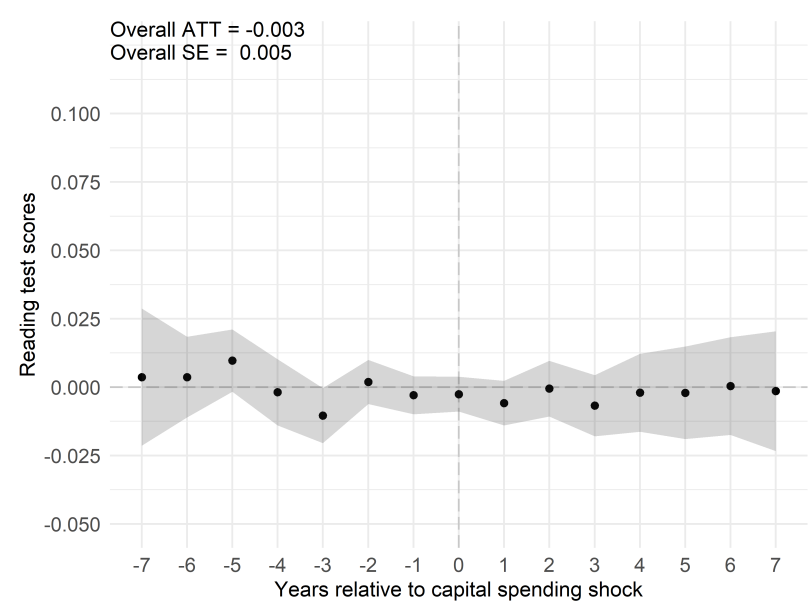

(D) Mathematics, distance placebo

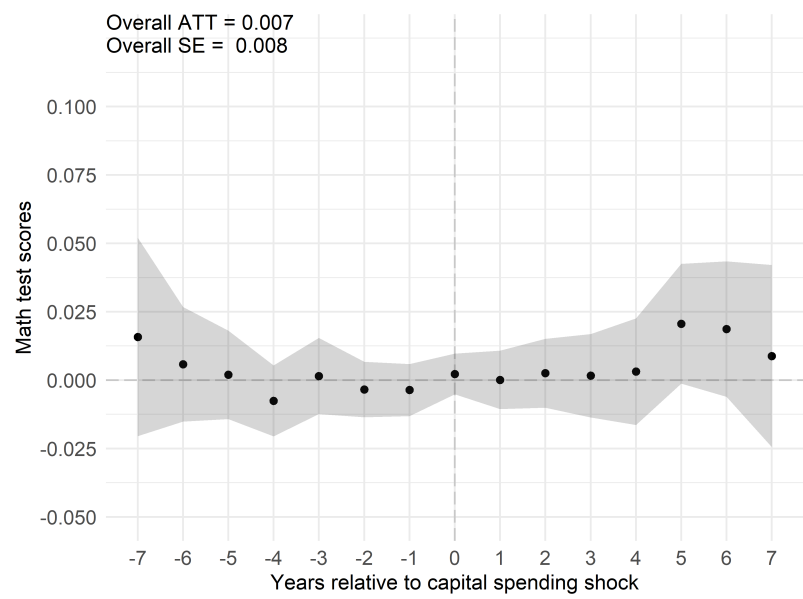

These figures show test score estimates generated using the Callaway and Sant'Anna (2020) procedure described in Section 4 Panels (A) and (C) show results of the baseline estimation approach when using small but positive shocks to library capital spending. Panels (B) and (D) show results when using shocks that occur 20-50 miles from a school district. All figures show bootstrapped 95 percent simultaneous confidence intervals. Unlike pointwise confidence intervals, simultaneous confidence intervals include the path of treatment over time with $95 \%$ confidence and account for the dependence of the presented coefficients across event-times. Standard errors are clustered by school district. 
Figure 6: Heterogeneous reading test score effects by student race and ethnicity
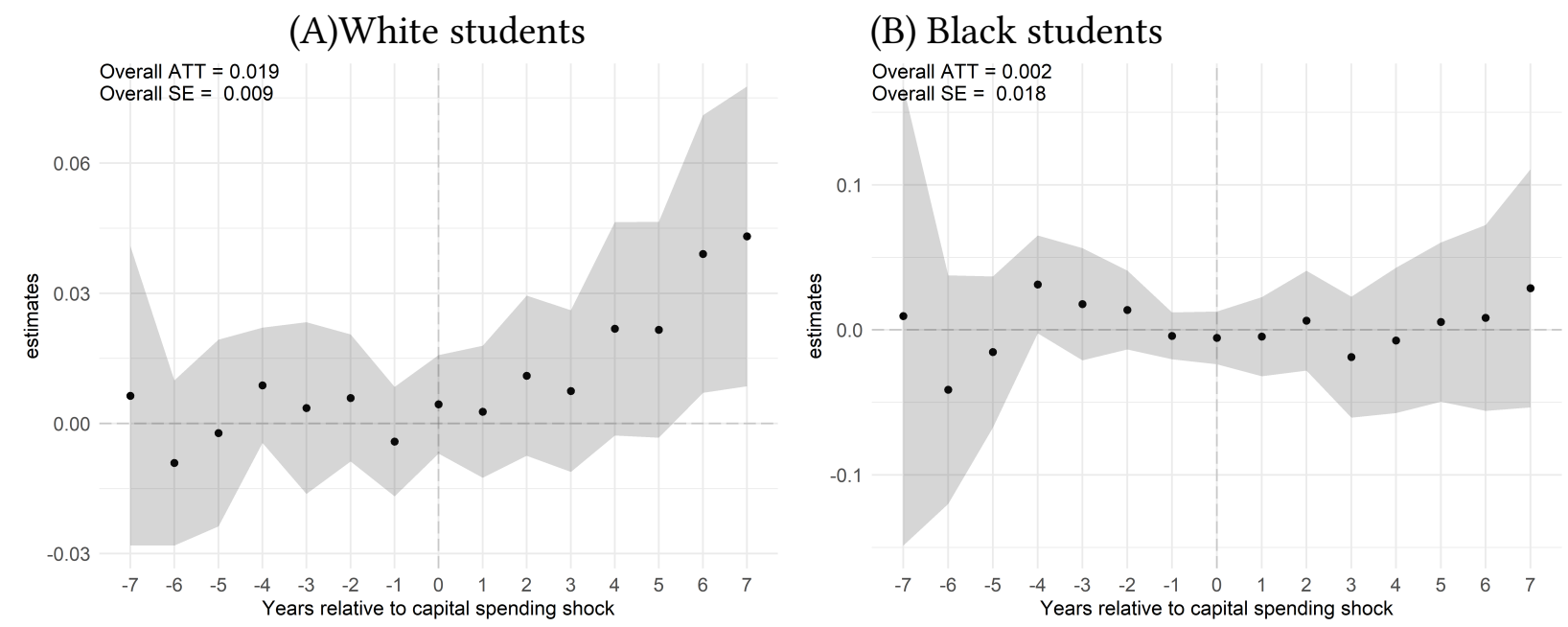

(C) Hispanic students
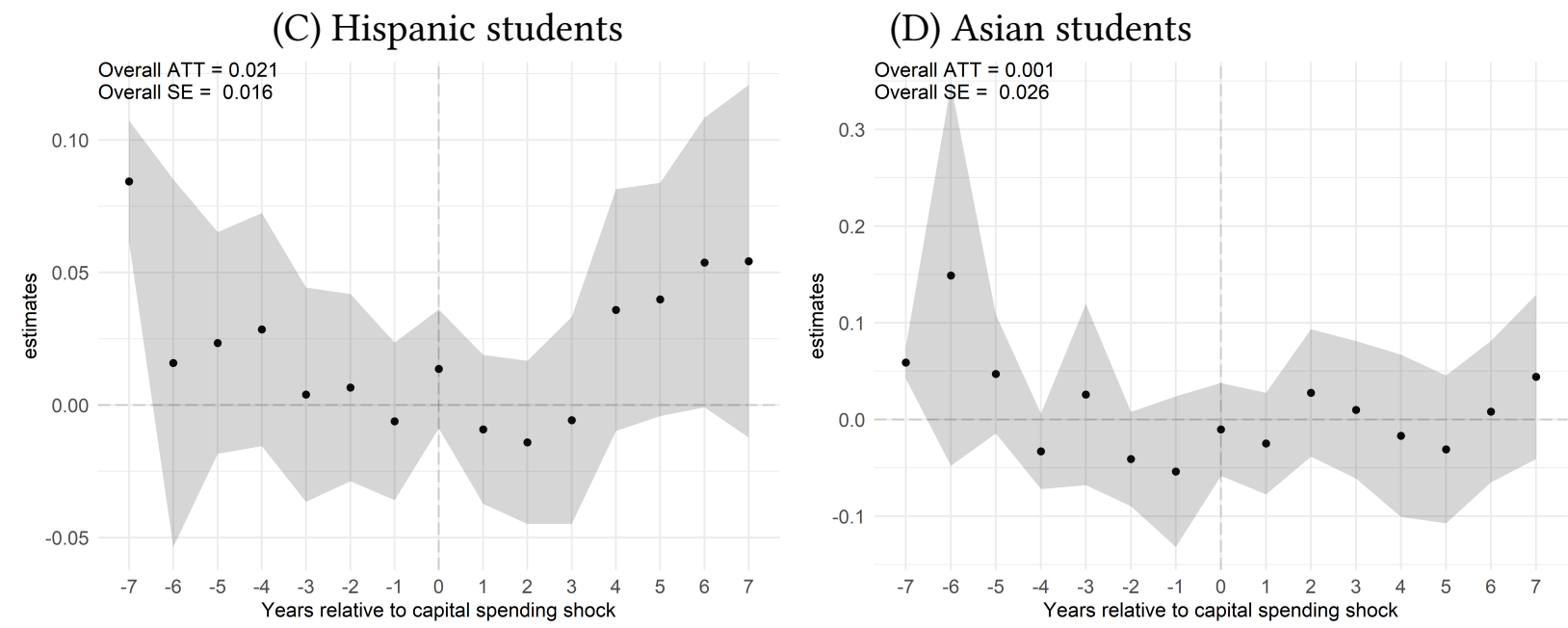

These figures shows test score estimates generated using the Callaway and Sant'Anna (2020) procedure described in Section 4 Effects are estimated separately for each indicated subgroup. 
Figure 7: Heterogeneous reading test score effects by student economic status

(a) Economically disadvantaged

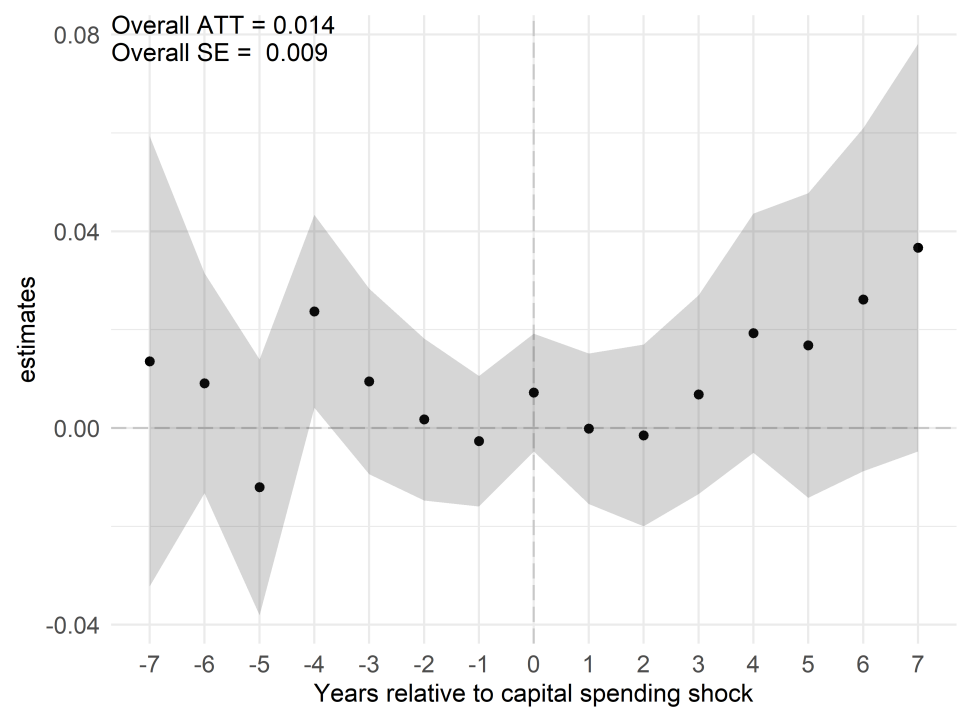

(b) Not economically disadvantaged

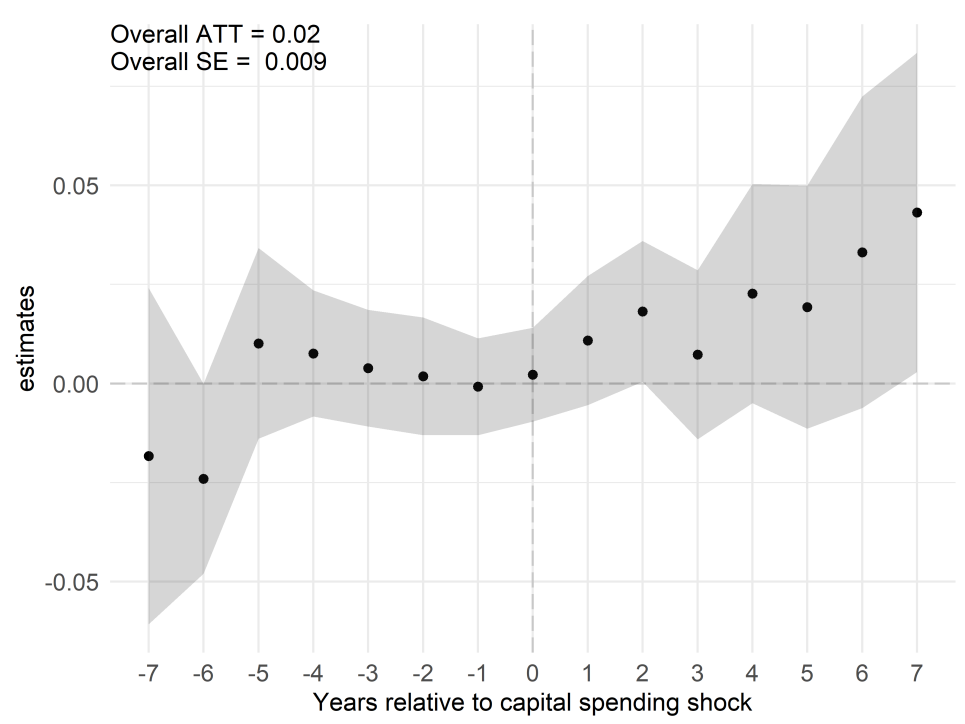

These figures shows test score estimates generated using the Callaway and Sant'Anna (2020) procedure described in Section 4 Effects are estimated separately for each indicated subgroup. 
Figure 8: Heterogeneous reading test score effects by student grades

(a) Grades 3-4

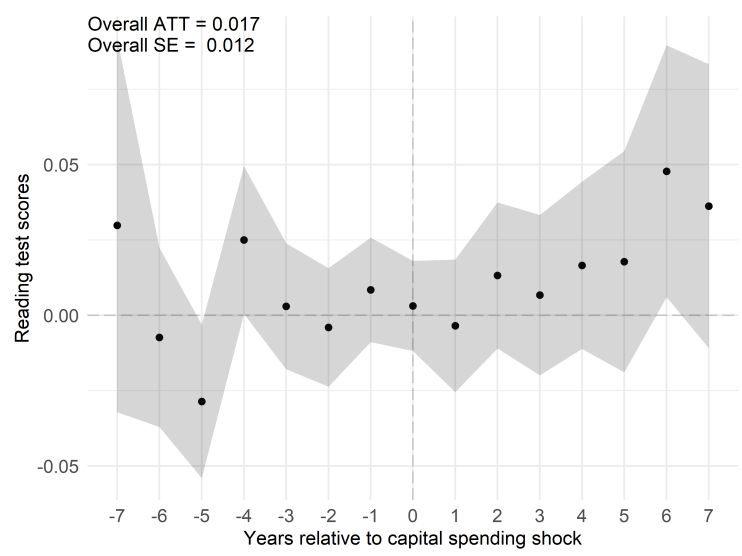

(b) Grades 5-6

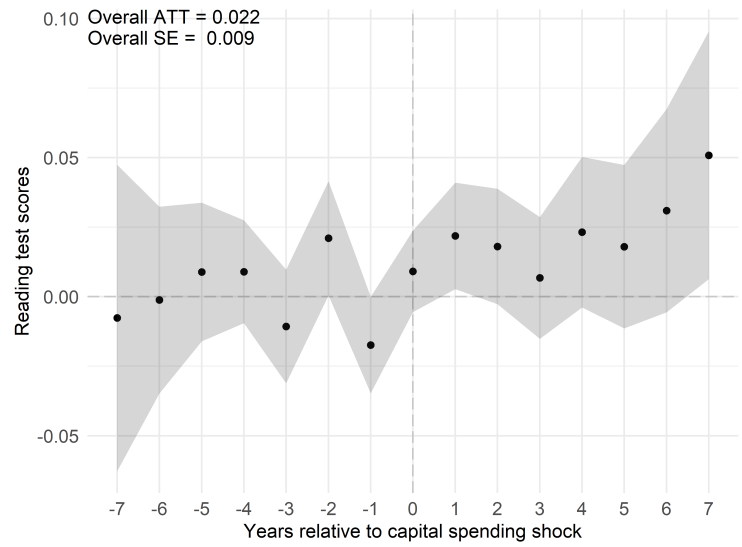

(c) Grades 7-8

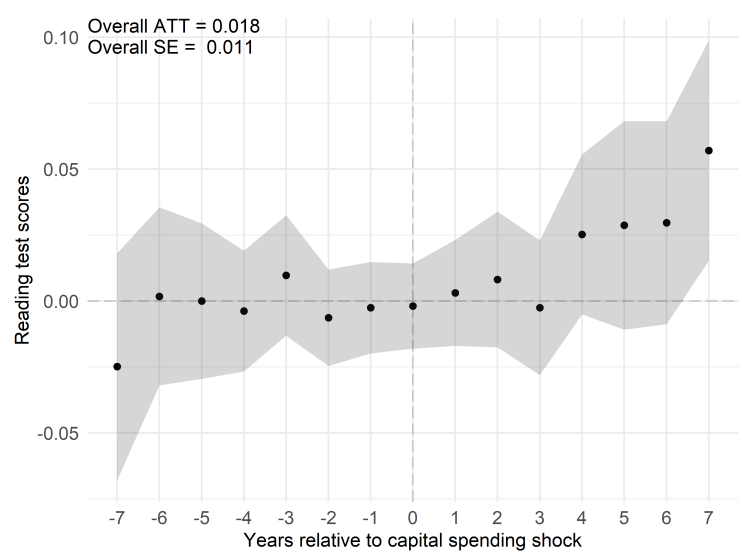

These figures shows test score estimates generated using the Callaway and Sant'Anna (2020) procedure described in Section 4 Effects are estimated separately for each indicated subgroup. 
Figure 9: Heterogeneous reading test score effects by school district size

(a) Smallest size tercile

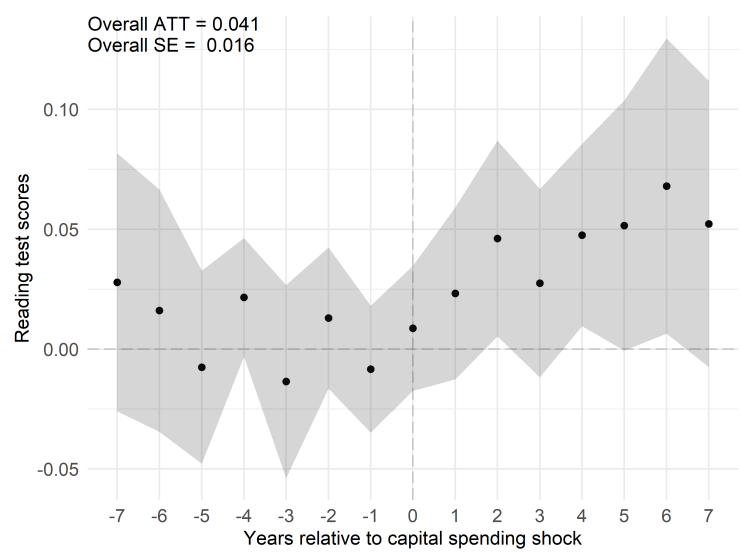

(b) Middle size tercile

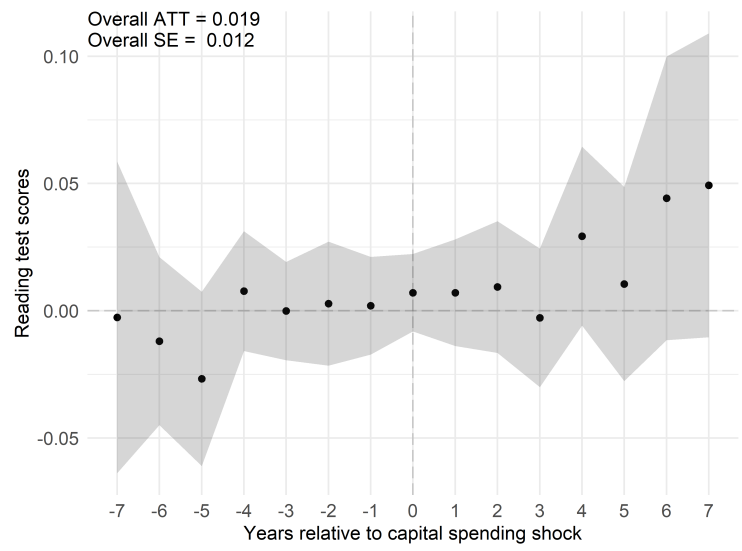

(c) Largest size tercile

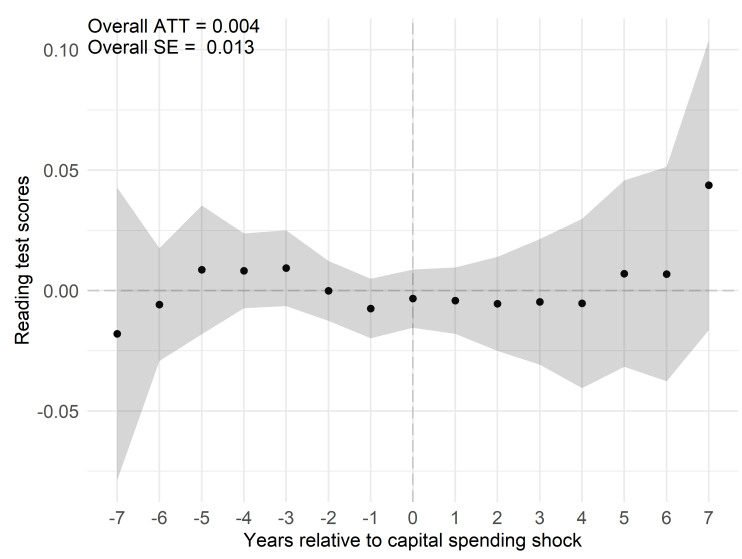

These figures shows test score estimates generated using the Callaway and Sant'Anna (2020) procedure described in Section 4 Effects are estimated separately for each indicated subgroup. 
Figure 10: Heterogeneous reading test score effects by school district capital spending

(a) Smallest spending tercile

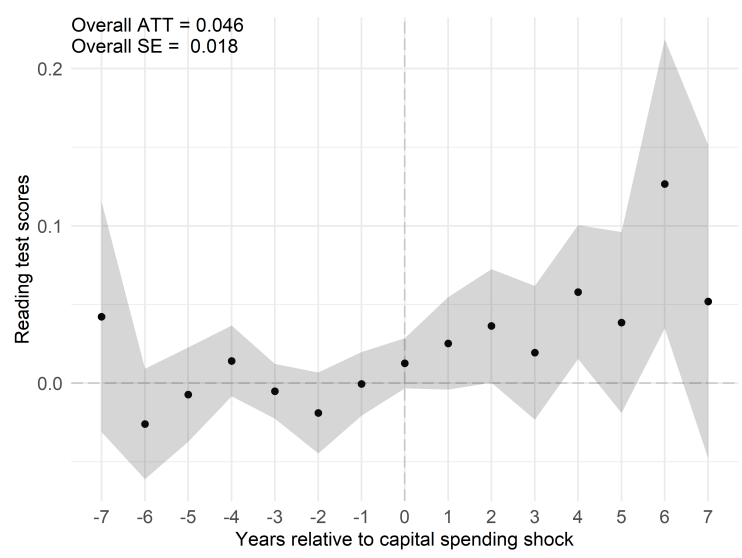

(b) Middle spending tercile

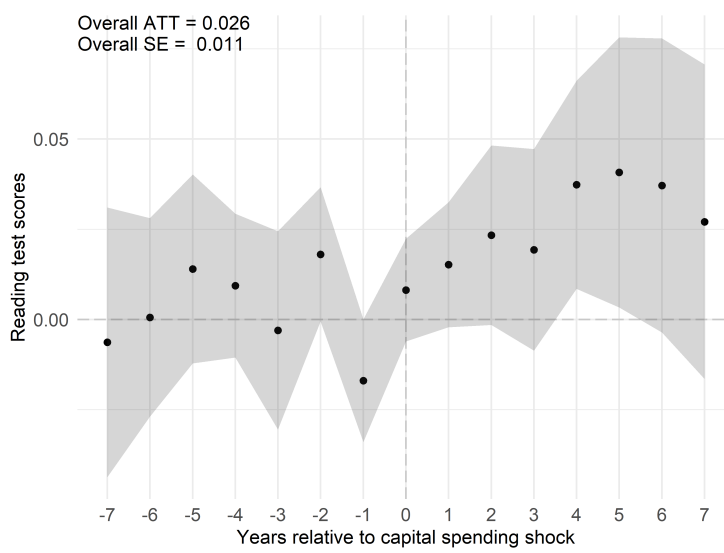

(c) Largest spending tercile

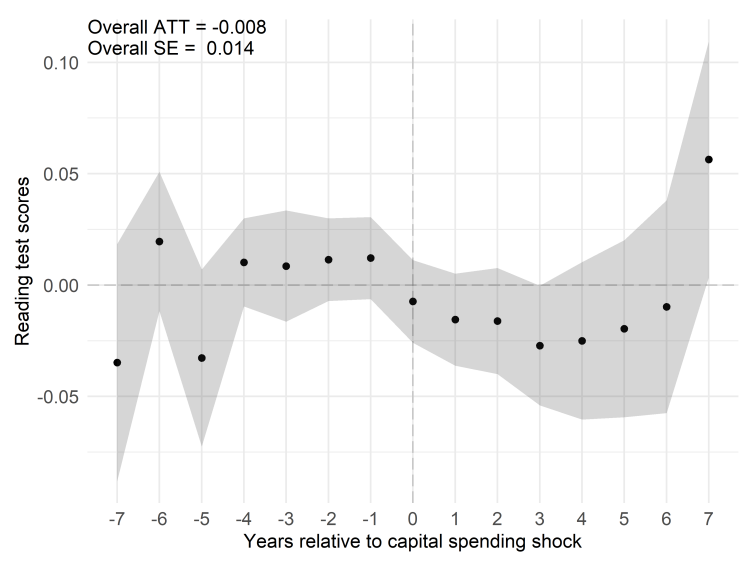

These figures shows test score estimates generated using the Callaway and Sant'Anna (2020) procedure described in Section 4 Effects are estimated separately for each indicated subgroup. 
Figure 11: Impact of library capital spending on local housing prices

(a) Library system level

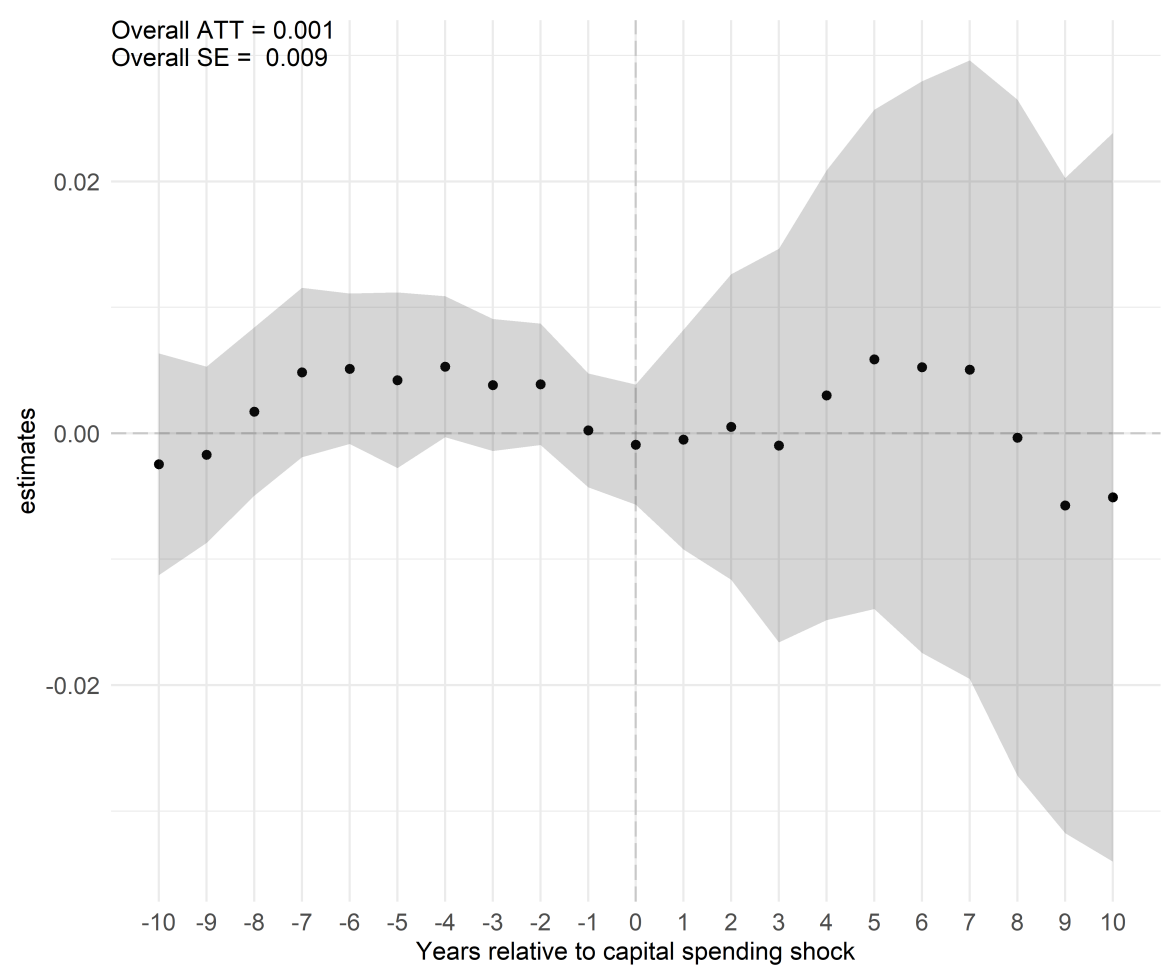

(b) School district level

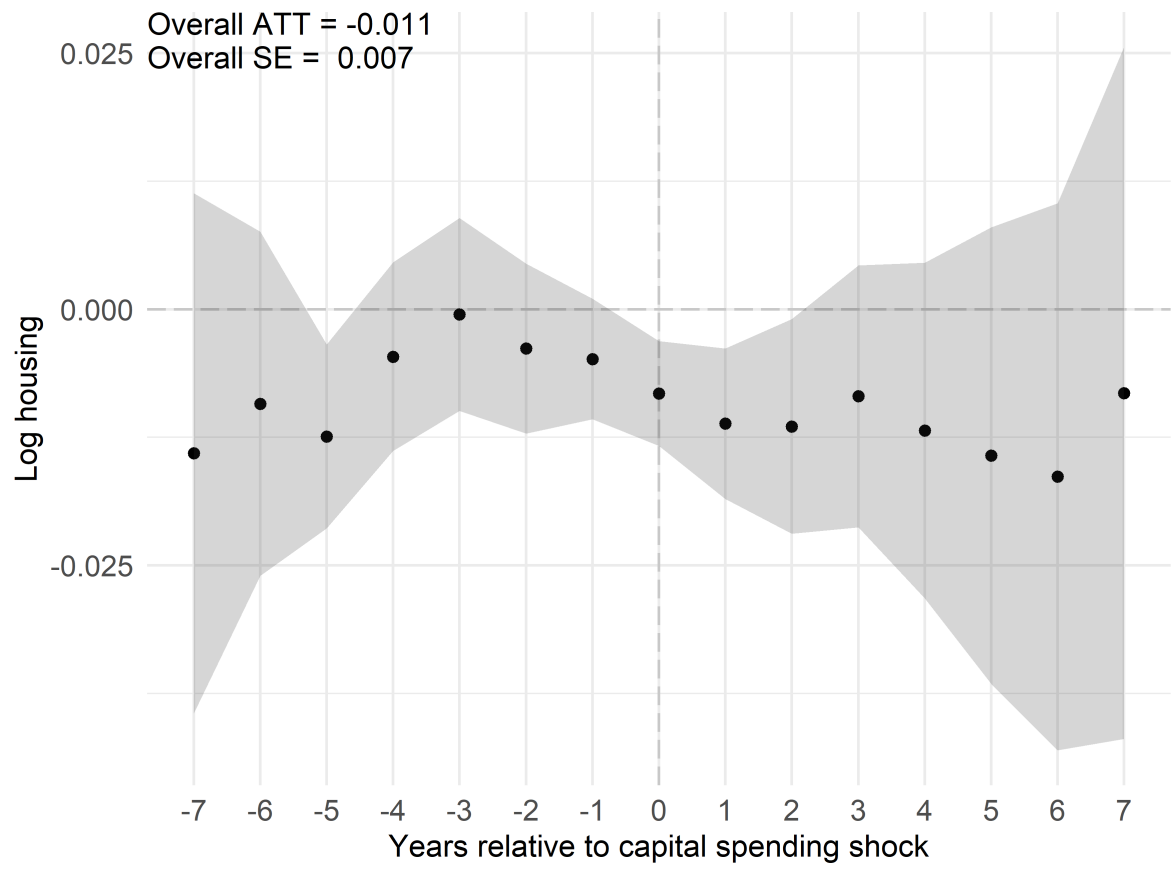

These figure shows housing price estimates generated using the Callaway and Sant'Anna (2020) procedure described in Section 4 Outcomes are logged housing price data from Zillow. Panel (a) shows results at the library system level, panel (b) shows results at the school district level. All figures show bootstrapped 95 percent simultaneous confidence intervals. Unlike pointwise confidence intervals, simultaneous confidence intervals include the path of treatment over time with $95 \%$ confidence and account for the dependence of the presented coefficients across event-times. Standard errors are clustered by school district. 
Table 1: Summary statistics: library system -by- year panel

\begin{tabular}{lcrrrrr}
\hline \hline & Obs. & Mean & 10th \% & Median & 90th \% & Std. Dev. \\
\hline Population Served (thousands) & 204,567 & 13 & 1 & 5 & 33 & 22 \\
Visits (thousands) & 187,354 & 68 & 3 & 23 & 186 & 118 \\
Children Event Attendance (thousands) & 193,878 & 3 & 0 & 1 & 9 & 7 \\
Books (thousands) & 199,797 & 43 & 8 & 24 & 99 & 55 \\
Total Circulation (thousands) & 199,269 & 103 & 4 & 35 & 255 & 207 \\
Children's Circulation (thousands) & 193,419 & 38 & 1 & 12 & 94 & 83 \\
Employees & 200,488 & 7 & 1 & 3 & 18 & 12 \\
Capital Spending (\$1,000s) & 198,297 & 70 & 0 & 0 & 71 & 535 \\
Total Operating Expenditures (\$1,000s) & 198,840 & 503 & 20 & 145 & 1,296 & 1,007 \\
Annual Payroll (\$1,000s) & 116,736 & 431 & 63 & 200 & 1,057 & 636 \\
\hline \hline
\end{tabular}

Notes: This table shows summary statistics describing our library-year panel described in Section 2 All summary statistics are at the library system -by-year level for libraries with no branches between 1992-2017. Data come from the IMLS's PLS census of almost all libraries in the United States. 
Table 2: Summary statistics: school district-by-year panel

\begin{tabular}{|c|c|c|c|c|c|c|}
\hline & Obs. & Mean & 0th \% & edian & oth $\%$ & 1. Dev. \\
\hline Library capital spending $(\$ 1,000 \mathrm{~s})$ & 311,334 & 257.11 & $1 \quad 0.00$ & 1.03 & 416.01 & $1,193.11$ \\
\hline Per-student library capital spending $(\$ s)$ & 311,334 & 188.62 & 0.00 & 1.12 & 282.26 & $1,130.96$ \\
\hline Child materials circulation (thousands) & 306,203 & 184.51 & 3.10 & 31.23 & 555.41 & 418.78 \\
\hline Child event attendees (thousands) & 306,677 & 15.90 & 0.37 & 4.17 & 47.49 & 30.44 \\
\hline Visits (thousands) & 304,305 & 328.30 & 9.00 & 76.43 & 991.22 & 627.05 \\
\hline Books (thousands) & 309,426 & 177.54 & 14.44 & 52.23 & 488.13 & 317.13 \\
\hline Employees & 309,107 & 33.78 & 1.33 & 7.73 & 97.97 & 67.57 \\
\hline Salary spending (thousands) & 249,506 & $1,806.40$ & 77.98 & 385.10 & $5,213.86$ & $3,528.56$ \\
\hline Operating spendin & 308,535 & $2,852.04$ & 61.43 & 459.98 & $8,232.28$ & $6,321.81$ \\
\hline Library systems & 311,334 & 2.01 & 1.00 & 1.00 & 4.00 & 2.77 \\
\hline Branches & 311,334 & 2.08 & 1.00 & 1.00 & 5.00 & 2.64 \\
\hline Reading & 311,334 & 0.05 & -0.39 & 0.05 & 0.50 & 0.36 \\
\hline Math test s & 296,720 & 0.05 & -0.44 & 0.06 & 0.55 & 0.39 \\
\hline Reading & 311,334 & 326.71 & 38.00 & 152.00 & 673.00 & 995.20 \\
\hline Math test takers & 296,810 & 316.62 & 38.00 & 150.00 & 651.00 & $1,001.15$ \\
\hline Share $N$ & 311,334 & 0.02 & 0.00 & 0.00 & 0.02 & 0.08 \\
\hline Share & 311,334 & 0.02 & 0.00 & 0.01 & 0.06 & 0.05 \\
\hline Share Hispanic & 311,334 & 0.13 & 0.00 & 0.05 & 0.40 & 0.19 \\
\hline Share Blacl & 311,334 & 0.08 & 0.00 & 0.02 & 0.24 & 0.16 \\
\hline hare free 1 & 311,334 & 0.39 & 0.13 & 0.37 & 0.66 & 0.20 \\
\hline hare & 311,334 & 0.08 & 0.03 & 0.08 & 0.13 & 0.04 \\
\hline Share & 311,334 & 0.47 & 0.17 & 0.47 & 0.76 & 0.22 \\
\hline Share BA+ & 311,334 & 0.24 & 0.12 & 0.20 & 0.43 & 0.13 \\
\hline hare s & 311,334 & 0.16 & 0.09 & 0.15 & 0.23 & 0.06 \\
\hline har & 311,334 & 0.11 & 0.03 & 0.10 & 0.19 & 0.06 \\
\hline Share & 311,334 & 0.07 & 0.04 & 0.07 & 0.11 & 0.03 \\
\hline ederal $\mathrm{r}$ & 252,405 & $1,046.90$ & 406.56 & 878.78 & $1,779.10$ & 858.35 \\
\hline & 252,405 & $6,126.90$ & $0 \quad 3,041.42$ & $5,780.38$ & $9,097.89$ & $2,950.01$ \\
\hline Local & 252,405 & $6,514.33$ & $\begin{array}{ll}3 & 2,268.95\end{array}$ & $5,246.821$ & $12,607.70$ & $4,749.14$ \\
\hline Total e & 252,405 & $13,590.16$ & $6 \quad 9,135.97$ & $12,183.621$ & $19,758.42$ & $5,152.79$ \\
\hline Capital & 252,405 & $1,129.01$ & 109.33 & 498.44 & $2,570.88$ & $2,132.60$ \\
\hline ises (per student, $\$ 1,000 \mathrm{~s}$ ) & 252,402 & 816.24 & 0.00 & 195.20 & $2,069.70$ & $2,000.45$ \\
\hline & 252,405 & $6,657.99$ & $9 \quad 4,711.59$ & $6,042.37$ & $9,575.35$ & $2,183.88$ \\
\hline Instructional salary expenses (per student, $\$ 1,000$ s) & 252,405 & $4,582.44$ & $43,214.06$ & $4,149.23$ & $6,596.17$ & $1,551.33$ \\
\hline
\end{tabular}

Notes: This table shows summary statistics describing our school district-year panel described in Section 2 All summary statistics are at the school district -by-year level for school districts with fewer than 20 library buildings within 5 miles of the main zip code of the school district. Data cover the years 2009-2018 because those are the years for which we have test score data. Data come from (1) the IMLS's PLS census of almost all libraries in the United States; (2) the SEDA test score dataset (see Fahle et al., 2019 for more details); and (3) the Common Core of Data-a database produced by NCES describing school-level and district-level financing information. Test-taker counts, student demographics, and the number of students on a free or reduced price lunch program come from the SEDA data. 


\section{Figure A1: Effect of capital expenditure shock on library use per person (library-level shocks)}

\section{(A) Log capital spending}

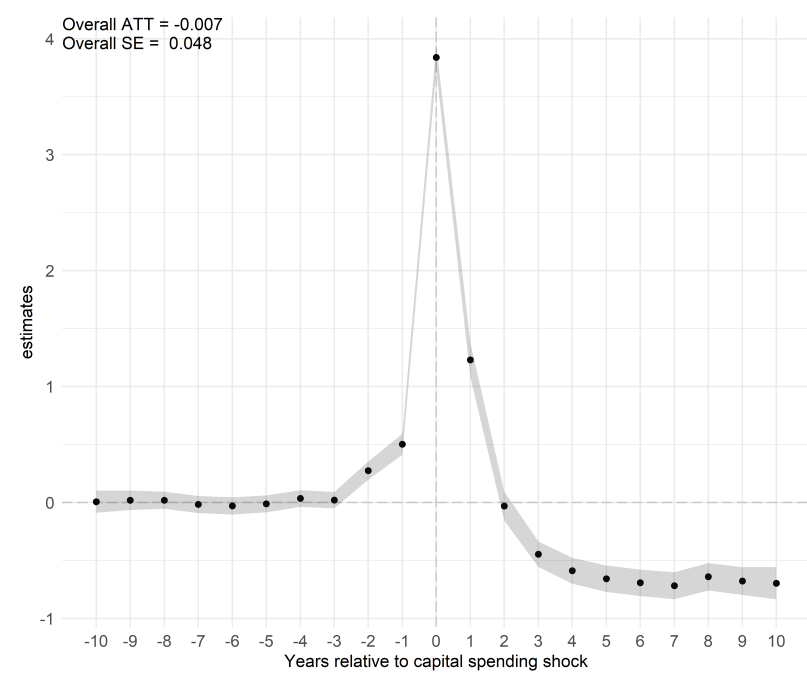

(C) Log children event attendance

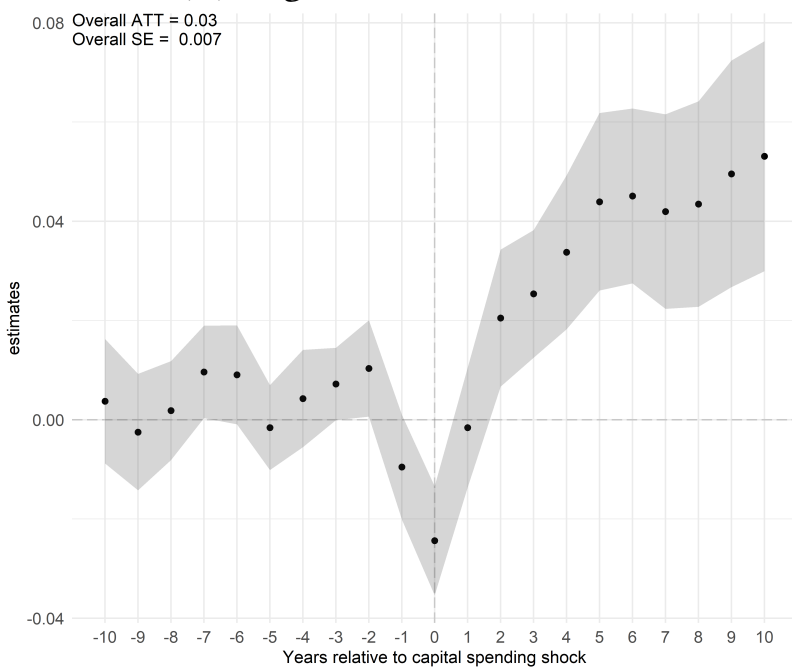

(B) Log children's circulation

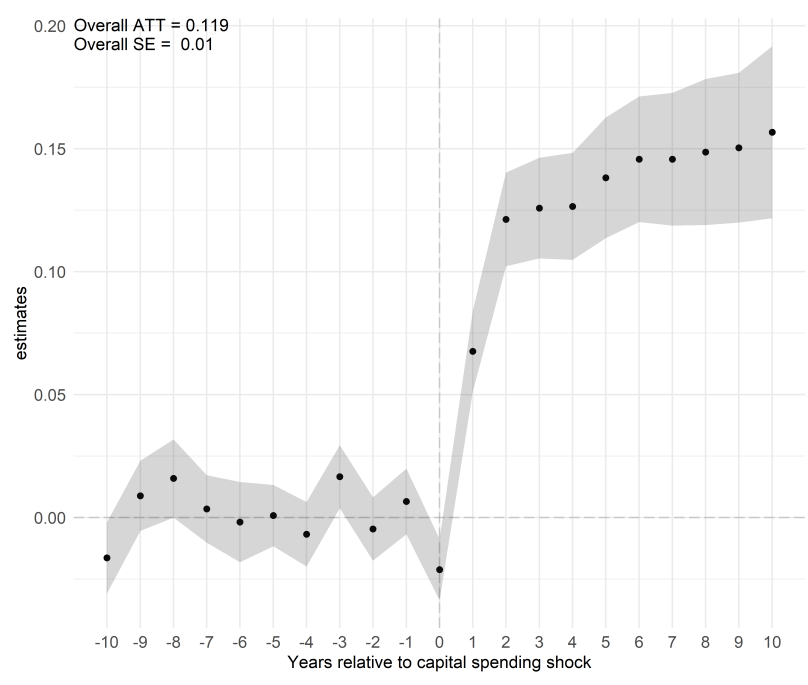

(D) Log visits

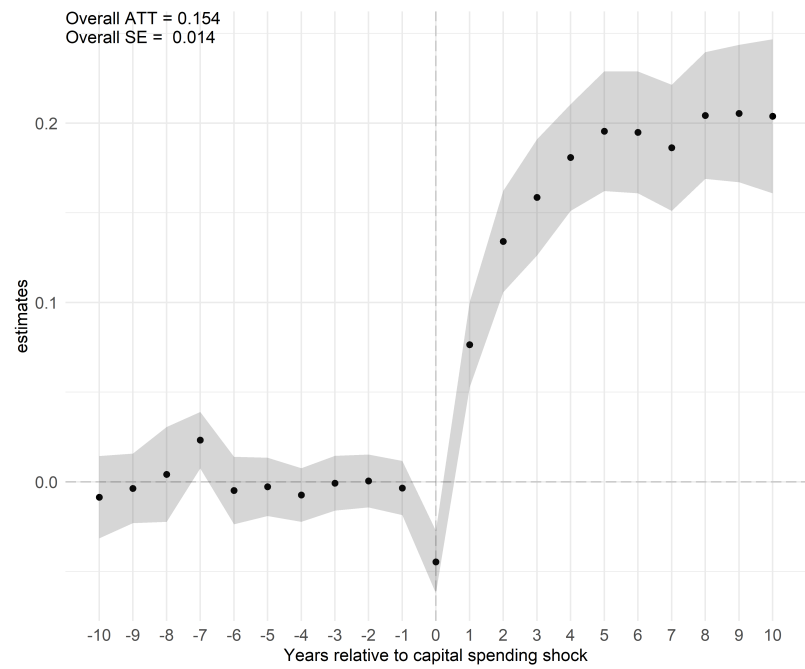

Event study estimates generated using the Callaway and Sant'Anna (2020) procedure described in Section 3 at the library-system level. A library spending shock is defined in Section 3 The outcome variables are (A) Log capital spending, (B) Log children's circulation, (C) log children's event attendance, and (D) log visits. Outcomes are normalized to a per-person measure by dividing by each library's service population. All figures show bootstrapped 95 percent simultaneous confidence intervals. Unlike pointwise confidence intervals, simultaneous confidence intervals include the path of treatment over time with $95 \%$ confidence and account for the dependence of the presented coefficients across event-times. Standard errors are clustered by library system. 


\section{Figure A2: Effect of capital expenditure shock on library resources}

(A) Log book stock

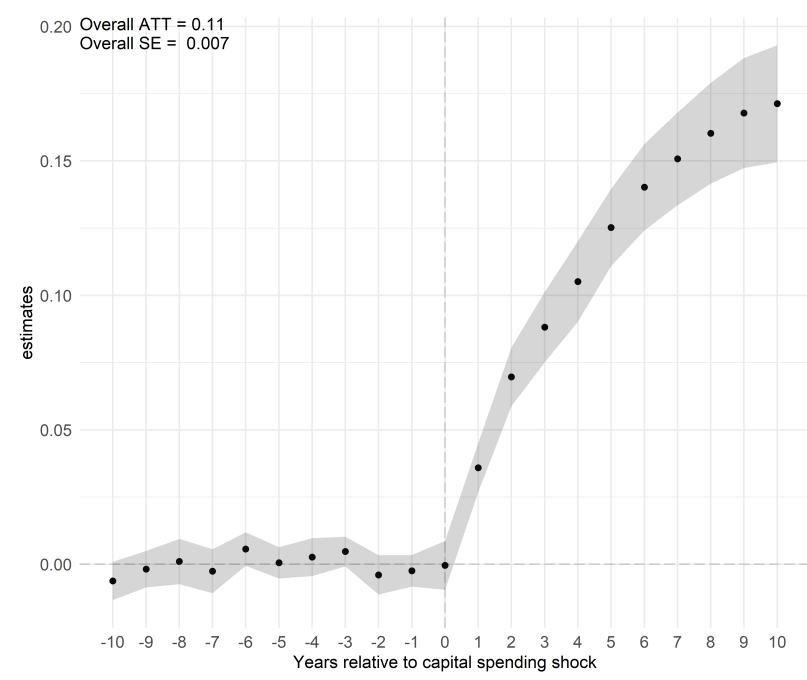

(C) Log salary spending

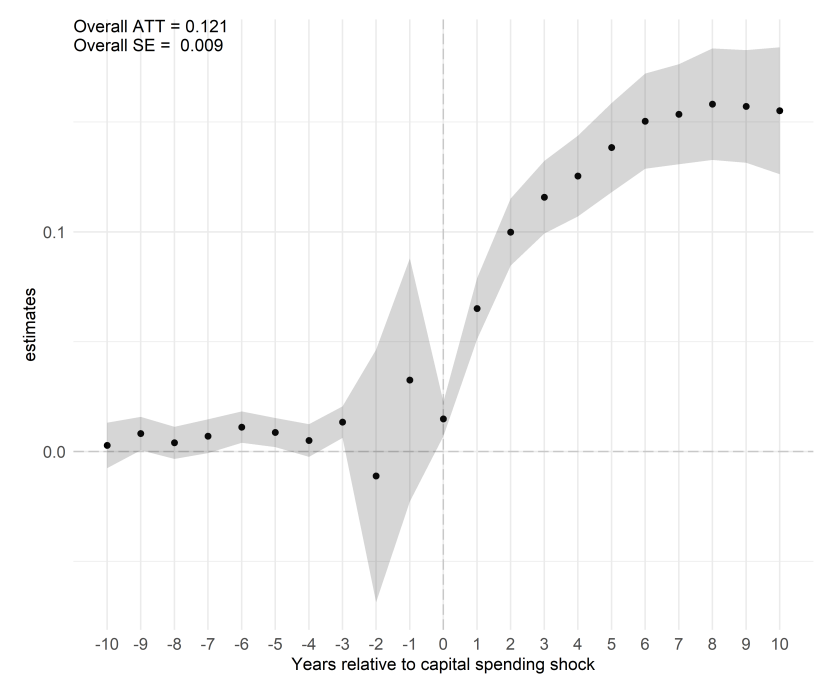

(B) Log number employees

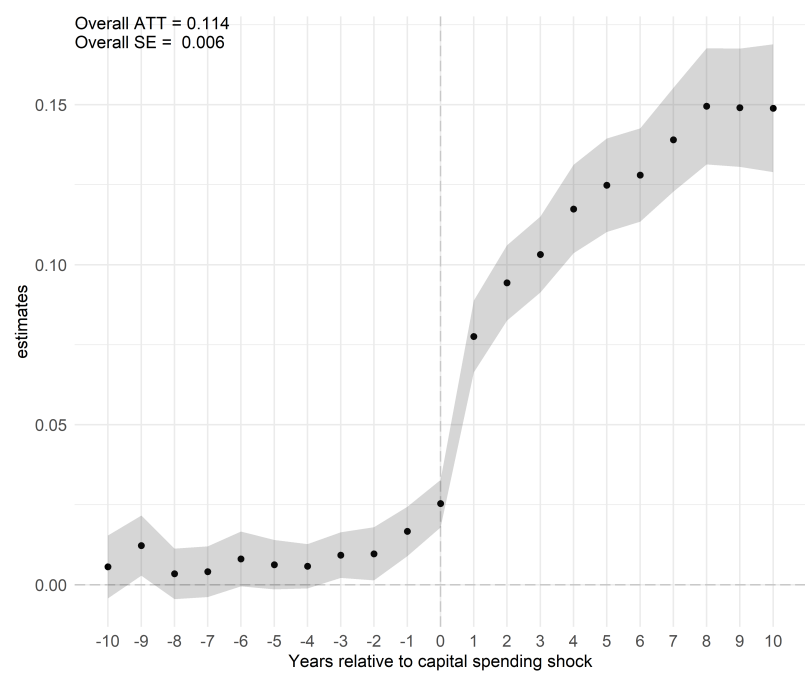

(D) Log operating spending

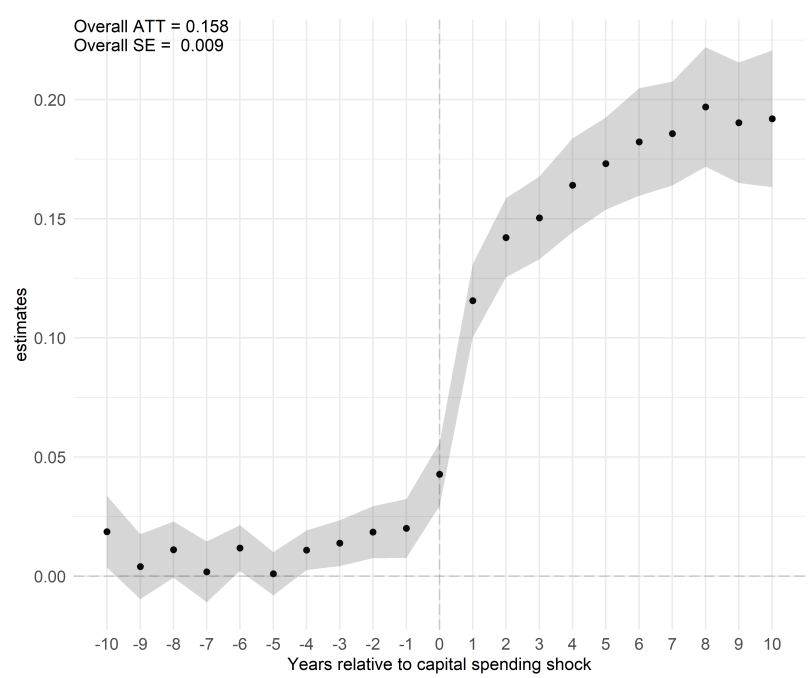

Event study estimates generated using the Callaway and Sant'Anna (2020) procedure described in Section 3 at the library-system level. A library spending shock is defined in Section 3 The outcome variables are (A) Log book stock, (B) Log number employees, (C) log salary spending, and (D) log operating spending. All figures show bootstrapped 95 percent simultaneous confidence intervals. Unlike pointwise confidence intervals, simultaneous confidence intervals include the path of treatment over time with $95 \%$ confidence and account for the dependence of the presented coefficients across event-times. Standard errors are clustered by library system. 


\section{Figure A3: Effect of capital expenditure shock on library resources per person}

(A) Log book stock

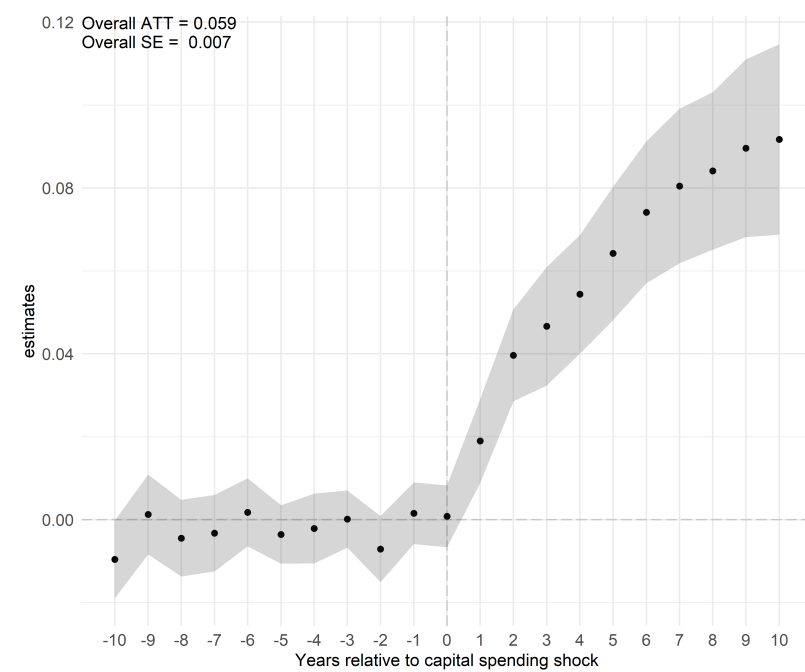

(C) Log salary spending

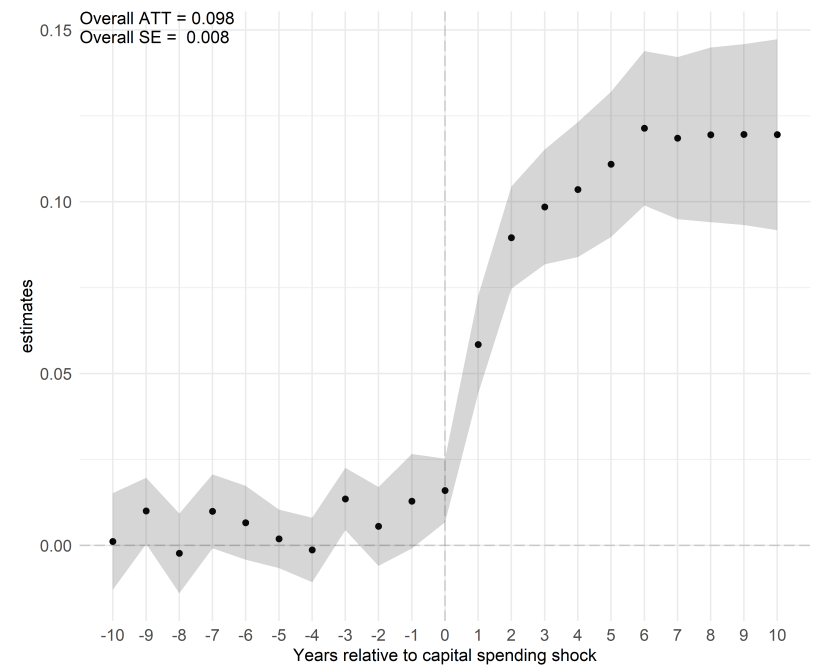

(B) Log number employees

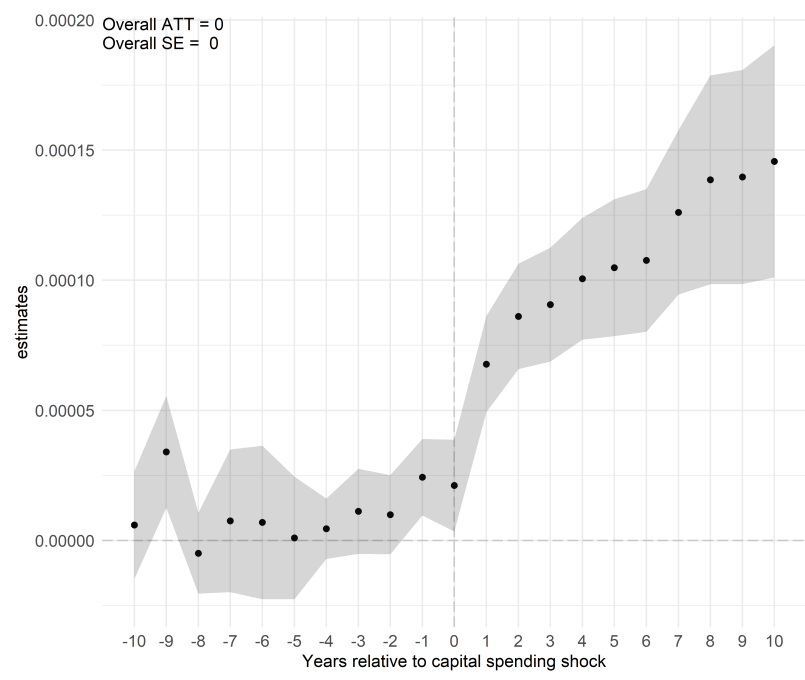

(D) Log operating spending

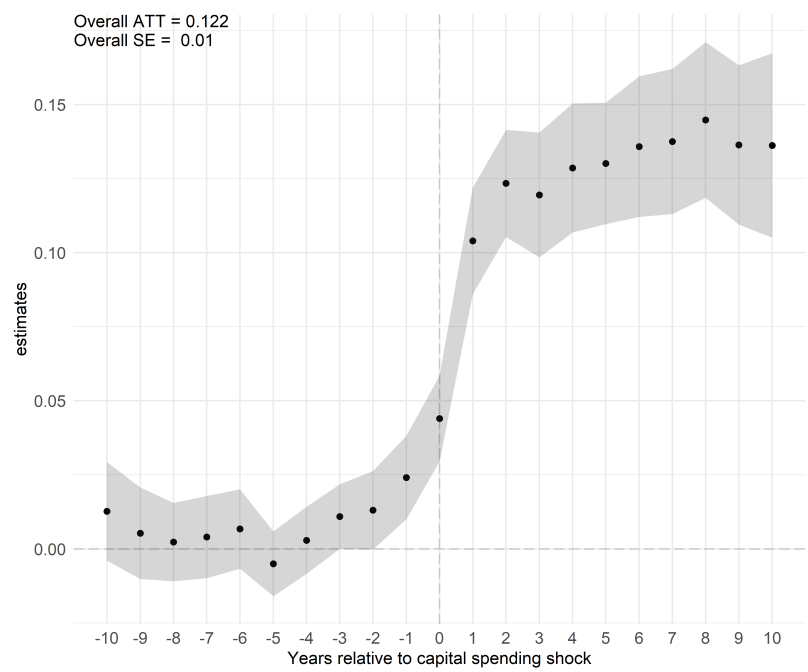

Event study estimates generated using the Callaway and Sant'Anna (2020) procedure described in Section 3 at the library-system level. A library spending shock is defined in Section 3 The outcome variables are (A) Log book stock, (B) Log number employees, (C) log salary spending, and (D) log operating spending. Outcomes are normalized to a per-person measure by dividing by each library's service population. All figures show bootstrapped 95 percent simultaneous confidence intervals. Unlike pointwise confidence intervals, simultaneous confidence intervals include the path of treatment over time with $95 \%$ confidence and account for the dependence of the presented coefficients across event-times. Standard errors are clustered by library system. 
Figure A4: Impact of capital expenditure shock on library resources (school-district shocks)

(A) Log book stock

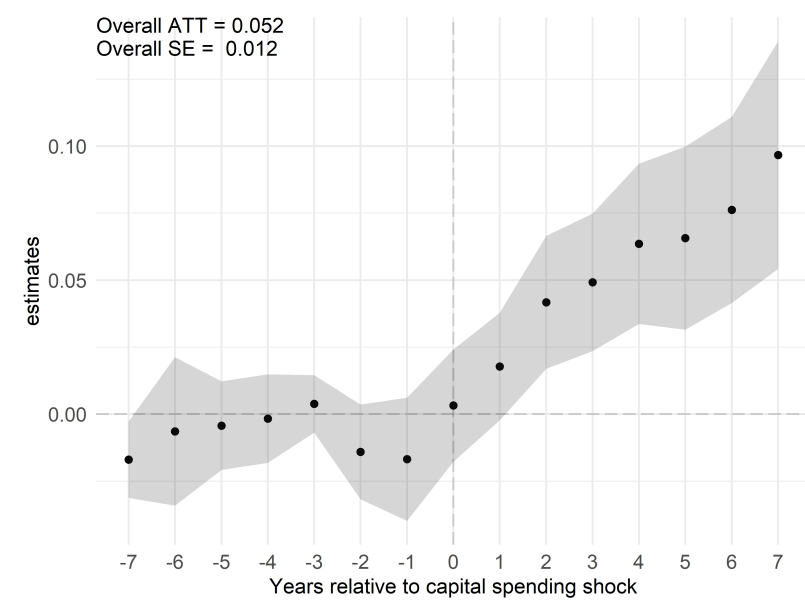

(C) Log salary spending

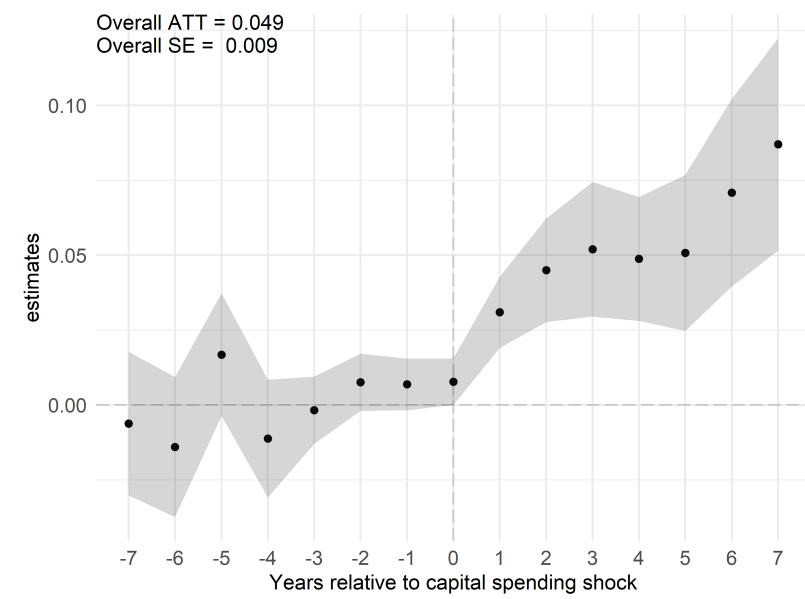

(B) Log number employees

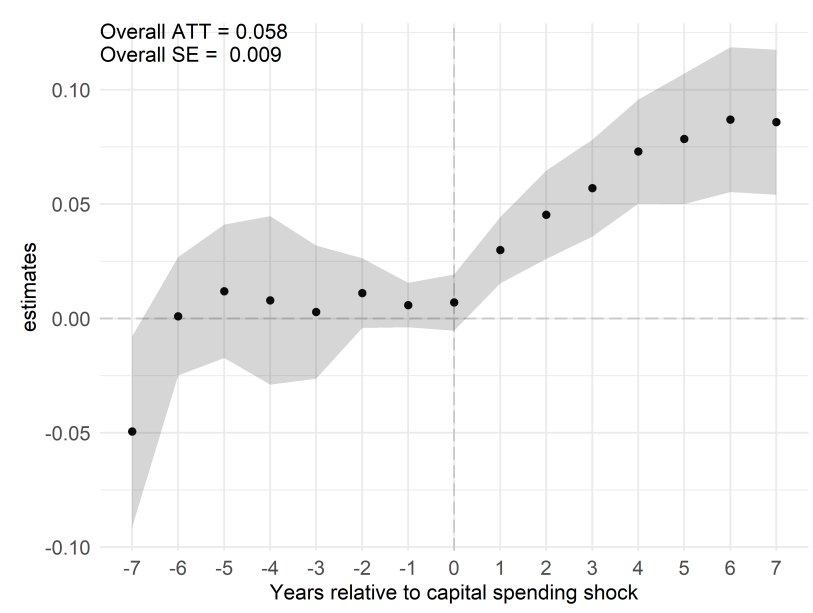

(D) Log operating spending

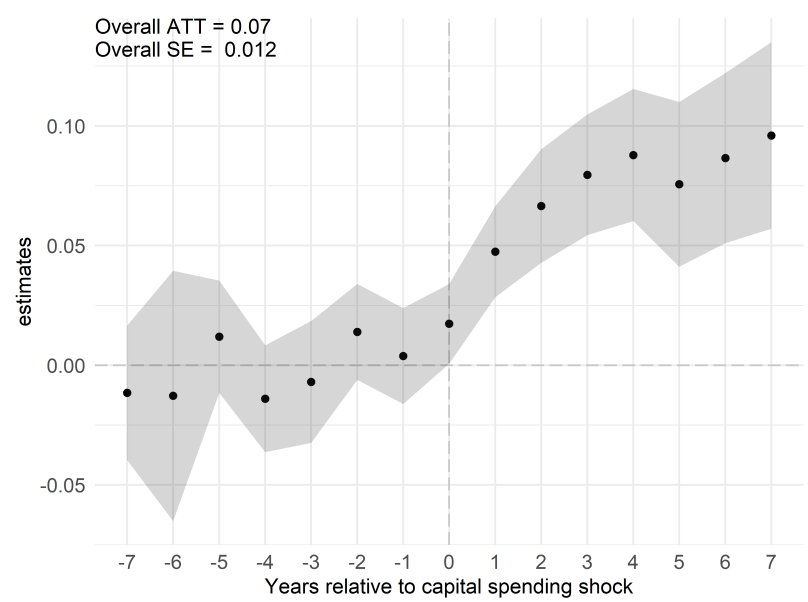

Event study estimates generated using the Callaway and Sant'Anna (2020) procedure described in Section 3 at the school district level. A library spending shock is defined in Section 3 The outcome variables are (A) Log capital spending, (B) Log children's circulation, (C) log children's event attendance, and (D) log visits. All figures show bootstrapped 95 percent simultaneous confidence intervals. Unlike pointwise confidence intervals, simultaneous confidence intervals include the path of treatment over time with $95 \%$ confidence and account for the dependence of the presented coefficients across event-times. Standard errors are clustered by school district. 
Figure A5: Dynamic correlation between capital expenditure shocks and school district characteristics

(A) Share Black students

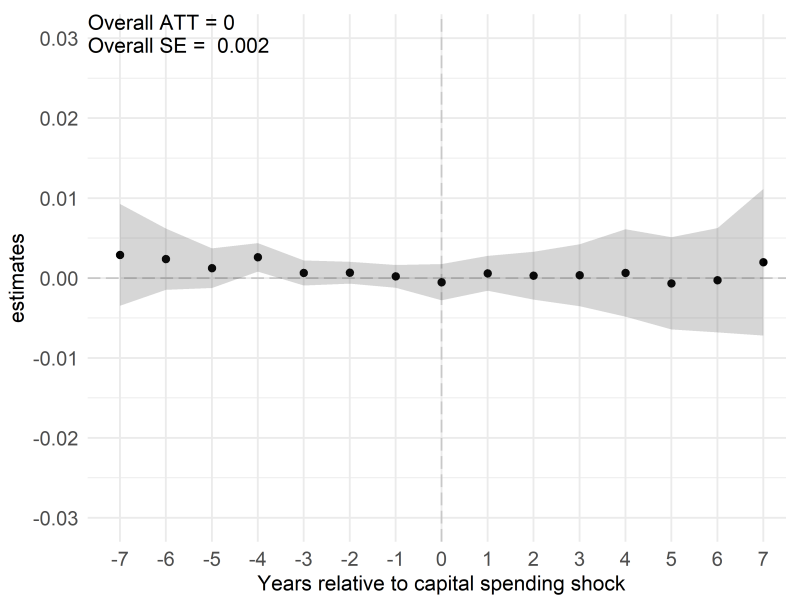

(C) Share Asian students

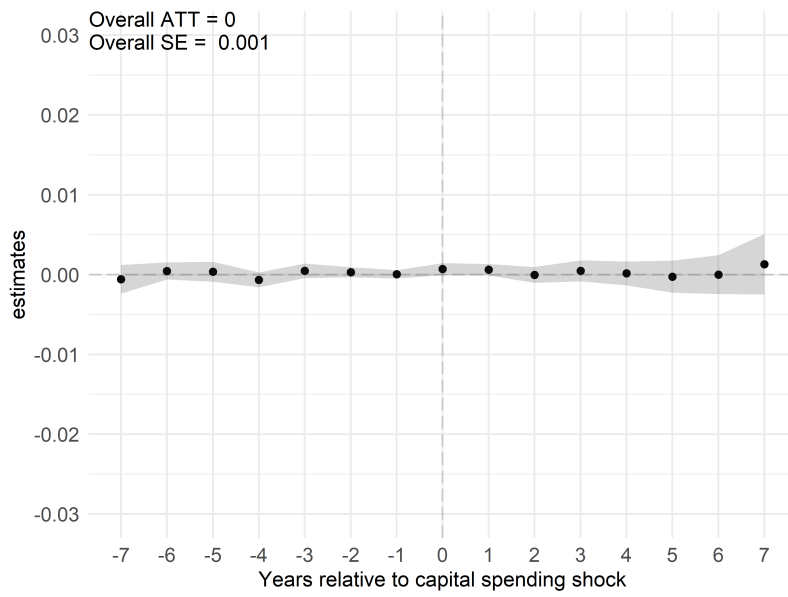

(B) Share Hispanic students

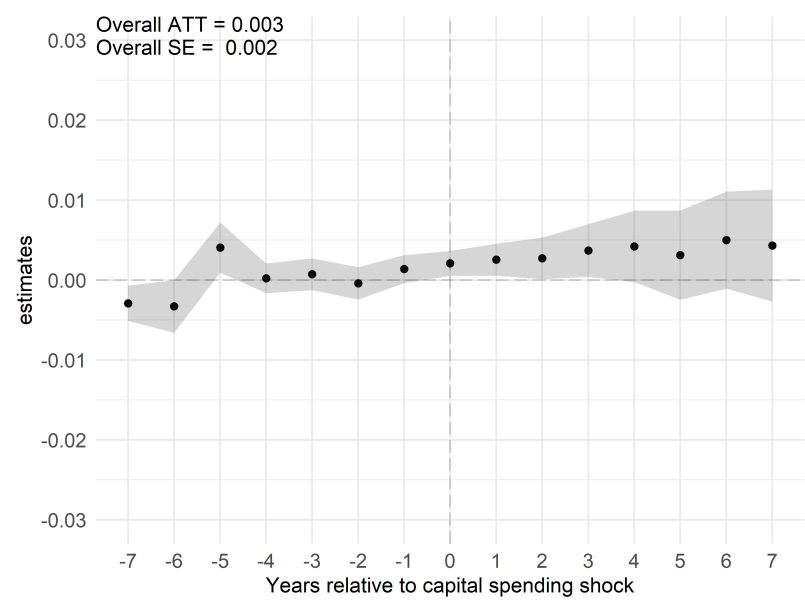

(D) Share Native American students

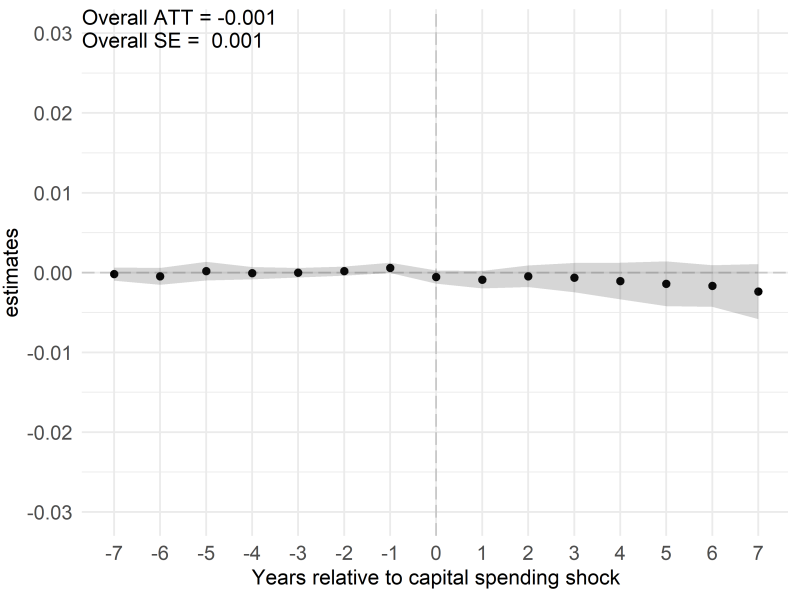

Event study estimates generated using the Callaway and Sant'Anna (2020) procedure described in Section 4 at the school district level. A library spending shock is defined in Section 4 The outcome variables are (A) Share Black students, (B) Share Hispanic students, (C) Share Asian students, and (D) log Share Native American students. All figures show bootstrapped 95 percent simultaneous confidence intervals. Unlike pointwise confidence intervals, simultaneous confidence intervals include the path of treatment over time with $95 \%$ confidence and account for the dependence of the presented coefficients across event-times. Standard errors are clustered by school district. 
Figure A6: Dynamic correlation between capital expenditure shocks and additional school district characteristics

(a) Share of students who qualify for free lunch

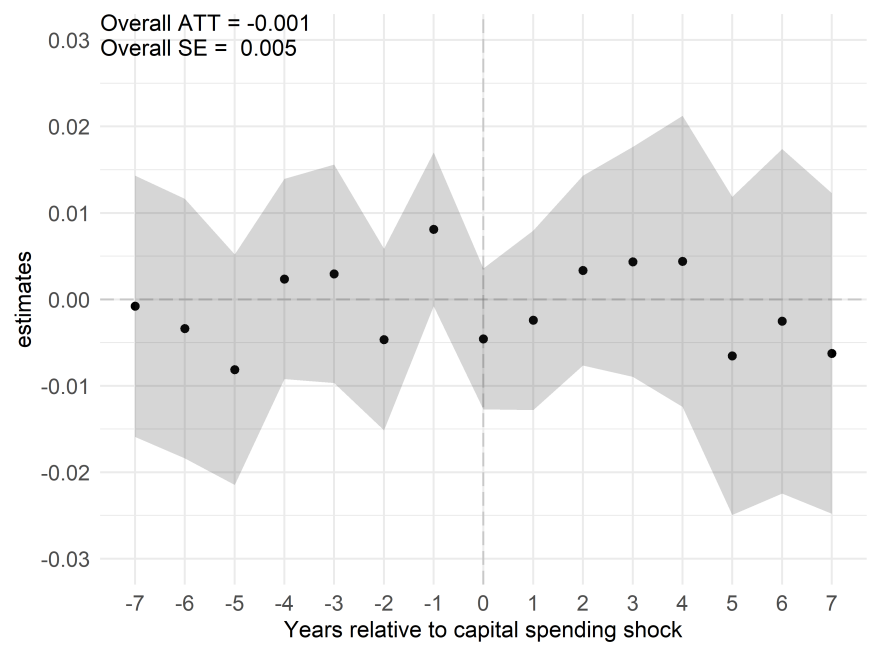

(b) Share of students who qualify for reduced price lunch

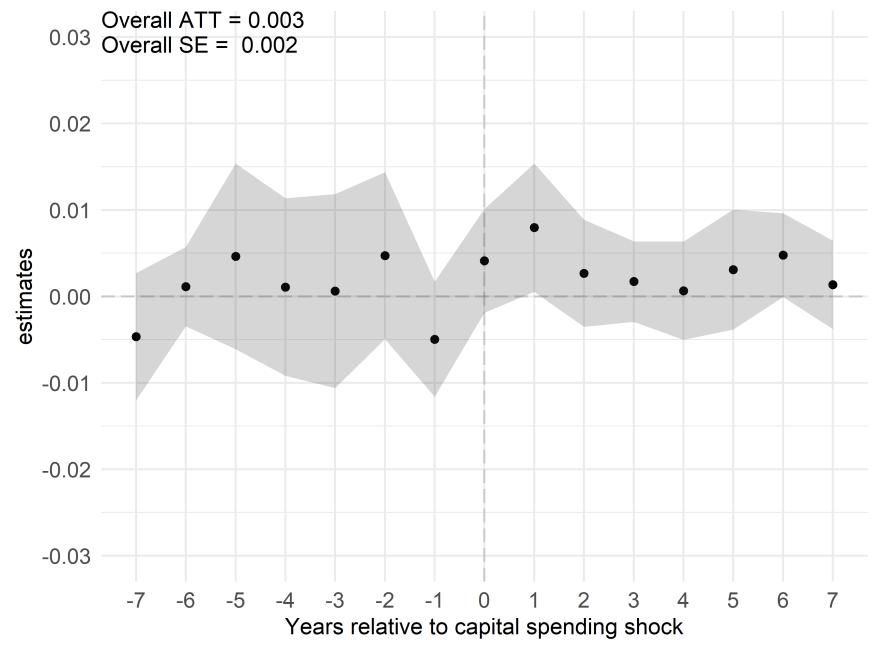

(c) Share of disadvantaged students

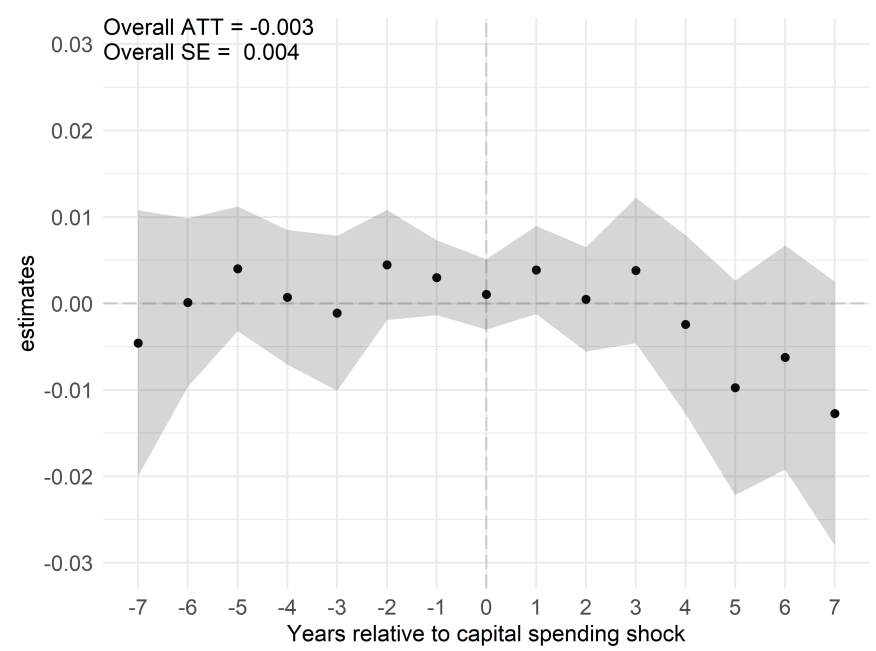

Event study estimates generated using the Callaway and Sant'Anna (2020) procedure described in Section 4 at the school district level. A library spending shock is defined in Section 4 


\section{Figure A7: Impact of capital expenditure shocks on community characteristics}

\section{(A) Share unemployed}

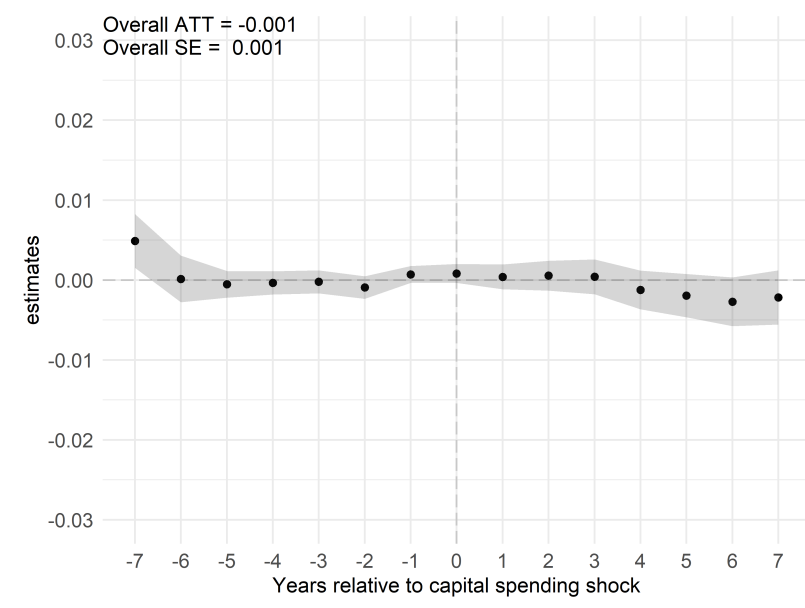

(C) Share BA-plus adults

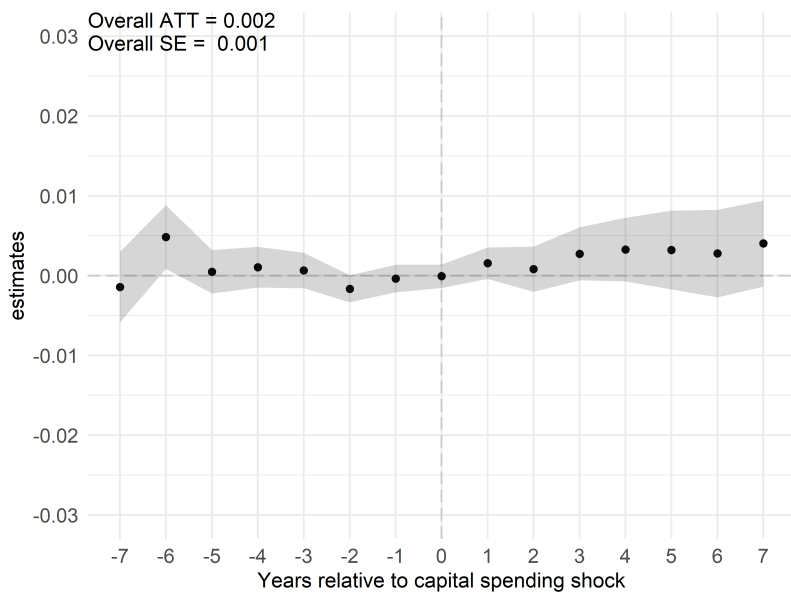

(B) Share SNAP eligible

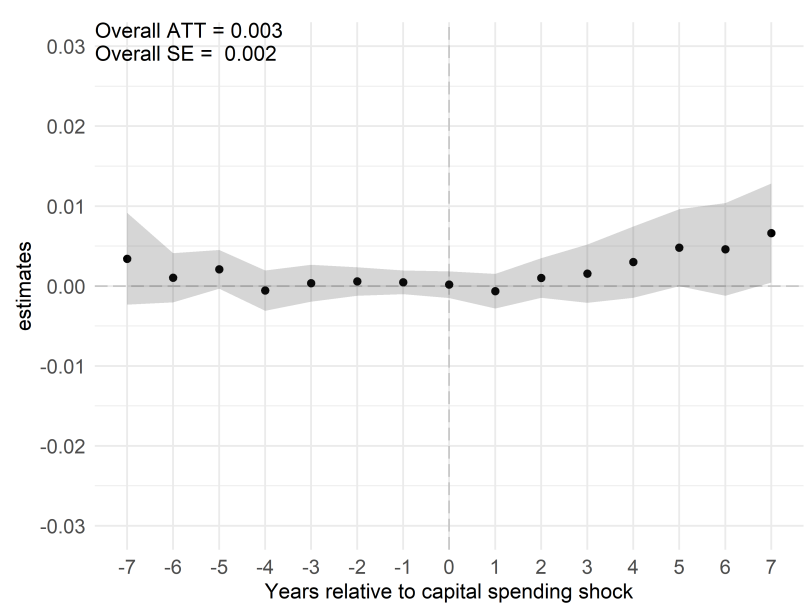

(D) Share single mother

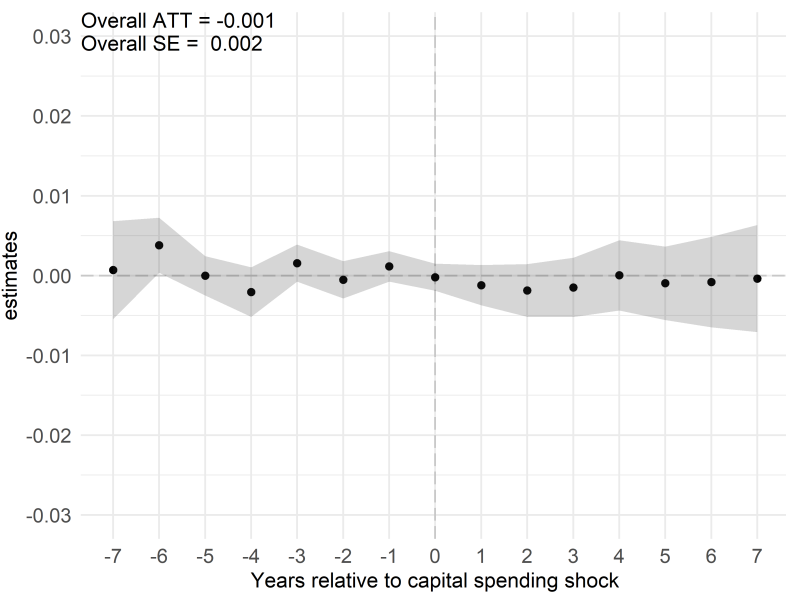

Event study estimates generated using the Callaway and Sant'Anna (2020) procedure described in Section 4 at the school district level. A library spending shock is defined in Section 4 The outcome variables are (A) Share unemployed adults, (B) Share SNAP-eligible adults, (C) Share BAplus educated adults, and (D) Share single mother adults. All figures show bootstrapped 95 percent simultaneous confidence intervals. Unlike pointwise confidence intervals, simultaneous confidence intervals include the path of treatment over time with $95 \%$ confidence and account for the dependence of the presented coefficients across event-times. Standard errors are clustered by school district. 


\section{Figure A8: Impact of capital expenditure shocks on school district finances}

\section{(A) Log total spending}

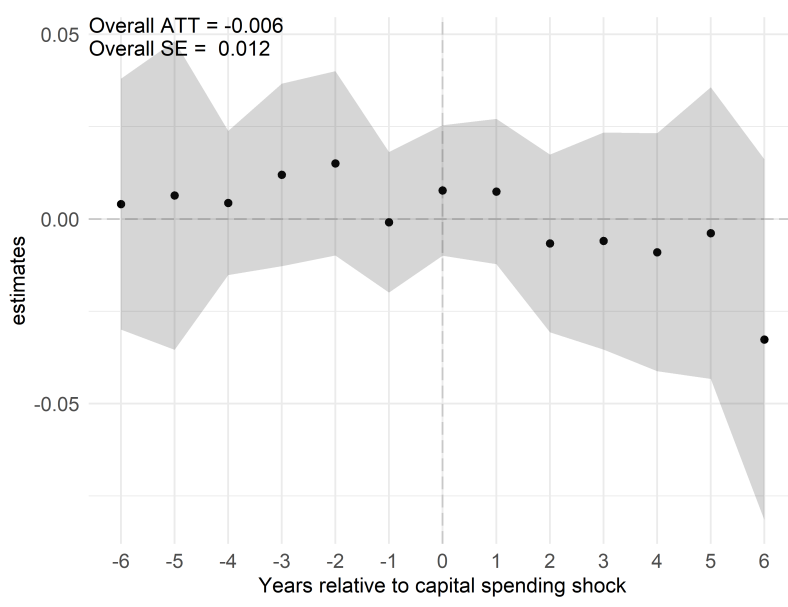

(C) Log salary spending

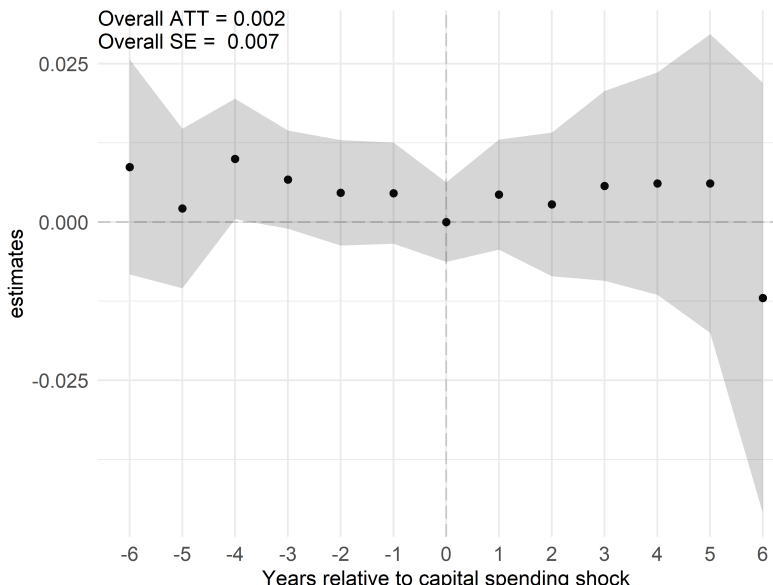

(B) Log capital spending

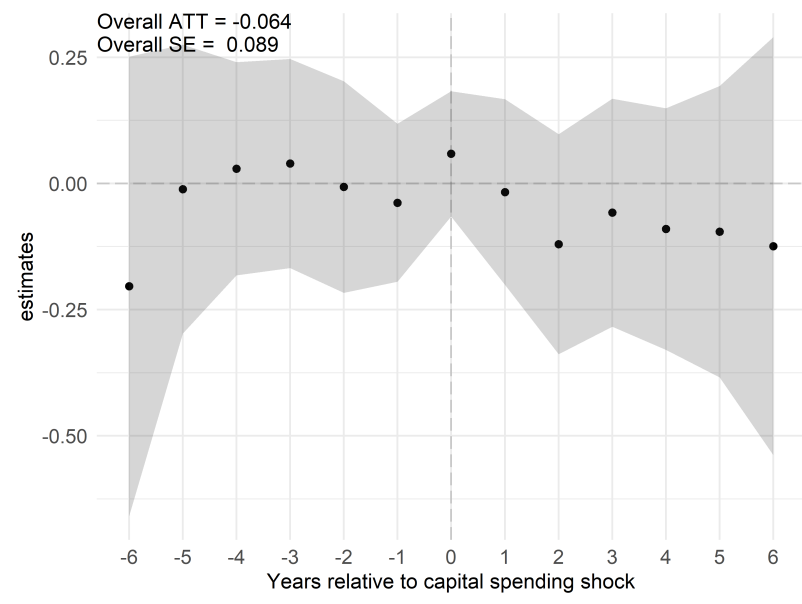

(D) Log instructional salary spending

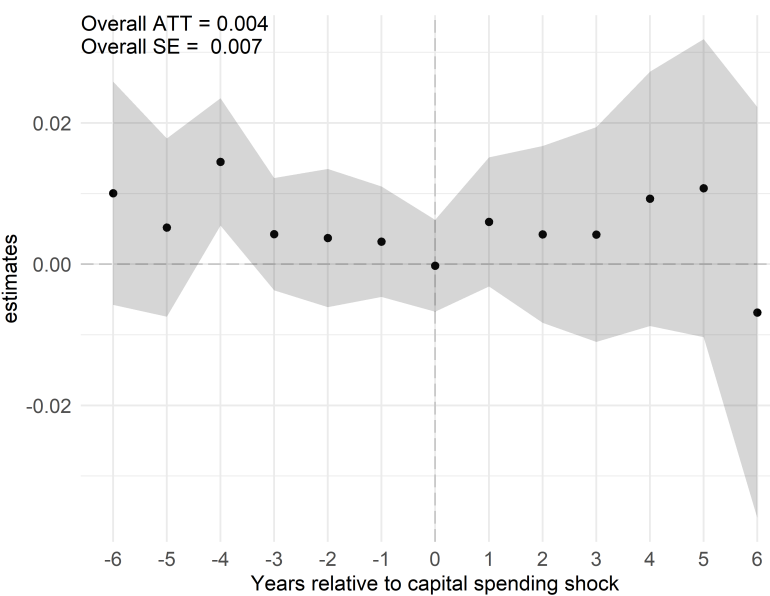

Event study estimates generated using the Callaway and Sant'Anna (2020) procedure described in Section 4 at the school district level. A library spending shock is defined in Section 4 The outcome variables are (A) Log total school spending, (B) Log capital school spending, (C) Log salary school spending, and (D) Log instructional salary school spending. All figures show bootstrapped 95 percent simultaneous confidence intervals. Unlike pointwise confidence intervals, simultaneous confidence intervals include the path of treatment over time with $95 \%$ confidence and account for the dependence of the presented coefficients across event-times. Standard errors are clustered by school district. 
Figure A9: Impact of capital expenditure shock on reading test scores, alternative ATT weights

(A) Simple weights

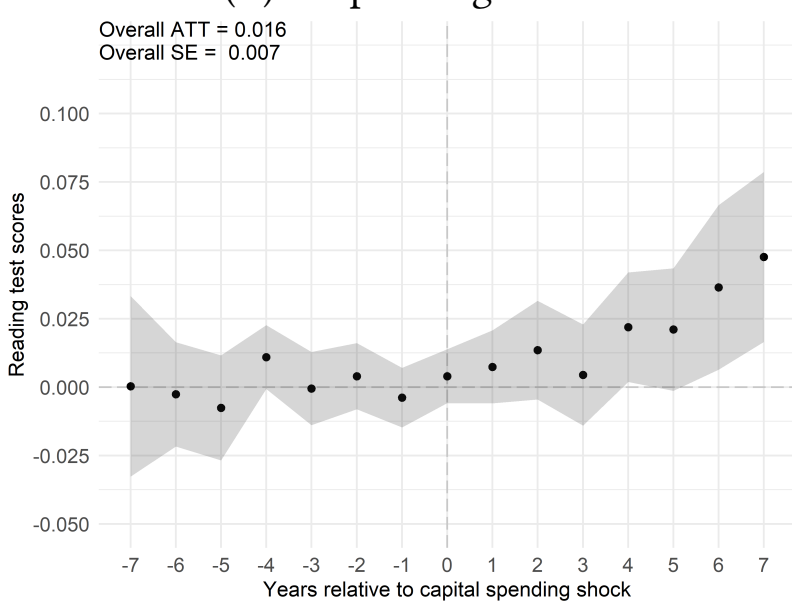

(C) Calendar weights

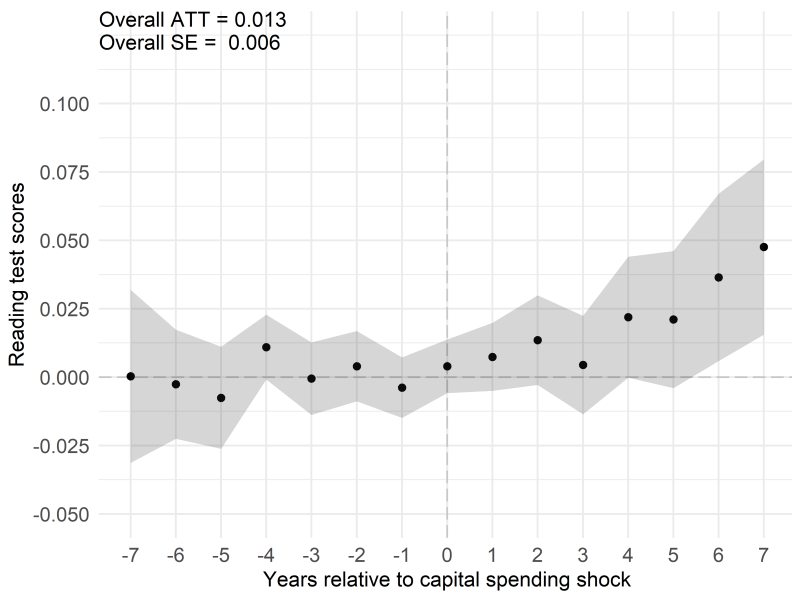

\section{(B) Group weights}

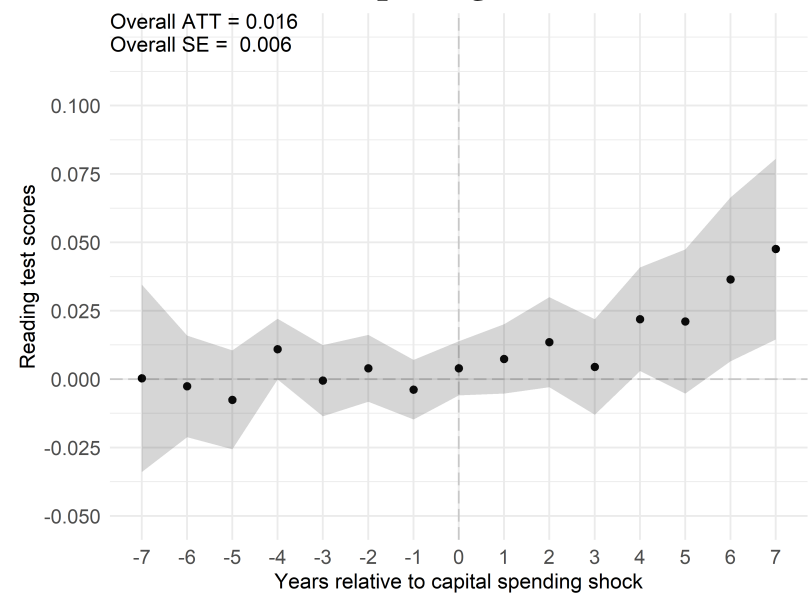

(D) Efficient estimator

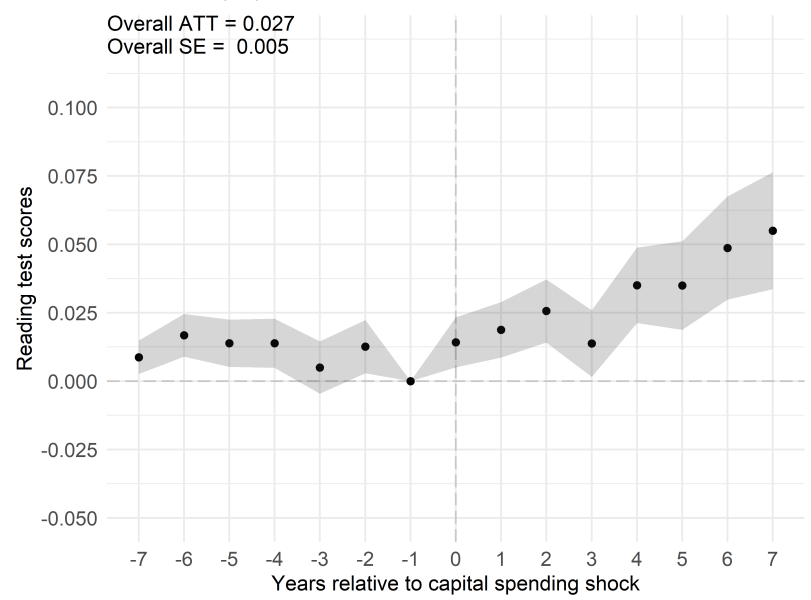

These figure shows district-level test score estimates generated using the Callaway and Sant'Anna (2020) procedure described in Section 4 Event study coefficients are identical for panels A-C, which use different weights to combine group-specific ATTs into an overall ATT. Panel D presents the method of Sant'Anna and Roth (2020). All figures show bootstrapped 95 percent simultaneous confidence intervals. Unlike pointwise confidence intervals, simultaneous confidence intervals include the path of treatment over time with $95 \%$ confidence and account for the dependence of the presented coefficients across event-times. Standard errors are clustered by school district. 
Figure A10: Impact of capital expenditure shock on reading test scores, alternative shock thresholds

(A) $\$ 600$ shock

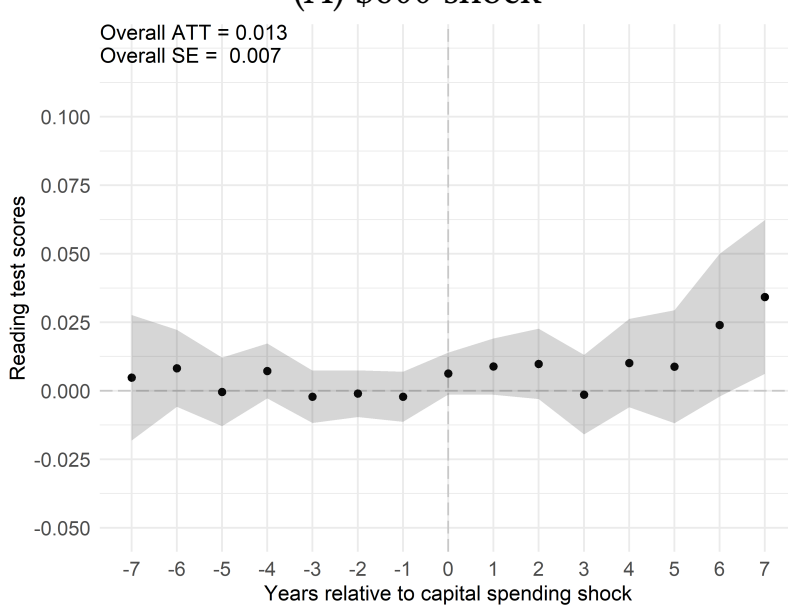

(C) $\$ 1,000$ shock

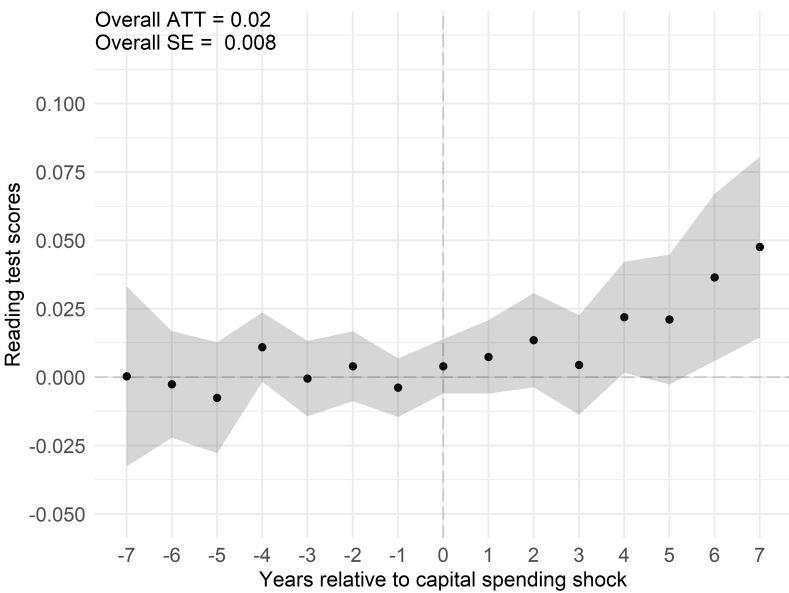

(B) $\$ 800$ shock

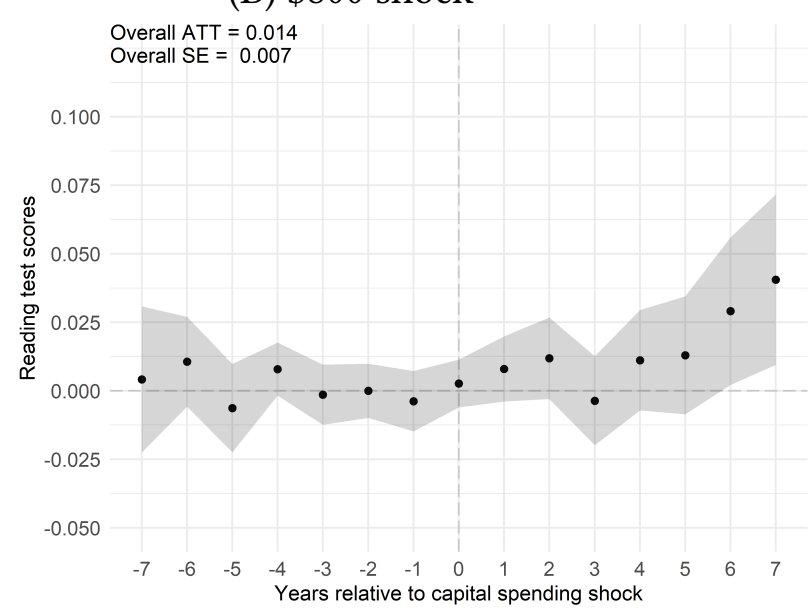

(D) $\$ 1,200$ shock

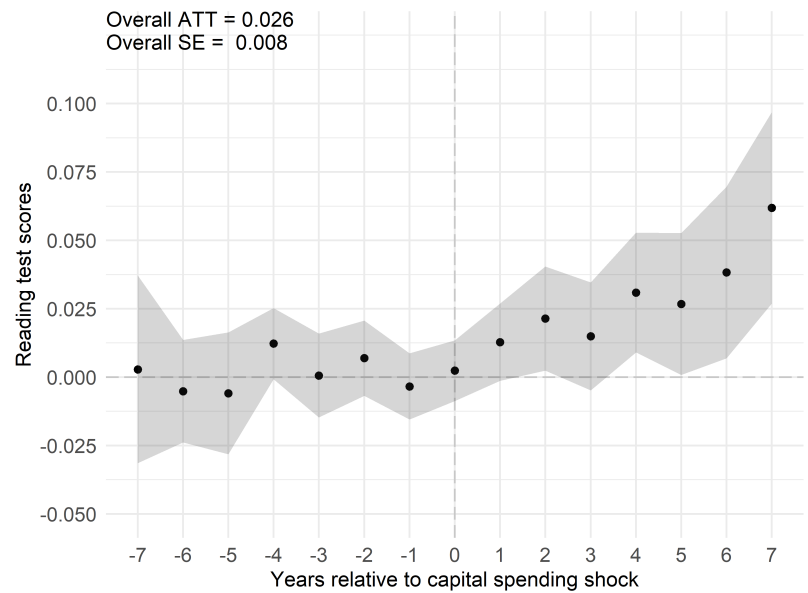

These figure shows district-level library outcome estimates generated using the Callaway and Sant'Anna (2020) procedure described in Section 4 for different definitions of capital spending shock thresholds, including our baseline shock size (Panel C). All figures show bootstrapped 95 percent simultaneous confidence intervals. Unlike pointwise confidence intervals, simultaneous confidence intervals include the path of treatment over time with $95 \%$ confidence and account for the dependence of the presented coefficients across event-times. Standard errors are clustered by school district. 
Figure A11: Impact of library capital spending shocks on child test scores, TWFE method

(a) Reading test scores

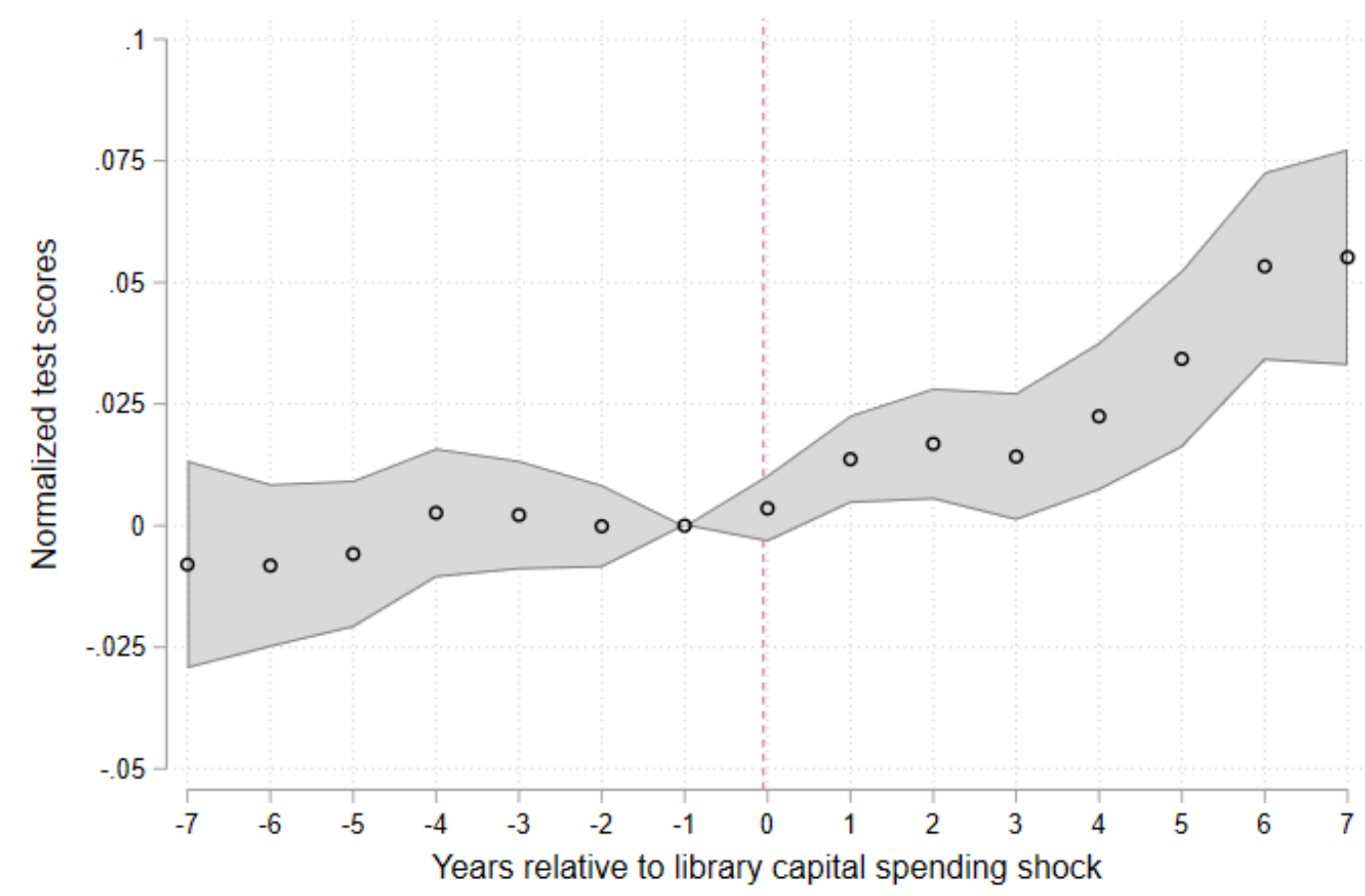

(b) Mathematics test scores

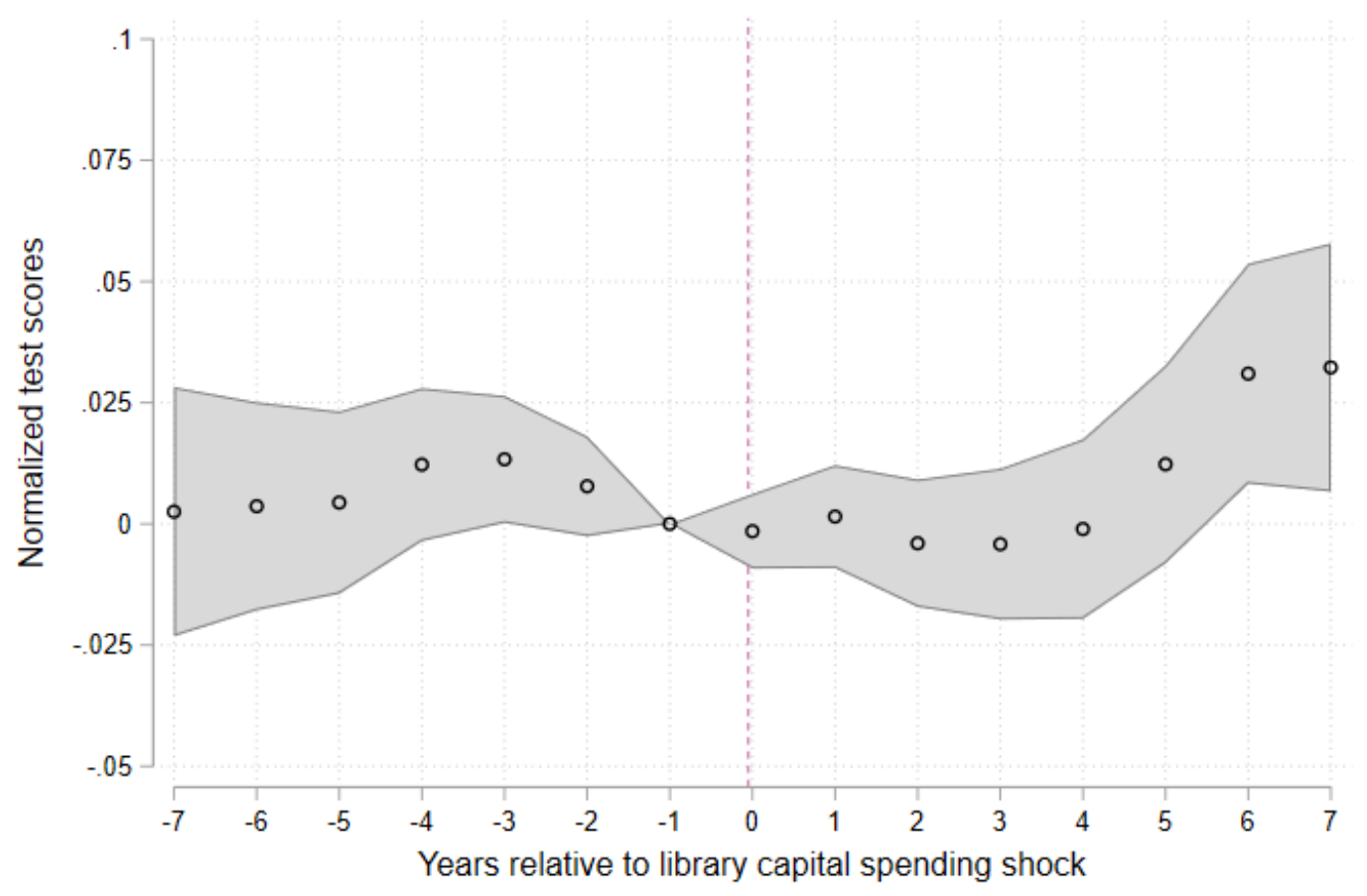

These figure shows test score estimates generated using the standard TWFE model discussed in Sections 3 and 4 Standard errors are clustered by school district. The model also includes district-grade and year fixed effects. 
Figure A12: Impact of library capital spending shocks on child test scores, TWFE method including time-varying SEDA controls

(a) Reading test scores

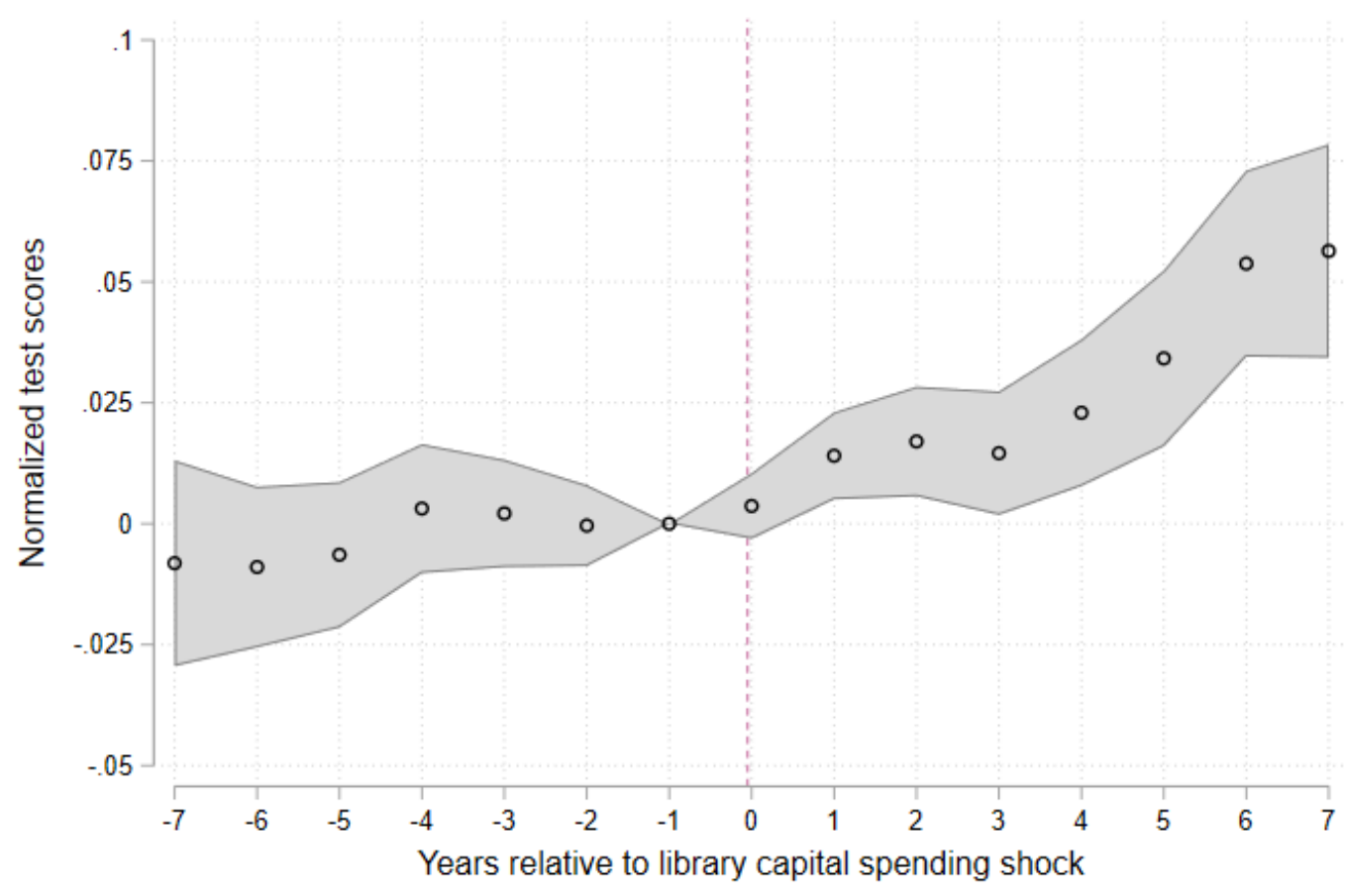

(b) Mathematics test scores

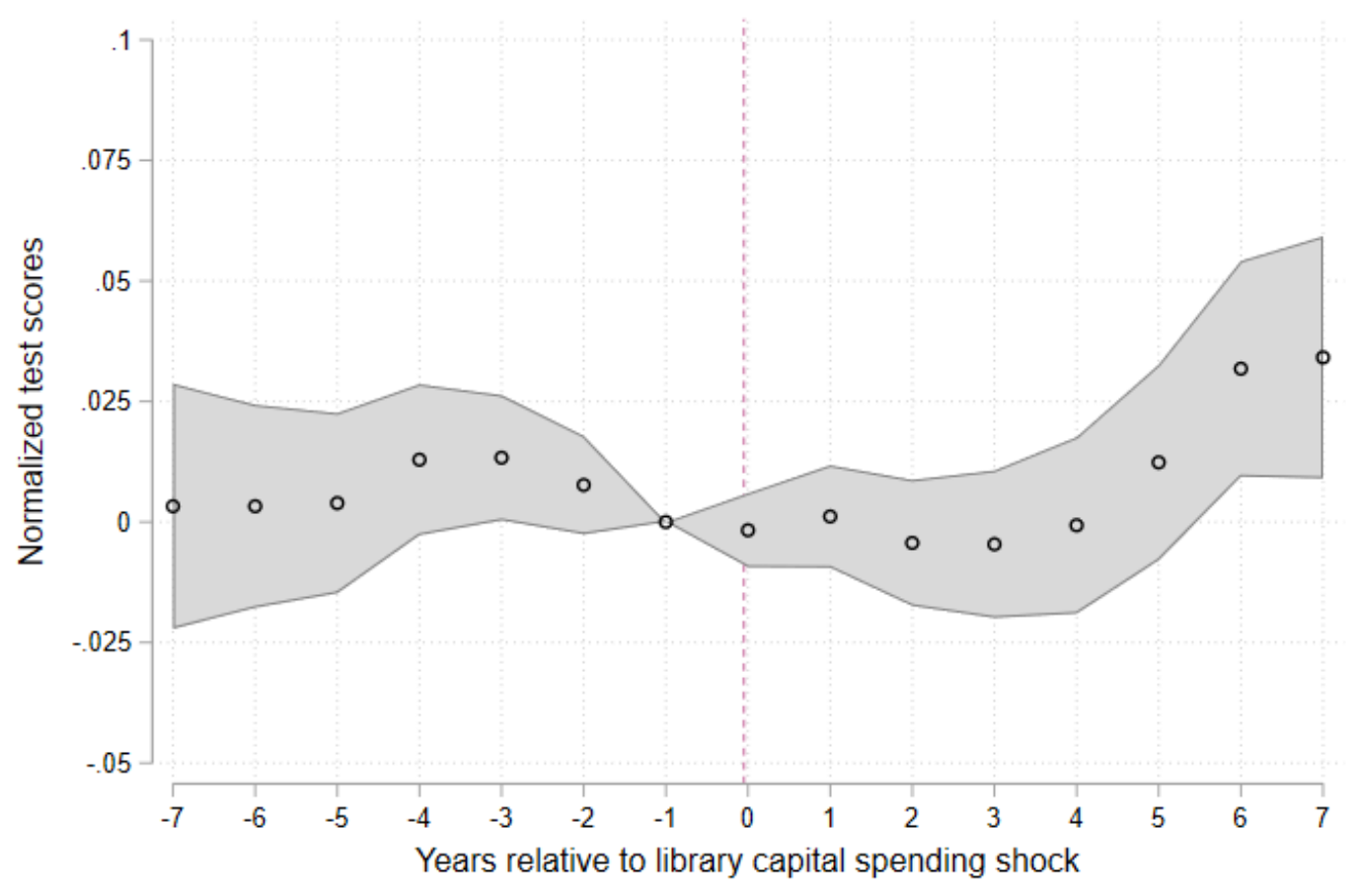

These figure shows test score estimates generated using the standard TWFE model discussed in Sections 3 and 4 Standard errors are clustered by school district. The model also includes district-grade and year fixed effects and the time-varying SEDA district covariates described in Section 4 
Figure A13: Impact of library capital spending shocks on child test scores, TWFE method including time-varying SEDA and CCD district finance controls

(a) Reading test scores

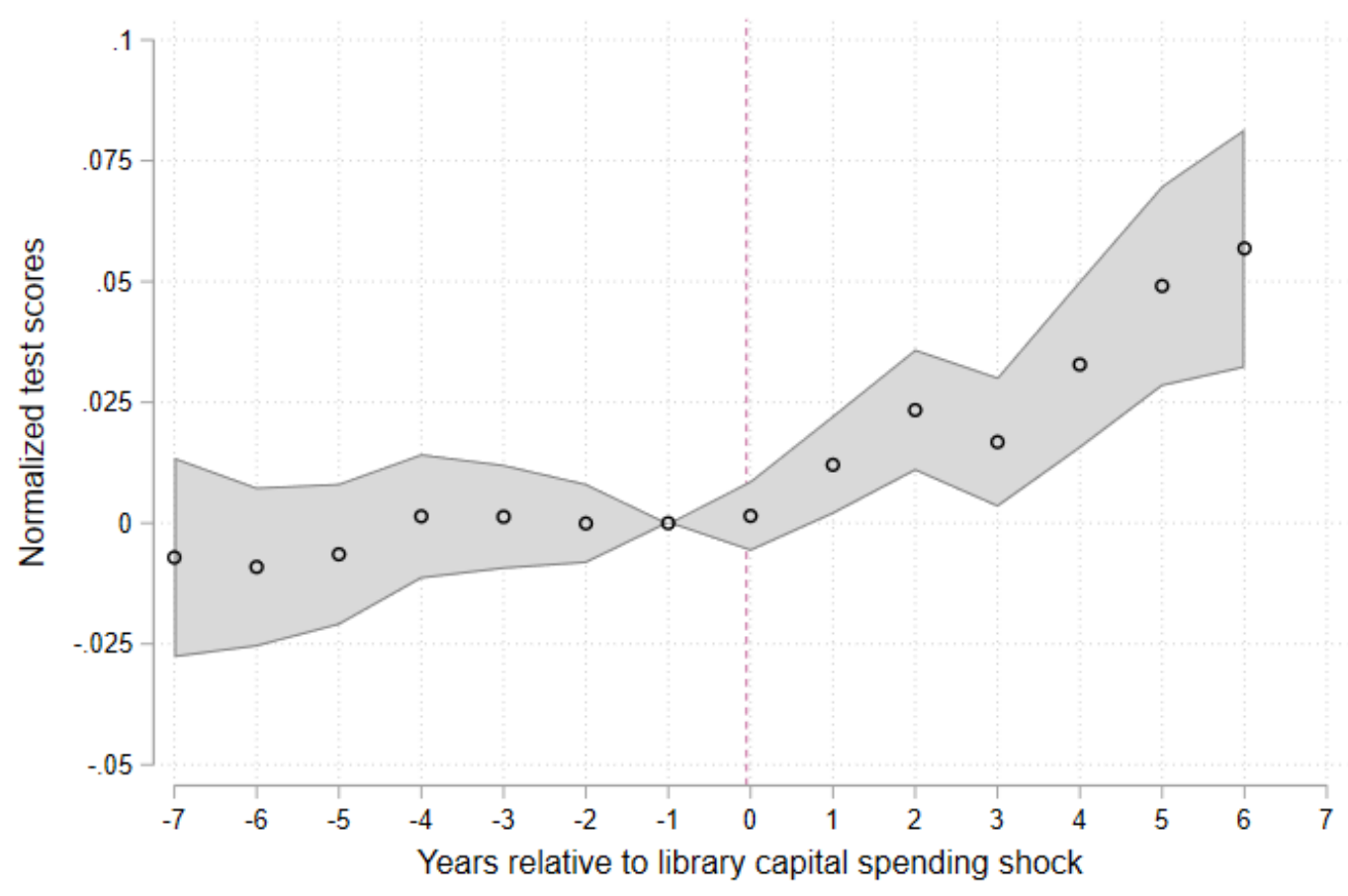

(b) Mathematics test scores

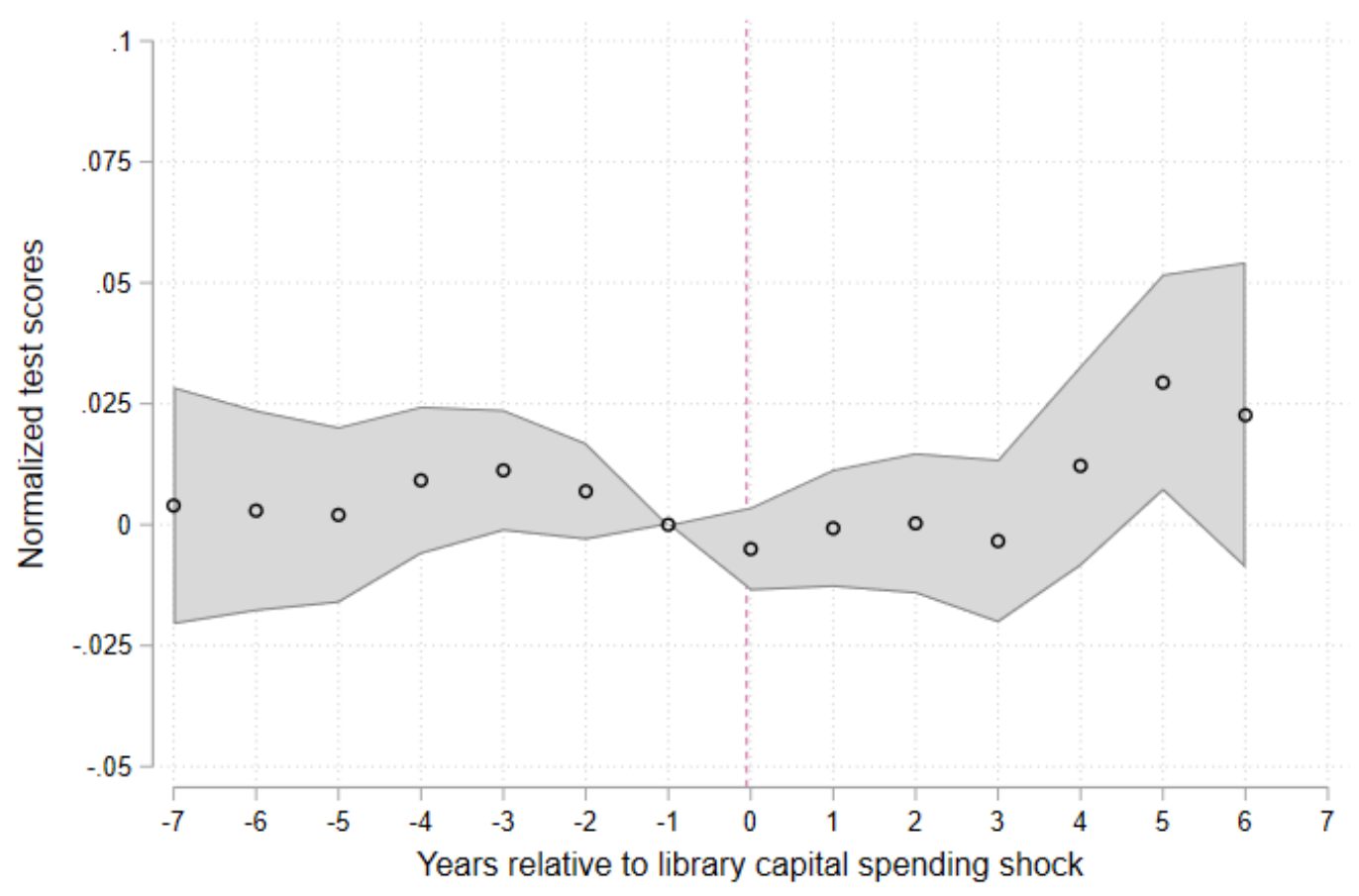

These figure shows test score estimates generated using the standard TWFE model discussed in Sections 3 and 4 Standard errors are clustered by school district. The model also includes district-grade and year fixed effects and the time-varying SEDA and district financial covariates described in in Section 4 
Figure A14: Impact of library capital spending shocks on child test scores, covariate matching approach

(a) Reading test scores

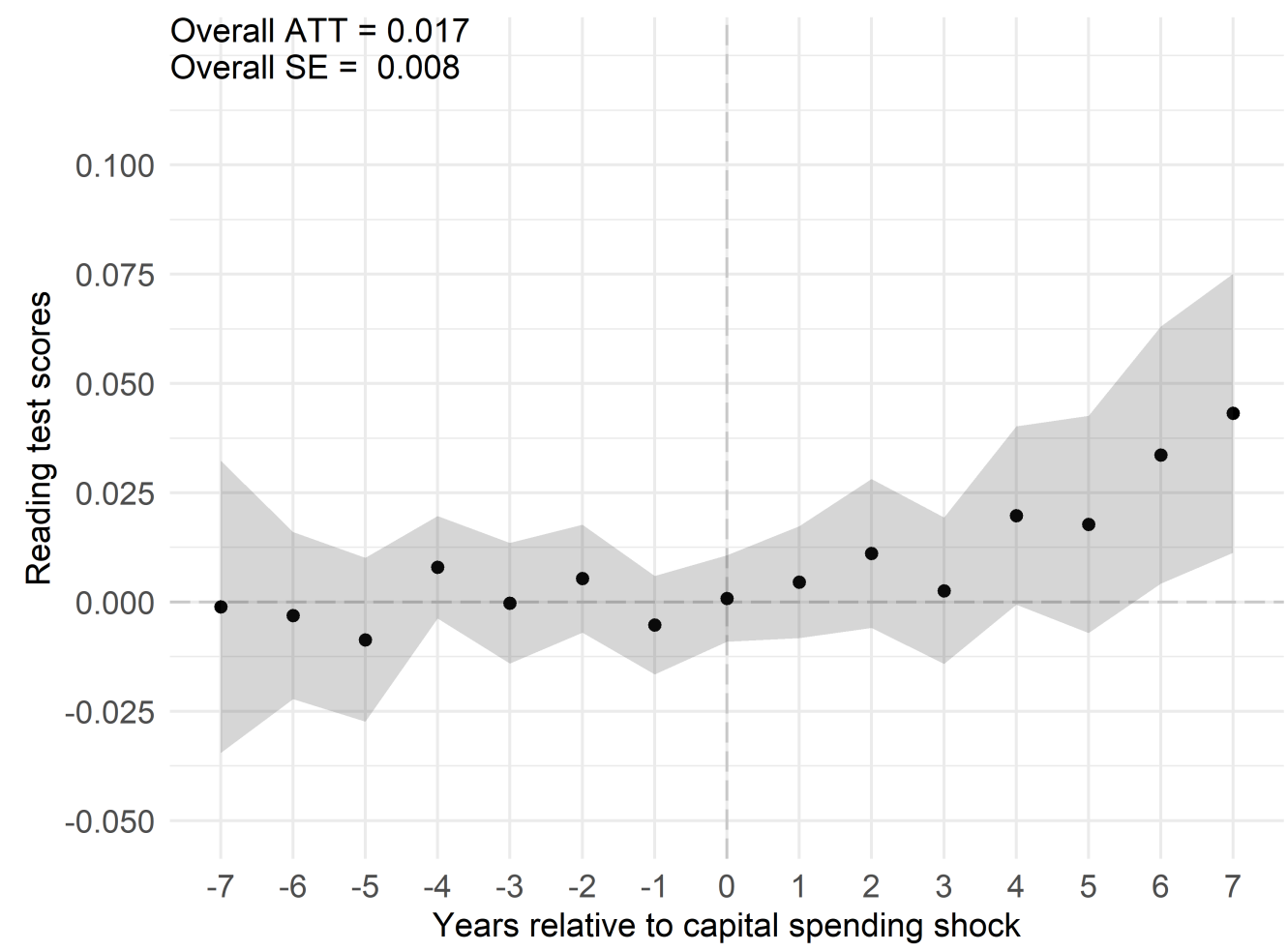

(b) Mathematics test scores

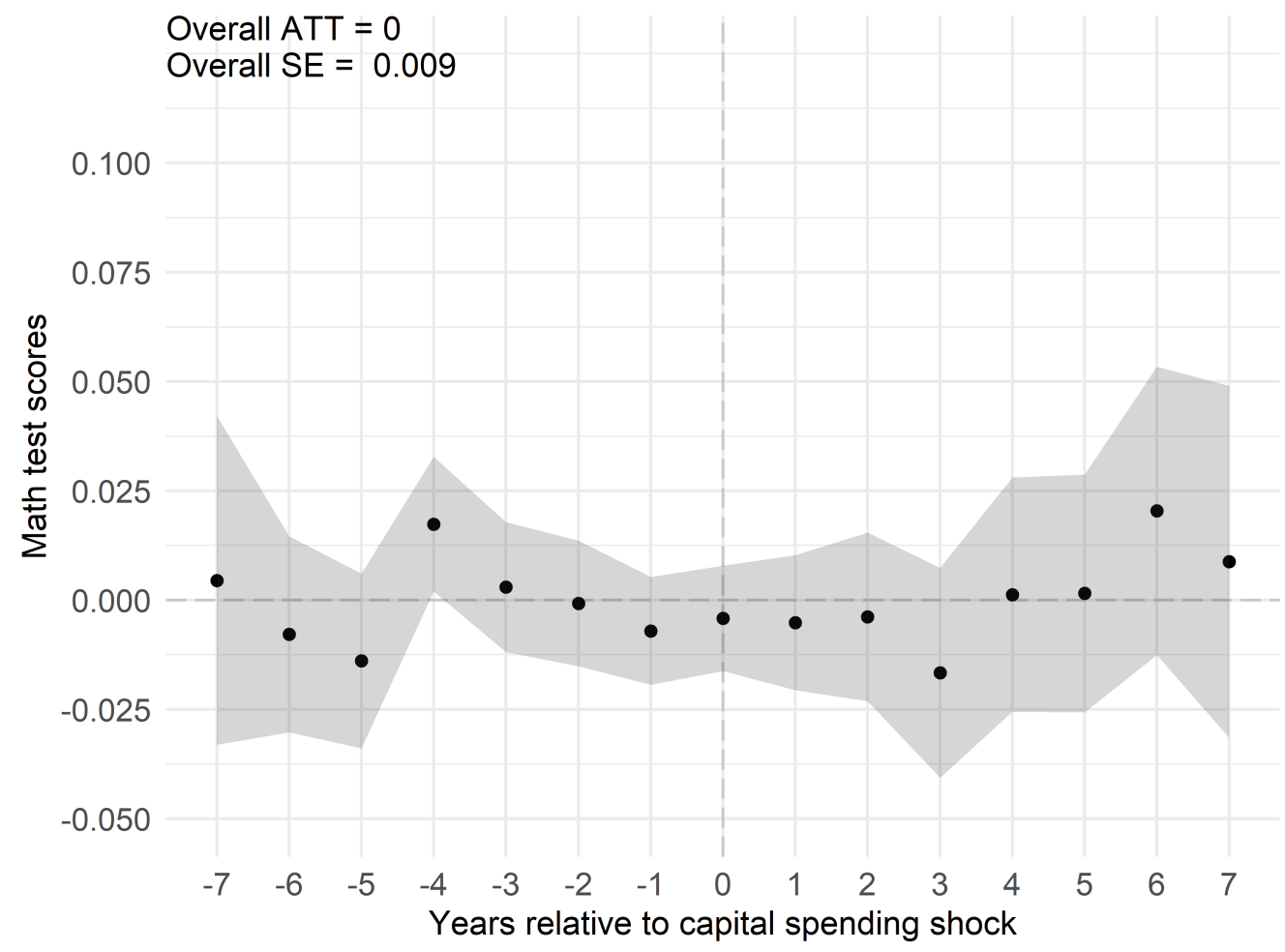

Event study estimates generated using the Callaway and Sant'Anna (2020) procedure described in Section 4 at the school district level. All figures show bootstrapped 95 percent simultaneous confidence intervals. Unlike pointwise confidence intervals, simultaneous confidence intervals include the path of treatment over time with $95 \%$ confidence and account for the dependence of the presented coefficients across event-times. Standard errors are clustered by school district. 
Figure A15: Impact of library capital spending shocks on child test scores, covariate matching approach with district financial covariates

(a) Reading test scores

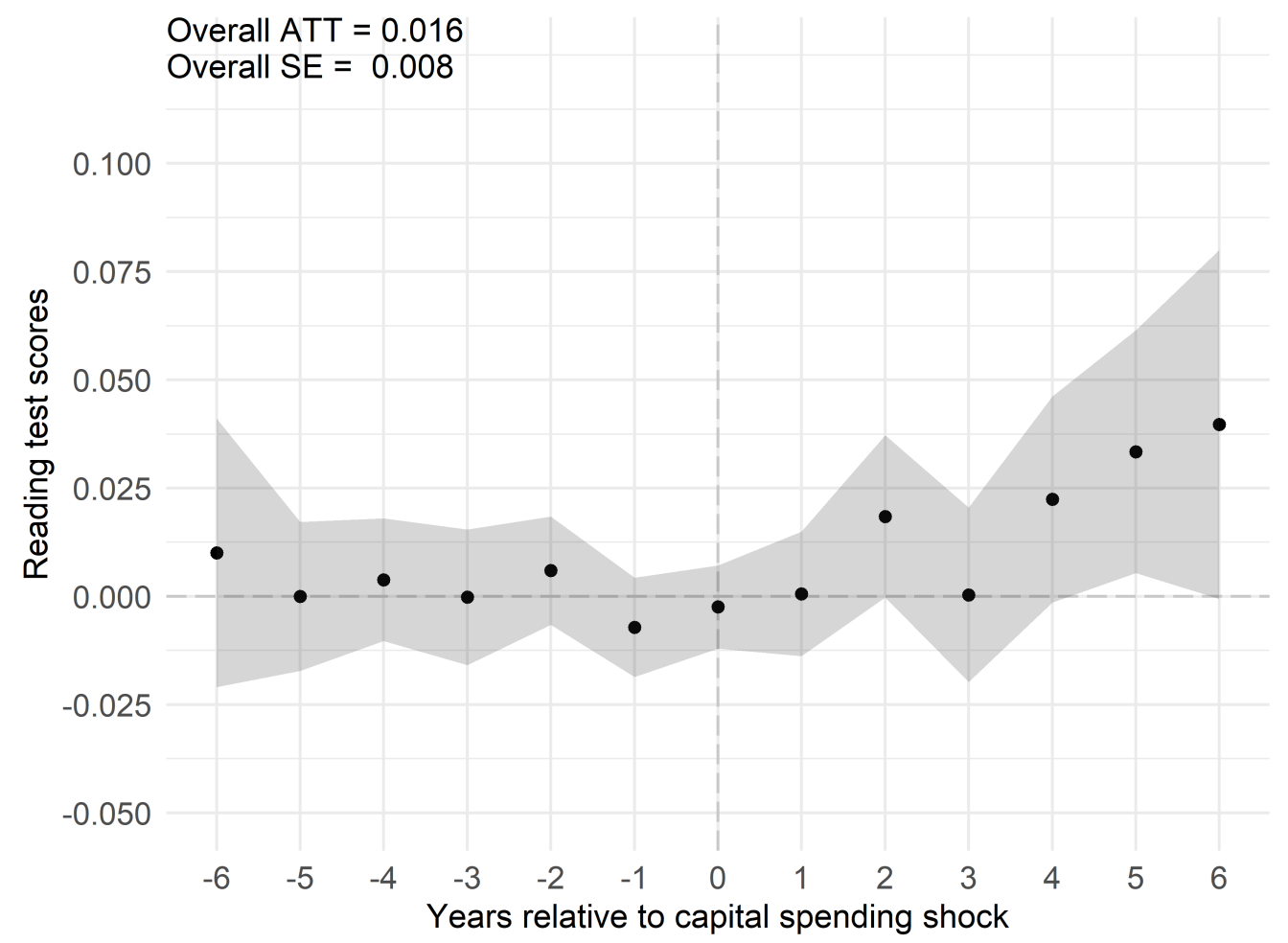

(b) Mathematics test scores

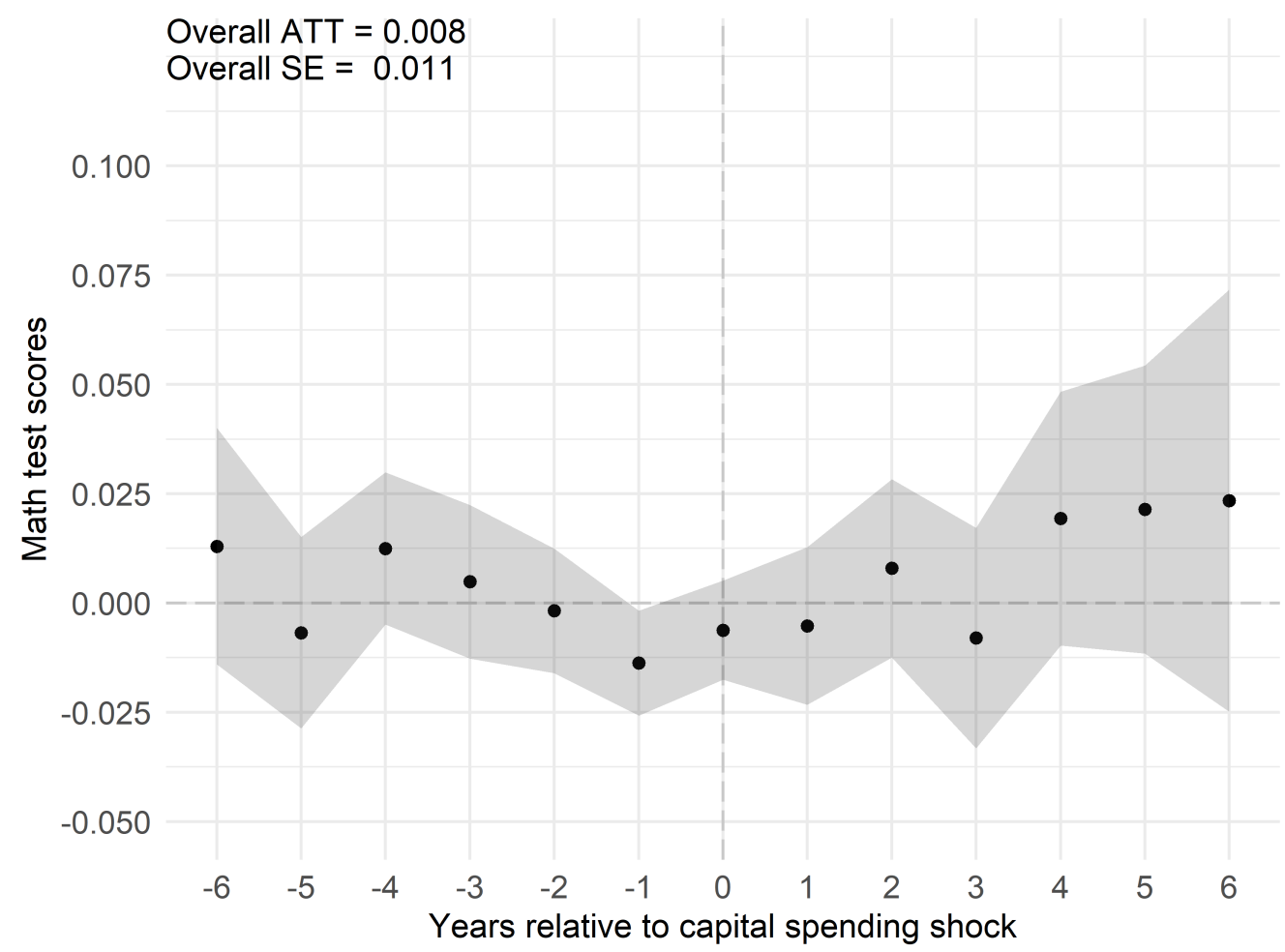

Event study estimates generated using the Callaway and Sant'Anna (2020) procedure described in Section 4 at the school district level. All figures show bootstrapped 95 percent simultaneous confidence intervals. Unlike pointwise confidence intervals, simultaneous confidence intervals include the path of treatment over time with $95 \%$ confidence and account for the dependence of the presented coefficients across event-times. Standard errors are clustered by school district. 